\title{
Dietary feedback effects and gender differences in stages of change for fat and fiber intake behavior
}

Janis M. Boury

West Virginia University

Follow this and additional works at: https://researchrepository.wvu.edu/etd

\section{Recommended Citation}

Boury, Janis M., "Dietary feedback effects and gender differences in stages of change for fat and fiber intake behavior" (2003). Graduate Theses, Dissertations, and Problem Reports. 1916.

https://researchrepository.wvu.edu/etd/1916

This Dissertation is protected by copyright and/or related rights. It has been brought to you by the The Research Repository @ WVU with permission from the rights-holder(s). You are free to use this Dissertation in any way that is permitted by the copyright and related rights legislation that applies to your use. For other uses you must obtain permission from the rights-holder(s) directly, unless additional rights are indicated by a Creative Commons license in the record and/ or on the work itself. This Dissertation has been accepted for inclusion in WVU Graduate Theses, Dissertations, and Problem Reports collection by an authorized administrator of The Research Repository @ WVU.

For more information, please contact researchrepository@mail.wvu.edu. 


\title{
Dietary Feedback Effects and Gender Differences in Stages of Change
} for Fat and Fiber Intake Behavior

Janis M. Boury, M. A.

\author{
Dissertation submitted to the \\ Eberly College of Arts and Sciences \\ at West Virginia University \\ in partial fulfillment of the requirements \\ for the degree of
}

\author{
Doctor of Philosophy \\ in \\ Psychology
}

\author{
Kevin T. Larkin, Ph.D., Chair \\ Stanley H. Cohen, Ph.D. \\ Lindsey L. Cohen, Ph.D. \\ Alfred L. Kasprowicz, Ph.D. \\ Joseph Panepinto, Ph.D. \\ Department of Psychology
}

\begin{abstract}
Morgantown, West Virginia University 2003
\end{abstract}

Keywords: Gender Role Socialization, Adults, Male, Female, Human, Health Behavior, Dietary Fat, Dietary Fiber, Feedback, Stages of Change, Stage, Transtheoretical, Targeted Messages, Tailored Messages, Decisional Balance, Pros, Cons, Pro/Con Ratio, United States 


\title{
Abstract \\ Dietary Feedback Effects and Gender Differences in Stages of Change for Fat and Fiber Intake
}

\author{
Janis M. Boury
}

The stages of change (SOC) model has addressed difficult changes people make to important habits such as smoking or diet. The SOC model includes several stages based on intention to change behavior, active change, and maintenance of change. This study had three purposes. The influence of cultural role expectations for males and females was explored for effects on decisional balance (DB) or the weighing of pros and cons before making changes. Second, changes in self-reported stage assignment following feedback for the hidden nutrients of fat and fiber were examined. Finally, the study compared the effects of feedback and tailored messages on change in fat and fiber intakes.

The study was an experimental control group design with 273 participants at baseline, 235 completing the intervention surveys, and 197 at post-intervention. Most of the participants had some college and members of the maintenance stage were slightly older than the other stages. Baseline included general and gender-specific DB measures, staging algorithms for fat and fiber, and a Food Frequency Questionnaire (FFQ). Staging algorithms were completed at intervention and post-intervention. The FFQ was completed again at post-intervention. Finally, the study included an intervention with three groups. The wait list control group (WLG) received a brochure on a healthy diet. The feedback group (FG) received feedback on their dietary intake plus the brochure. The enhanced feedback group (EFG) received suggestions for change based on their dietary habits plus the feedback report and brochure.

Women rated the pros on the general DB slightly higher than men but ratings were similar for the gender-specific DB. Cons on the gender-specific DB were higher for males in the early stages compared to the late stages or to women in the early stages. The late stages did not significantly differ for men and women on cons. For low-fat SOC, late stage members receiving negative feedback (more than $30 \%$ of calories from fat) were more likely to regress to earlier stages $(24 \%)$ than those who did not receive feedback (7\%). Likewise, for high-fiber SOC, late stage members receiving negative feedback (less than $20 \mathrm{~g}$ fiber) were more likely to regress to earlier stages $(33 \%)$ than those who did not receive feedback (9\%). Finally, there was an interaction for Gender and Treatment Group on change in fat intake. Males exhibited a significantly greater reduction in "\% of calories from fat" than females, but only in WLG. A similar pattern was seen among participants in EFG but not in FG.

These findings confirm gender role socialization issues and their effect on healthy dietary behaviors need further exploration. Furthermore, dietary feedback may improve accuracy of staging for hidden nutrients, but there are serious limitations related to monitoring behaviors on subsequent FFQs. 


\section{Acknowledgment}

I wish to thank all those who supported me in my research. I am thankful to Kevin Larkin, my advisor in the truest sense of the word, who taught me research technique and scientific thinking and motivated me whenever problems arose. I appreciate the guidance of my committee Stan Cohen, Al Kasprowicz, Joe Panepinto, Georg Eiffert, and Lindsey Cohen. They helped shape my research and assisted in its completion. I would like to thank Debra Krummel, who expanded my understanding of research in the real world and the complexities of dietary behavior. I am thankful to my parents who instilled a love of learning in me. But most of all I am grateful for my husband Michael Frasher, who always encouraged me in my chosen path and endured sharing his life with a graduate student. Michael, we have reached the other side of the mountain. 


\section{Page}

Introduction . . . . . . . . . . 1

Purpose ................ 22

Methods ............... 24

Results ............... 36

Discussion ............... 46

Conclusions .............. 58

References ...............6 60

Data Tables ............. 76

Appendix A ............. 90

Appendix B ............. 98

Appendix C .............. 99

Appendix D ............. 103

Appendix E ............. 104

Appendix F . . . . . . . . . . . 105

Appendix G ............ 106

Appendix H ............. 108

Appendix I . . . . . . . . . 110

Appendix J ............. 111

Appendix K . . . . . . . . . . 114

Appendix L . . . . . . . . . 115 
List of Tables

Page

Table 1: Gender Differences in Reported Dietary Training 77

Table 2: Gender Differences for Other Health Behaviors 78

Table 3: Number (Percentage) of Male and Female Participants Assigned to SOC 79 for Low-Fat or High-Fiber Dietary Behaviors

Table 4: Differences in Mean Age for SOC for Low-Fat and High Fiber Dietary $\quad 80$ Behavior

Table 5: $\quad$ Dietary Intake Compared to Gender and Low-Fat or High-Fiber SOCs $\quad 81$

Table 6: Effects of Stage Assignment on Completion Rates for Males and Females 82

Table 7: Mean Pro and Con Ratings for General or Gender-Specific Decisional 83 Balance (DB) Measures by Gender and Low-Fat SOC

Table 8: Mean Pro and Con Ratings for General or Gender-Specific Decisional 84 Balance (DB) Measures by Gender and High-Fiber SOC

Table 9: Baseline to Phase 2 Change of Low-Fat Stage Based on Feedback Type 85

Table 10: Phase 2 to Phase 3 Change of Low-Fat Stage Based on Feedback Type 86

Table 11: Baseline to Phase 2 Change of High-Fiber Stage Based on Feedback Type 87

Table 12: Phase 2 to Phase 3 Change of High-Fiber Stage Based on Feedback Type 88

Table 13: Effects of Gender and Treatment Condition on Pre-post change in \% of 89 Calories from Fat and in Fiber (g/day)

Table 14: Effects of Stage and Treatment Group on Pre-Post Change in \% of 90 Calories from Fat and in Fiber (g/day) 
Since 1957, the American Heart Association ([AHA]; Page, Stare, Corcoran, Pollack, \& Wilkerson, 1957) has recommended Americans consume a diet low in fat to help prevent cardiovascular disease. As the years have passed, the AHA has expanded and refined its recommendations based on the accumulation of findings linking poor dietary behavior to the leading causes of death and the development of many chronic diseases (Krauss et al., 1996; 2000). Arriving at similar conclusions, the National Research Councils (NRC, 1989a), AHA (1996; 2000) and the United States Department Health and Human Services (USDHHS, 1988; $1990 ; 2000)$ indicated dietary behavior played a major role in the development of chronic diseases including cardiovascular disease, diabetes, gallbladder disease, obesity, and some cancers. These organizations also provided recommendations and national goals for diets low in fat and high in fiber. Despite this expanding set of recommendations and an increasing number of direct intervention strategies aimed at altering poor dietary behavior, Americans have continued to consume diets high in fat and low in fiber (NRC, 1989a; USDHHS, 1988; 1990; 2000). One current dietary intervention strategy employs the stages of change model originally developed for smoking cessation (DiClemente \& Prochaska, 1982; Prochaska \& DiClemente, 1983). The purpose of the current study is to examine the application of the stages of change model to dietary behavior, focusing particularly on the issues of gender differences in staging, difficulties with self-report methods for stage assignment, and issues relating to tailoring messages for dietary change.

\section{Effects of Dietary Behavior on Health}

In an analysis of epidemiological research on the causes of death in the United States, McGinnis and Fogge (1993) estimated diet and activity patterns accounted for at least 300,000 deaths a year. The typical Western, typical American, or westernized dietary pattern associated 
with chronic disease incidence and course consisted of high-fat intakes, especially from saturated fats and trans-fats; and low-fiber intakes from fruits, vegetables, or whole grains (Fung et al., 2001; Hu et al., 1999; Stemmerman, Nomura, Heilbrun, Mower, \& Hayashi, 1985; Wardlaw, Snook, Lin, Puangco, \& Kwon, 1991). Typical Western dietary patterns constituted significant risk factors for four of the ten leading causes of death: heart disease, some cancers (colorectal, breast, and prostate), stroke, and diabetes (Centers for Disease Control and Prevention, National Center for Chronic Disease Prevention and Health Promotion, CDC-NCCDPHP, 2002). These four leading causes of death accounted for 1.6 million $(63.2 \%)$ of 2.4 million deaths in the United States in 1999. Two other behavioral risk factors for chronic diseases, smoking and sedentary activity patterns, are also increased in prevalence with Western acculturation by nonWestern ethnic groups (Bourne, Lambert, \& Steyn, 2002) or with typical Western dietary practices in the United States (Cronin, Krebs-Smith, Feuer, Troiano, \& Ballard-Barbash, 2001). These additional disease-promoting factors provided possible confounding effects in epidemiological studies on the association between dietary behavior and chronic disease development or course.

Studies with various ethnic groups found consistent relations between westernized diets and increased rates of chronic disease or associated risk factors. For ethnic groups adopting a westernized diet, increased chronic disease or risk rates included the following: obesity and elevated cholesterol in Chileans (Albala, Vio, Kain, \&Uauy, 2002); cardiovascular disease in Native Americans (Alpert, Goldberg, Ockene, \& Taylor, 1991) and Africans (Vorster, 2002); coronary heart disease in Japanese Americans (Marmot \& Syme, 1976); cancer in Japanese (Tominaga \& Kuroishi, 1997); cardiovascular disease, diabetes, and obesity in Australian aborigines (O'Dea, 1991); and mortality rates from diabetes, myocardial infarctions, and 
hypertension in Mexicans (Rivera et al., 2002). Similarly, epidemiological and cross-sectional studies in western populations found associations between high-fat or low-fiber diets and chronic diseases. Typical Western diets were related to higher incidence rates for the following: heart disease (Willett et al., 1993); colon cancer (Cronin et al., 2001); stroke (Gillman, Cupples, \& Millen, Ellison \& Wolf, 1997; Joshipura et al., 1999); and diabetes (Salmeron, Ascherio, et al., 1997; Salmeron, Manson, et al., 1997). Based on epidemiological data, Henderson, Ross, and Pike (1991) found that approximately 155,000 new cases of colorectal cancer in 1990 were associated with diets high in animal fat and low in fiber. Seventh Day Adventists provided another dietary group of interest as their religion promotes a vegetarian diet close to the prudent diet. Compared to general populations from similar backgrounds, Seventh Day Adventists have been shown to exhibit lower chronic disease incidence rates for the following: cardiovascular disease and diabetes (Alexander, Lockwood, Harris, \& Melby, 1999); cardiovascular disease (Toohey et al., 1998); prostate cancer (Miles, Beeson, Phillips, \& Fraser, 1989), diabetes, hypertension, and arthritis (Fraser, 1999). They also had longer life expectancies than the surrounding populations (Fraser \& Shavlik, 2001).

Of all the conditions produced by poor dietary behavior, obesity has become the most obvious and has carried direct ties to many chronic diseases constituting the leading causes of death. Obesity resulted in 300,000 premature deaths annually in the United States, based on current estimates (CDC-NCCDPHP, 2002) with current health cost estimates of $\$ 93$ billion per year (Finkelstein, Fiebelkorn, \& Wang, 2003). Garrow (1992) reported obesity influences the development of non-insulin dependent diabetes (NIDD). Mortality risk from cardiovascular disease and cancer also rose with increasing obesity (USDHHS, 1988; CDC-NCCDPHP, 2002). Björntorp (1985) reported cardiovascular disease and NIDD increased with abdominal obesity 
(waist to hip ratio). Obesity has also been shown to exacerbate hypertension, gallstones, digestive disease, some types of arthritis, and sleep apnea (USDHHS, 1988, 2000).

The experimental literature on the connection between changing dietary behavior and health consequences has varied greatly in design and quality. Design characteristics have ranged from one-time dietary interventions (Jenkins, Wesson, Wolever et al., 1988) to intensive interventions lasting for as long as one year with contact during follow-up periods lasting several years (Bemelmans, Broer, Feskins et al., 2002; Gould, Ornish, Kirkeeide et al., 1992; Gould, Ornish, Scherwitz et al., 1995; Rowley, Su, Concotta et al., 2001; Rutledge, Hyson, Garduno et al., 1999). Dietary intervention studies examined a single dietary factor such as cereal fiber (Bemelmans et al., 2002; Jenkins et al., 1998; Kabir, Oppert, Vidal et al., 2002; Wardlow, Snook, Lin et al., 1991), multiple dietary factors (Baer, 1993; Conlin, Chow, Miller et al., 2000; Gleason, Bourdet, Koehn et al.; 2002; Howard, Abbott, \& Swinburn, 1991; Perez-Jimenez, Lopez-Miranda, Pinillos et al., 2001; Rowley et al., 2001), or dietary factors combined with other lifestyle changes such as smoking cessation and exercise (Diehl, 1998; Gould et al., 1992; Gould et al., 1995; Rutledge et al., 1999). Delivery methods for intervention studies have consisted of group sessions (Bemelmans et al.2002; Diehl), provision of food (Conlin et al., 2000; Gleason et al., 2002; Jenkins et al., 1988; Kabir et al., 2002; Wardlow et al., 1991) individual counseling (Buzzard, Asp, Chlebowski et al., 1990), and combined methods (Baer, 1993; Diehl, 1998; Gould et al., 1992; Gould et al., 1995; Rowley et al., 2001; Rutledge et al., 1999). Natural or laboratory environments have been involved in assessing dietary features. Despite methodological variations and associated limitations, results of these studies have determined several healthy dietary factors. Factors associated with improved health outcomes or biomarkers included high fiber levels from vegetables, fruits, and whole grains; low levels of fats especially 
saturated fats and trans-fats, and low levels of refined carbohydrates; and moderate levels of vegetarian or lean protein and moderate total energy intake. Researchers named these healthy dietary factors prudent diets for western populations (Fung et al., 2001) and traditional diets for populations with non-Western origins (Howard et al., 1991; O'Dea, 1991).

Studies exploring the diet-disease connection have usually employed risk factor measures such as serum cholesterol levels, blood pressure, insulin sensitivity or reactivity, weight loss, and waist circumference reduction. Cardiovascular disease risk factors such as blood cholesterol and blood pressure improved with either the prudent diet or combined lifestyle changes in several groups including: hypertensives (Conlin et al., 2000; Moore et al., 2001), normotensives (Sandstrom, Marckmann, \& Bindslev, 1992), male managers (Baer, 1993), Aborigines in a community intervention ( Rowley et al., 2001), high risk factor enrollees in a dietary intervention (Bemelmans et al., 2002; Gleason et al., 2002) and high-risk enrollees in a lifestyle intervention (Diehl, 1998; Rutledge et al., 1999). Howard, Abbott, and Swinburn (1991) reported improvements in serum cholesterol for obese individuals after change to a low-fat, high-fiber diet and improvements in both serum cholesterol and glucose tolerance for a group with diabetes after change to a prudent diet. Improvements in glucose metabolism with dietary change were found in a normal sample (Perez-Jimenez et al., 2001) and in diabetics (Jenkins et al., 1988; Kabir et al., 2002). Examining individual factors, Wardlaw et al. (1991), found replacing saturated fats with vegetable oils improved serum cholesterol levels in a group of healthy men. The Ornish program of low-fat vegetarian diet, exercise, and lifestyle changes demonstrated reversal in arterial stenosis for several groups of cardiac patients at risk of surgical intervention (Gould et al., 1992; Gould, et al., 1995; Ornish et al., 1998). 
Reviews of the literature for dietary behaviors have generally found some type of benefit from changing to healthier eating patterns. In a meta-analysis of 17 reports for dietary intervention trials lasting 3 to 6 months, Brunner et al. (1997) determined there were significant improvements in cardiovascular risk factors with modest reductions in dietary fat intake. Hu and Willett (2002) reviewed 147 studies addressing various components of diet relating to disease rates and based upon their analysis and critique, recommended adoption of the prudent diet. Hu, van Dam, and Liu (2001) determined increasing dietary fiber and replacing saturated fats with unsaturated fats improved risk factors for diabetics. High vegetable and fruit intakes have been shown to be associated with protective effects for stroke and cardiovascular disease (Ness \& Powles, 1997). Willett (1997) reviewed epidemiological and experimental studies and concluded there was evidence for the role of saturated fat as a risk factor for prostate cancer. Similarly, he found evidence for the benefit of replacing dietary saturated fat with olive oil and for increasing vegetable intake for preventing the development of breast cancer (Willett, 2001). Margetts, Little, and Warm (1999) concluded improvements in diet and exercise behaviors were associated with a small but positive effect on blood pressure. Risk for colorectal and gastric cancers were reduced by diets relying on unrefined carbohydrates instead of refined carbohydrates (Jacobs, Marquart, et al., 1995; Jacobs, Slavin, and Marquett, 1995). The combined findings of these reviews support the health benefits on diets high in fiber from fruits, vegetables, and whole grains; and low in fat or its constituents of saturated fats and trans-fats.

\section{Current American Dietary Patterns}

In the 20 years between 1970 and 1990, the percentage of calories from fat consumed by Americans on average declined from $36.4 \%$ to $34.1 \%$ (Ernst, Sempos, Briefel, \& Clark, (1997). More recent estimates suggested continuing decline in national averages to $32.8 \%$ of daily 
calories in 1996 (Dixon \& Ernst, 2001). This improvement was still well above the recommended 30\% or less of calories from fat (NRC, 1989a: USDHHS; 1988; 1990. 2000). Ernst, Sempos, et al. (1997) identified several dietary trends resulting in these lower fat intakes, including increased consumption of low-fat yogurt, poultry, and fish with decreased consumption of whole milk and red meat. Yet, despite reduced dietary fat intake, overweight (including obesity) has increased from $47.4 \%$ of the population in 1980 to $64.5 \%$ in 2000 (Centers for Disease Control and Prevention, National Center for Health Statistics [CDCNCHS], 2002). During this time, obesity rates doubled from $15.1 \%$ to $30.9 \%$.

The increases in obesity appeared to be partially the result of Americans' tendency for replacing reduced fats with carbohydrates (NRC, 1989b). This tendency for increased carbohydrates was demonstrated by a $13.4 \%$ increase in sweetener consumption from the early eighties to 1994 (Jones-Putnam \& Duewer, 1995). American youths consumed 224 kilocalories (kcal) of added sugars per day and adults consumed $142 \mathrm{kcal}$ per day above the suggested amounts for healthy diets (Krebs-Smith, 2001). Bowman (1999) reported persons eating a high percentage of calories from added sugars had diets that were higher in daily calories and lower in protein, fiber, and most micronutrients. The health problems of excess fat and carbohydrate intakes are aggravated by unmet Recommended Daily Allowances (RDA) of certain micronutrients and low intakes of dietary fiber (NRC, 1989b). Dietary fiber is low primarily because Americans consume few fruits and vegetables (National Health and Nutrition Examination Survey [NHANES III], 1994). Fruit and vegetable intakes are so low, only 49\% of Americans eat three or more servings of vegetables per day including potatoes, $8 \%$ eat one or more servings of dark green or orange vegetables per day, and $28 \%$ eat two or more servings of fruit per day (USDHHS, 2000). 
Given the clear links between dietary behavior, obesity, and chronic disease, the last two decades have witnessed increased attempts by the health professions to improve Americans' diets. Part of the problem encountered in these efforts to reduce fat consumption and increase fiber consumption was the failure to recognize a need for different interventions in persons who report different levels of readiness to change their dietary habits. The stage of change model (Prochaska \& DiClemente, 1983; Prochaska, DiClemente, \& Norcross, 1992) has been adapted to readiness to change for dietary behavior.

Stages of Change

Prochaska and DiClemente developed the stages of change model from studies of smokers who ceased smoking on their own or with therapy program assistance (DiClemente \& Prochaska, 1982; Prochaska \& DiClemente, 1983). They found smokers progressed through certain stages of change characterized by patterns of behavior, intention, and time factors. The five stages (Prochaska, DiClemente, \& Norcross, 1992) were as follows: 1) pre-contemplation, 2) contemplation, 3) preparation, 4) action, and 5) maintenance. Pre-contemplation described people with no intention of changing their poor habits or addictions. They were generally unaware of the risks, unconcerned, or relapsed from action or maintenance stages. Contemplation described people who were thinking of changing within six months but not in the next month. People in the preparation stage planned to make the change within a month. They sometimes engaged in preliminary behaviors such as gathering information on withdrawal coping methods. By the action stage, people have changed their behaviors but for less than six months. In the maintenance stage, the behavioral change has been in place for more than six months. Relapse to an earlier stage usually occurred several times in the course of cessation. 
Those who relapsed to the precontemplation stage often remained in the stage indefinitely and considered further attempts to change as futile.

Further research on the stages of change model (Prochaska, DiClemente, Velicer, Ginpil, \& Norcross, 1985) added predictive refinements based on Janis \& Mann's (1977) decisionmaking theory. In this theory, a person resolved conflict and chose to act or not act based on the balance of expected positive and negative outcomes categorized as follows: a) gains or losses for self, b) gains or losses for significant others, c) approval or disapproval from self, and d) approval or disapproval from others. Computing the difference (or balance) between the positives and negatives resulted in an estimation of the likelihood of a person pursuing this course of action. For example, a person who perceived great gains for self and others to change behavior accompanied by few losses would endorse a readiness to change and display increased effort toward behavior change. Prochaska et al. (1985) reduced the eight factors from decision making theory to a single dimension and calculated the benefits and costs (or pros and cons) of changing behavior and termed this dimension decisional balance. Research findings have shown highest benefits (pros) in the action stage and lowest in the precontemplation stage with a shift to a positive decisional balance occurring by the action stage. Based on the success of the model with smokers, Prochaska and DiClemente and others began to apply the model to a variety of health problems. They determined early in their work that most intervention programs were designed for people in the action stage and typically resulted in a lack of change for people in the earlier stages. They recommended matching interventions to an individual's stage to improve success.

Based on the Prochaska and DiClemente model, persons can be categorized into stages of change for improving and maintaining specific dietary behaviors. To assign to stage, participants 
respond to 4 to 7 questions or items arranged as a staging algorithm. As an example for reducing dietary fat, the first question would ask if participants have limited the fat in their diet. If they responded positively, a second question on the length of time for dietary change classified them in the maintenance stage for dietary fat reductions lasting more than six months and to the action stage for reductions lasting less than six months. If participants indicated they had not limited fat in their diet, a third question would be asked about their intention to limit fat. A positive answer for intent directed participants to a question on how soon they intend to change. Less than a month classified participants to the preparation stage and more than a month to the contemplation stage. No intention to change classified participants to the precontemplation stage. Curry, Kristal, and Bowen (1992) conducted the first study using the stages of change algorithm applied to reducing dietary fat levels. A discussion of research conducted on the stages of change model applied to dietary behavior and the model's limitations follows.

\section{Research on Stages of Change Applied to Dietary Behavior}

Forty-four research articles using the stages of change model have examined dietary factors including diet, fat, fiber, fruit and vegetable intakes. Two basic types of study exist: 1) the applicability of the stages of change model to dietary behavior (model testing), and 2) the utility of stages of change for improving dietary behavior (intervention). Model testing studies can be further divided into: a) studies employing assessment classification methods for adapting the stages of change model to dietary intake behavior, b) studies comparing stages of change and psychosocial factors to examine the predicted relations to other elements of the model, and c) studies examining model generalizability to other populations. Review Table A1 (see Appendix A) provides a summary of the model testing research including authors, sample populations, measures, and percentage of population categorized to each stage. Review Table A2 (see 
Appendix A) provides similar information for the intervention studies with the addition of the research groups and the results of the intervention by stage (the percentage of the population assigned to each stage was seldom reported in these studies). For comparison purposes, precontemplation, contemplation, and preparation may be referred to as the earlier stages and action and maintenance as the later stages.

The descriptions of these research studies included measures commonly used in dietary research. For example, food frequency questionnaires (FFQ) are often used to estimate dietary intakes. FFQs consist of a list of foods with portion sizes and intake frequency estimates over a period of time. Estimates of intakes can also be derived from 24-hour food recalls, which question persons about their eating habits over the past 24 hours. Multiple food recalls on nonconsecutive days are considered the most accurate measures of dietary intakes but FFQs have acceptable reliability with food recalls for estimating dietary fat intakes (Kristal, Beresford, \& Lazovich, 1994; Kristal, Vizenor, Patterson et al., 2000; Neuhouser, Kristal, McLerron et al., 1999).

It is beyond the scope of this paper to critically evaluate each study. Rather, several key problems affecting the application of the transtheoretical or stages of change model to dietary behavior will be highlighted in the following sections. These problems include: a) the difficulties associated with assessing fats and fiber as intake due to the respondents' lack of knowledge regarding the fat and fiber content of various foods, b) the failure to consider gender differences in assessing stages of change and decisional balance, and c) the design of effective interventions for changing dietary behavior without providing participants in these programs with accurate feedback regarding their actual fat and fiber intake. 


\section{Hidden Nutrients as a Staging Factor}

Several studies reported problems with designating a stage of change based on selfreports of hidden nutrients such as fat and fiber (Brug, Hospers, \& Kok, 1996; Glanz, Kristal, Tilley et al., 1998; Greene, Rossi, Reed et al.1994; Greene \& Rossi, 1998; Hargreaves \& Schlunct, 1999; Ounpuu, Woolcott, \& Greene, 2000; Rossi, 1993; Sporny \& Contento, 1995). Susan Rossi (1993) separated the maintenance group into true maintainers and pseudomaintainers (i.e., individuals whose self-reports of a low-fat diet conflicted with actual fat intakes greater then $30 \%$ based on a quick dietary screening measure). Rossi viewed pseudo-maintainers as closer to the earlier stages for intention to change and possible interventions than the later stages. She suggested that researchers utilize estimated fat levels from ratings for several food choices as part of a more accurate staging algorithm. Steptoe, Wijetunge, Doherty, and Wardle (1996) evaluated the stages of change, dietary fat intake, and decisional balance in a British population. They suggested inaccurate dietary self-reports lead to stage misclassifications and to inappropriate intervention. Sporny and Contento (1995) found men self-assigned in the maintenance stage had estimated fat intakes well above recommended levels. Some of the studies addressed the problem of assessing fat and fiber levels by assigning individuals to the action or maintenance stages based on estimated nutrient intakes (Greene et al., 1998) rather than selfreports. Brug and van Assema (2000) recruited participants for a nutrition education program. They assigned people to the precontemplation stage based on high dietary fat intakes and no current attempts to "eat less fat." The authors also noted a fairly large number of precontemplators with no stated interest in changing their behavior still joined an intervention program. This method for staging to the precontemplation stage possibly incorrectly assigned 
pseudo-maintainers who actually were willing to return to preparation or action stages once they received dietary feedback.

Another strategy for improved dietary staging consisted of asking for consumption levels of five high fat foods (Auld et al., 1998). This strategy produced additional problems as shortening an FFQ to five high-fat foods significantly lowered its predictive ability for dietary estimates compared to 24-hour food recalls and food diaries used in most dietary research (Thompson \& Byers, 1994). In a variation on self-staging for dietary fat, Hargraves et al. (1999) designed a two-part algorithm. The first part asked participants if they avoided high-fat foods and provided several examples. The second part of the algorithm inquired about their current use of or intention to change five fat-reducing or fat-replacing behaviors. Based on this algorithm, those in the action and maintenance stages still had dietary fat intakes above recommended levels. The optimal process for combining a typical staging algorithm for dietary fat reduction and a separate estimate of fat intake remained unclear.

Some studies have designed stages of change for five servings a day of fruit and vegetables $(\mathrm{F} \& \mathrm{~V})$ based on the National Cancer Institute's "5 a Day" program (1986). The strategy may improve self-observation of behavior but adds confusion over serving size and the nutrient quality of some fruits and vegetables such as filtered juices or fried potatoes. Most of the studies examining stage of change for F\&V have not compared the groups for actual intakes of fiber or daily servings of fruit and vegetables. Brug, Glanz, and Kok (1997) found large numbers of a Dutch population had self-staged to the action and maintenance groups but based on an FFQ, actually consumed very low intakes for fruit or vegetables. Of course, these more direct staging methods still involved self-report and were still subject to underreporting because of poor recall, lack of motivation, or social constraints (e.g., demand characteristics). Variations in the 
wording of the questions used in the algorithm have also provided sources of additional error. For example, wording for the behavior change element has ranged from the general question "Have you tried to reduce the level of fat in your diet?" to the specific question "Do you consume no more than $30 \%$ of your calories per day as fat?" Obviously the format of the question will greatly influence how the participant is staged.

The typical algorithm for dietary change has met with inconsistent results because smoking behavior and dietary behavior differ in critical ways. Dietary habits are largely learned and for the most part do not involve food addictions comparable to smoking as a delivery system for nicotine. Unlike smoking cessation, people cannot engage in food cessation. Thus the goals for dietary change always involve behavioral increases, decreases, or substitutions rather than the elimination of behavior. Most people have difficulty reporting a behavior like fat consumption. Much of this difficulty arises from the lack of knowledge regarding fat content of foods and the difficulty in detecting fat levels in foods (Boury, 1998). As Ni Mhurchu, Margettes, and Speller (1997) discussed, the complexity of dietary behavior also makes stage classification difficult. Bowen, Meischke, and Tomoyasu (1994) described several differences in reducing dietary fat compared to smoking cessation. The goal for dietary fat reduction was less specific than for smoking cessation and involved changes in many dietary behaviors. The time factor for stabilizing complex dietary behaviors to the maintenance stage may have benefited from extension to a period longer than six months (Boyle, O'Connor, Pronk, \& Tan, 1998). Dietary relapse tended to involve a gradual return to old habits rather than a smoker's sudden resumption of behavior. Also, many high-fat foods remained socially desirable compared to the prevailing social consensus on the negative aspects of smoking. Many of these factors have contributed to the generally inconsistent findings depicted in review Tables A1 and A2 (see Appendix A). 


\section{Gender differences in stages of dietary behavior}

Men in the United States suffer higher morbidity and mortality rates from diseases with an association to health behaviors such as dietary behaviors (CDC-NCCDPHP, 2002). Death rates for heart disease, stroke, all cancers, colorectal cancer, and diabetes are higher for men than for women. Prevalence rates for myocardial infarction and stroke are higher in men. Men also have higher risk factors for several chronic diseases (CDC-NCHS, 2002). Serum cholesterol is slightly higher overall with much higher rates occurring in males until the age of 44 when other factors such as heart disease treatment and mortality may begin affecting rates. Overweight is also higher in men although obesity is higher in women. Health promoting behaviors including prudent dietary patterns are generally lower in men (CDC-NCCDPHP; Holtzman et al. 2000).

Early attempts to explain these differences focused on internal and external locus of control (LOC) from Rotter's Social theory (Rotter, 1966). Based on this theory, men's risky health behavior arose from their tendency to have an external LOC. The attempted explanation proved problematic when demographic variables including age (Morganti et al., 1988) and religious background (Eden et al., 1984), were shown to have a stronger influence on LOC than gender. The large number of studies utilizing college and high school student samples accounted for part of the early LOC gender findings relating to health behaviors. AbuSabha and Achterberg (1997) reviewed several predictors of nutrition and health promoting behaviors and concluded the research on locus of control was inconclusive.

The Health Belief Model (Janz \& Becker, 1984) has been commonly used in health behavior research but has not been specifically applied to gender differences. According to the model, when individuals perceived threat from illness (susceptibility, severity), beliefs about the benefits and costs (barriers) of healthful behaviors affected the likelihood of engaging in the 
healthful behaviors. Modifying variables (cues to action), such as education, influenced beliefs about susceptibility, severity, benefits, and barriers. In a review of social cognition models such as the Health Belief Model, Ogden (2003) reported it had some utility for shaping research design but a) had serious conceptual problems including unspecific constructs, b) the cognitive categories and items selected for study were correlated leading to conclusions that were true by definition, and c) assessment of the constructs may have created or changed cognitions and behavior merely by asking the questions during assessment. As stages of change addressed most of the concepts in the Health Belief Model, the Health Belief Model was not utilized in this study.

More recently, Courtenay (2000) described social and cultural influences on the development of the masculine role, influences on men for conforming to the accepted masculine role definition, and role pressure effects on men's health behaviors. Addis and Mahalik (2003) have refined the gender-role socialization approach for explaining gender differences in seeking help for physical and mental health issues. The gender-role socialization model addressed the disadvantage of fixed sex differences that merely described and accepted gender-related findings in research and led to a lack of innovation in health programs (Addis \& Mahalik). Gender-role socialization approaches provided needed flexibility for addressing individual and group differences and provided the basis for changing some behaviors associated with the masculine stereotype. Common threads in the societally-accepted American masculine role included strength, self-reliance, independence, emotional control, physical endurance, denial of pain, and perpetual interest in sex. Male relatives, peers, the media, and the culture trained boys in these role characteristics. Violating the understood behaviors associated with the masculine role invited scorn, typically accompanied by feminine comparisons, and subordination to other males 
(Courtenay). In focus groups with college men, Davies et al. (2000) found men's perceived social pressure to be viewed as independent and invulnerable interfered with adopting healthier lifestyles. In Western cultures, healthy behaviors including dietary behaviors were assigned to the feminine sphere of endeavors (Courtenay, 1998; 2002). In addition to women having a caretaker role expectation, Western culture endorses thinness for women (Garner et al., 1980). This ideal body image for women has been associated with high rates of body dissatisfaction and concern about appearance for women compared to men (Pingitore, Spring, \& Garfield, 1997; Pliner, Chaiken, \& Flett, 1990; Reboussin et al., 2000). This pattern of concern with body image has been shown to be higher for college-educated women (Caldwell, Brownell, \& Wilfey, 1997). Body satisfaction was also related to age with younger women indicating less satisfaction than older women (Reboussin et al.) For older women, body function had greater importance than body appearance. Thus, the combined cultural expectations for taking care of others and maintaining one's appearance provided women with more incentive than men for healthier eating or at least for lower calorie eating behavior.

The research studies reporting demographic variables have commonly reported a gender effect for staging persons on fat and fiber intake (Auld et al., 1998; Currey, Kristal, \& Bowen, 1992). More men than women were typically assigned to the precontemplation stage and more women than men were assigned to the later stages. Consistent with the staging effect, more men express a low decisional balance with a relatively low pros to high cons ratio for dietary change and more women had a high decisional balance with high pros to low cons ratio. The general consensus among the researchers who have interpreted the gender effect was that a higher interest in health existed in women compared to men. This consensus ignored individual differences and failed to provide strategies for promoting change in men. The general health 
issues commonly used in decisional balance scales aligned with cultural expectations for feminine interests in health and nutrition. Thus the gender effect observed in studies like these may have been an artifact of the nature of the questions included in the decisional balance scales.

Winett (1995) recommended designing health promotion programs using marketing principles. Taking the lesson from the Viagra ${ }^{\circledR}$ phenomenon, decisional balance assessment might be quite different if it included men's health issues such as increased virility, vigor, and youthfulness gained from eating healthy diets. Focusing on these issues may also encourage men to consider or act on changing their diets and lead to assignment to higher stages. Several relations between diet and health may then have greater saliency for men. For example, messages might include: a) "I can decrease my chances of suffering impotence from diabetes by eating a low-fat diet," b) "Keeping my cholesterol low though diet means fewer visits to the doctor," and c) "My prostate will last longer if I just moderate the fat in my diet." Increasing the saliency of messages to men's issues may allow for better assessment of decisional balance for dietary behavior change and more effective tailoring of interventions for men.

\section{Dietary Feedback as an Intervention}

For stage of change intervention studies, the greatest reduction in dietary fat has been reported among the action stage members, as expected from the model (Campbell, DeVelis et al., 1994) or the preparation and action groups (Beresford et al., 1997; Green \& Rossi, 1998). The reductions tended to be small but significant. The limited duration of some of the studies may have explained some of the problem in obtaining more robust findings. More recently, increases in fiber or fruit and vegetable consumption have been observed in these intervention studies (Siero, Broer, Bemelmans, Meyboom-de Jong, 2000). Prochaska, Norcross, et al. (1992) included an extra variable, a cash award competition for weight loss and treatment attendance, at 
one of two worksites. At both sites, those in the action stage had similar weight loss. However, at the competition site, precontemplators exhibited a significant weight loss similar to those in the action stage compared to no weight loss for precontemplators at the non-competition site. Prochaska, Norcross, et al. did not discuss this finding regarding stage of change. The stage of change model predicted precontemplators would not respond to behavioral approaches because they had not made the decision to change. Instead, the cash award finding suggested behavior management techniques using positive reinforcement contingencies can be effective at any stage. Demonstration of the utility of stages of change model for actual dietary behavior improvement awaits additional research.

Even precontemplators might be induced to change if provided initially with single easy steps presented attractively. An interesting variation on tailored interventions was conducted by Winett et al. (1991). Computerized feedback on intended purchases was provided at a local supermarket. Information to improve selections was provided using successive approximations, simple changes in routine food purchases, and obtaining commitment to select better purchases. The control group received general nutrition and shopping information. The intervention succeeded in lowering high-fat food purchases and increasing high-fiber grain purchases with maintenance or continued improvement at follow-up. Finckenor and Bryd-Bredbenner (2000) did find dietary fat reduction in the earlier stages but this was with undergraduates taking a nutrition class. Class sections were randomized to a standard nutrition class or an experimental class receiving nutrition information, processes appropriate to earlier stages of change, and enhancements such as taste tests. Apparently, the experimental classes received a mixture of processes appropriate to earlier and later stages. Highly individualized skill development or 
intensive group interventions have been successful at modifying these complex dietary behaviors.

Tailoring has come to include individualized messages that may be stage matched or primarily action oriented and may be delivered by a variety of means from individual counseling (Calfas et al., 2002) to computer generated mailings derived from lists of hundreds of messages (Brug \& van Assema, 2000). Campbell et al. (1994) found tailoring effective for fat reduction but not for increasing fruit and vegetable consumption. Lutz et al. (1999) examined tailored, tailored with goal setting, and non-tailored newsletters delivered monthly for four months. All three types of newsletters were all equally effective at increasing fruit and vegetable consumption compared to a control group. Methods combining tailoring with other strategies such as physician counseling have also been effective with dietary change (Campbell et al.; Kristal, Curry, Shattuck, Feng, \& Li, 2002; Delichatsios, Hunt, Lobb, Emmons, \& Gillman, 2001). Tailoring has generally been found to be more effective than non-treatment but the advantages of tailoring versus non-tailored promotion and education efforts remained unclear.

Treatment intensity has varied in dietary intervention studies. Most stage of change studies examining changes in dietary intake employed treatment conditions with multiple participant meetings (Siero et al., 2000), classes (Finckenor \& Byrd-Bredbenner, 2000; Kristal, Glanz, Tilley, \& Li, 2000; Prochaska, Norcross, et al., 1992), counseling sessions (Steptoe, Kerry, Rink, Hilton, 2001), or counseling by a physician with follow-up reminders (Beresford et al., 1997). Greene and Rossi (1998) provided a treatment group with one dietary feedback report and found no difference between control and treatment groups at 6, 12, or 18 months. Single tailored message reports were examined in a primary care center (Campbell et al., 1994) and the reports were stage matched and provided messages relating to psychosocial factors determined 
during original assessment. The tailored message group did lower their fat intake but did not increase fruit and vegetable intake compared to the control group. Dietary feedback was also examined in studies that did not utilize stages of change assessment. One study provided participants with feedback on intakes of fat, fruit, and vegetables, but the treatment group received additional information based on the initial assessment of their attitudes, social supports, and self-efficacy (Brug, Steenhuis, van Assema, Glanz, \& De Vries, 1999). Both groups significantly decreased their fat intakes and increased their intakes of fruit and vegetables suggesting the feedback had a positive effect but without a "no treatment" control group for comparison. Another study providing a single feedback report found no difference between the feedback and control groups in decreasing their fat intake (Raats, Sparks, Geekie, \& Shepherd, 1999). Armitage and Conner (2001) provided participants with a single sentence report stating current fat intake and found significant decreases in fat intake for the treatment group compared to the control group. In this case, those receiving high fat intake reports lowered their fat levels and those receiving low fat intake reports maintained their fat intake levels. The exact relation of treatment intensity and necessary message components for dietary feedback was not determined. In sum, although the findings are not entirely consistent, there is evidence that minimal feedback interventions may result in dietary behavior change.

Investigators continue to examine the effective components of stage of change model and tailored messages for improving dietary behavior. Staging difficulties, bias from self-selection, intensity of intervention contacts, number of contacts, reinforcement strategies, and other treatment components serve to confuse the available recommendations. Put more simply, are people not ready for change? Or, do the interventions require too much rapid change for all but the few who respond well to the weak and distant reinforcement of health benefits? 


\section{Purpose of the Study}

One purpose of this investigation is to explore gender differences in both stages of change and decisional balance ratings. Some stages of change research has found more men than women in the precontemplation stage and more women than men in the action stage (e.g. Auld, 1998). Similarly, the standard decisional balance scale based on general health issues (e.g., reducing dietary fat improves health) or taste and convenience issues has commonly revealed gender differences with more men endorsing lower pro ratings and pro-con ratios for changing to a healthier diet than women's ratings. This is usually interpreted as indicating men are less interested in health. Alternately, however, men may have more interest in a subset of men's health issues which to date have not been explored in the standard decisional balance scales. This study examines whether gender differences remain when decisional balance scales include items pertinent to a specific set of men's health issues related to virility, vigor, and youthfulness. It is hypothesized men will respond with higher pro ratings and pro-con ratios on an instrument designed around men's health issues than ratings based on general health benefits. Women are expected to respond similarly to either general health items or to items addressing women's health issues.

Previous research on stages of change has found people could reasonably estimate specific foods they eat each day, such as the number of fruits and vegetables (Laforge, Greene, \& Prochaska, 1994) but not the level of hidden nutrients such as fat or fiber in their diets. Researchers have consistently found people underestimate their dietary fat intake and overestimate their dietary fiber intake (e.g., Greene, Rossi, Reed, Willey, \& Prochaska, 1994; Rossi, 1993). Many people may inaccurately report information regarding stages of change based on these biased estimates of their diet. Some researchers attempted to improve the accuracy of 
stage of change assessment by reassigning participants based on the more reliable estimates of fat or fiber intakes based on an FFQ or 24-hour food recall (Auld et al., 1998; Glanz et al., 1994; Greene, Rossi, Reed, Willey, and Prochaska, 1994). In these investigations, a large number of participants initially assigned to the maintenance stage were reassigned to the precontemplation stage. To date, the research has not examined the influence of dietary feedback on assigning persons to various stages of change. A second purpose of this investigation will be to examine the effect of providing dietary feedback upon participants' reports for stage of change.

Research findings indicate the majority of people need more than general information regarding fat and fiber intake to successfully change their dietary habits, largely because of limited knowledge of the best sources for reducing fat intakes and increasing fiber intakes (e.g. Auld et al. 1998). It is hypothesized receiving dietary feedback on fat and fiber intakes alone will result in less dietary change than receiving more specific feedback with suggestions for lowering fat and increasing fiber based upon an individual's FFQ analysis. In addition, behavior analysis suggests the problem with some behavior change strategies may be the expectation for too much change in a short period of time (e.g., reduce all sources of dietary fat in six months.) The third purpose of this investigation explores the effectiveness of individually tailored interventions based on developing a plan using a series of smaller steps from a specific dietary analysis compared to feedback alone. It is hypothesized these tailored interventions using small specific steps will be effective for all of the stages of dietary change except those participants in the precontemplation stage.

In summary, this study includes several purposes: 1) comparing men and women regarding gender specific or general benefits and costs of dietary change; 2) examining the effect of accurate feedback for hidden dietary levels of fat and fiber on reported stage of change; and 3) 
comparing the effect of dietary behavior change across the stages among participants in a feedback group, an enhanced feedback group, and a no feedback control group.

Methods

\section{Participants}

Adults over 18 years of age who completed a mailed enrollment packet were included in the study. Of 615 packets mailed and approximately 35 distributed by friends, colleagues and other participants, 273 were returned for a $42 \%$ response rate. The participants had a mean age of 42.8 years $( \pm 14.4)$. Five participants had partially incomplete background information.

Midpoints for the age groups from the baseline FFQs were used for individual ages for these individuals. One participant's SOC for low-fat dietary behaviors was incomplete at baseline.

Recruiting strategies varied in degree of success. Because respondents were not asked to list the source for their recruiting information and recruiting methods overlapped in time, exact sources for recruits were unknown. Based the prevailing recruiting strategy in use at a given time and addresses provided during initial contact, participants were estimated to have come from the following sources: 9 from the PEIA webpage, 62 from the hospital mass email to employees, 45 from the study webpage, 31 from friends or associates, 30 recruited by other participants, 27 from the events calendar notice in the metropolitan newspaper, 24 from the posters mailed to the health clubs and gyms, 20 from the notices placed in the West Virginia newspapers, 8 from the undergraduate psychology classes, 6 from the paid ad in a major metropolitan newspaper, and 11 from the posters on university bulletin boards.

Eighty-six percent of the participants returned the second survey leaving 87 men and 148 women in the study at the second phase. The final questionnaire was returned by $72 \%$ of the original participants with 71 men and 126 women included in the final analysis. Three 
participants did not complete the background information form with contact information and could not be included in the remaining mailings. Ten packets from the second mailing were returned by the Post Office with no forwarding address. Several undergraduates participated at the end of the semester for the extra credit points for their psychology classes but five did not complete the final phase. The remaining 58 participants dropped out of the study for unknown reasons.

Measures

Background Information and Health Behaviors. The background information form (see Appendix B) requested information on date of birth, gender, and education level. One multiple response item addressed previous dietary training. Health classes in school included high school or undergraduate classes and training for certification such as personal trainers or culinary arts. National diet programs included commercial programs such as Weight Watchers and organized groups with local meetings such as Overeaters Anonymous. A category for advice seeking was created from the item for "Other: please specify." Advice seeking included a variety of sources as follows: reading magazines and books, television viewing, internet information, and advice from personal trainers, doctors, and family members.

Rates of tobacco use were assessed through the Health Behaviors Questionnaire (see Appendix C) devised for this study as recommended by Wang, Eddy, and Fitzhugh (1992) and based on previous investigations (Lubin et al., 1984). The Surgeon General's (USDHHS, 1989) report on smoking reviews the dose-response relation between the number of cigarettes smoked, the length of time for smoking, and mortality rates particularly from lung cancer. Lubin et al. reported on an epidemiological survey in Western Europe. The relative risks for filtered cigarettes were calculated at 1.0 for 1-9 cigarettes per day, 2.0 for 10-19 cigarettes per day, 2.6 
for 20-29 cigarettes per day and 5.8 for $30+$ cigarettes per day. Lubin et al. also noted a decreasing risk associated with smoking cessation. In a meta-analysis, Dallongville, Marecaux, Fruchart, and Amouyel (1998) concluded smokers consumed more calories from fat and less fiber and vitamins than nonsmokers consumed. The Health Behaviors Questionnaire collects a self-report of current levels of cigarette smoking and time since quitting. For purposes of this study, smoking was measured in number of cigarettes per day.

Activity levels used in the Health Behaviors Questionnaire reflect prescription guidelines reported by Pollock (1978). There are three levels as follows: 1) sedentary - little physical activity, 2) minimally active - low energy cost or frequency less than three times a week, and 3) active - at least 30 minutes of aerobic activities three times per week. Level of activity has been associated both with cardiovascular benefits and weight reduction, most likelihood of fitting into a busy schedule, and least risk of injury. A smaller increase in cardiovascular benefits has been found with an increase from moderate activity to vigorous activity. Specific information on reliability and validity of this activity rating system has not been reported.

For alcohol consumption, Moore and Gernstein (1981) summarized several national surveys and suggested the following classification system: abstainers, light drinkers (up to three drinks or 1.5 ounces of alcohol per week), moderate drinkers (up to two drinks or one ounce of alcohol per day), and heavy drinkers (two + drinks or more than one ounce of alcohol per day). Williamson et al. (1987) reported adult drinkers (nondrinkers excluded) consumed 10\% of their calories per day from alcohol. Moderate drinking has not been associated with disease in healthy adults (USDHHS, 1988). For this study, the Moore and Gernstein classification system was used. Alcohol consumption was estimated from the FFQ alcohol (gm) intake. 
Stages of Change Algorithms. This study employs the Curry et al. (1992) algorithm for staging dietary behavior and avoids the issue of self-assessment based on estimated level of fat intake below $30 \%$ of daily calories. This algorithm includes the assessment levels from the standard approach to staging for any health behavior (Prochaska \& Velicer, 1997). These assessment levels address four questions as follows: "1. I solved my problem more than six months ago. 2. I have taken action on my problem within the past six months. 3. I am intending to take action in the next month. 4. I am intending to take action in the next six months." (Prochaska, Norcross, \& DiClemente, 1994, p. 68). The Curry et al. algorithm utilizes confidence rather than intention to change in the next month for assignment to the preparation stage. Confidence is a measure of self-efficacy as described by Bandura (1997). AbuSabha and Achterberg (1997) in a review of health related psychosocial factors found that self-efficacy was a consistently good predictor of health behaviors. The staging questions and algorithms for dietary fat and fiber are included in the Health Behaviors Questionnaire (see Appendix C). For some analyses, stages were combined into the early and late stages. The early stage consisted of the precontemplation, contemplation, and preparation stages based on participant lack of change. The late stages included the action and maintenance stages or person who had changed their behavior but for varying lengths of time.

Food Frequency Questionnaire. Food Frequency Questionnaires (FFQ) presented a series of questions about food intake patterns over a period of time, generally one to three months (see Appendix D). Response sets are computer analyzed with comparison to an algorithm derived from a large nutrient database (Schakel, Sievert, \& Buzzard, 1988). Kristal, Shattuck, Henry, and Fowler (1990) reported the development and utility of the (FFQ) in estimating nutrient levels in a person's diet during a specified period of time. The FFQ begins with 19 adjustment questions on 
food choices and preparation methods. One example asks, "Did you eat cookies during this time period?" A "yes" response leads to a question on how often low-fat cookies such as vanilla wafers were consumed with choices ranging from "almost always" to "never." Other questions clarify the type of fat used during cooking or after cooking, the level of fat in milk products, and behaviors surrounding the consumption of meat such as eating the skin on chicken or turkey. The second section of the FFQ asks respondents for a rating of their consumption frequency and serving size for 122 specific food and beverage items. Foods are grouped into these categories: "Fruits and Juices"; "Vegetables"; "Meat, Fish, Poultry, Lunch Items"; "Breads, Snacks, and Spreads"; "Breakfast Foods"; "Dairy Products"; "Sweets"; and "Beverages." Frequency choices range from "less than once a month" to "2+ times per day" for foods or "6+ per day" for beverages. For each food, the FFQ lists the amount for a medium serving such as "1/2 cup" for most vegetables and "1 cup" for spaghetti. The participant rates their usual serving size as small, medium, or large in comparison to the example. A third section asks four summary questions on the use of fat in cooking or after cooking, the usual consumption of vegetables, and the usual consumption of fruit with choices ranging from "less than 1 per day" to "5+ per day."

As noted by Kristal, Shattuck, Henry, and Fowler (1990), dietary assessment lacks a "gold standard" assessment for comparison with other assessments. Direct observation of participants over time would be accurate but extremely difficult to achieve in community settings. There are three methods used for determining nutrient intake: food diaries or recalls, FFQs, and brief screeners for a single nutrient, usually fat. All three methods have accuracy problems related to self-report. For food diaries or recalls, participants list everything they have consumed, amounts, brands, condiments such as ketchup for either three or four non-consecutive days. Participants write their eating behaviors in a diary or respond to questions from a trained 
interviewer during a recall. FFQs such as the one used in this study ask the participant to list their eating patterns for an extensive list of food for a longer time period generally ranging from one to three months. Brief screening instruments ask the participant a series of questions about their consumption or habits regarding a nutrient usually dietary fat behavior. Kristal et al. reported the means for percentage of calories from fat for several assessment methods as $32.6 \%$ (an earlier version of the FFQ), 32.4\% (two Four-Day Diet Records), 33.3\% (Self-Administered Short Questionnaire), and 31.5\% (Telephone-Administered Short Questionnaire). The correlation between the FFQ and the two Four-day Diet Records were reported as a weighted kappa statistic of 0.64 for calories from fat.

Martin et al. (1997) provided additional validation of the 12/92 revision of the FFQ used in this study. Using a control group from the clinical trials of the Diet and Breast Cancer Prevention Trial, the FFQ was compared to the mean of food diaries collected over a one-year period. After a baseline, the food diaries for three nonconsecutive days were collected quarterly for the first year. The FFQ was collected by mail survey after the food diaries were collected (six months average time period between collection of the FFQ and the previous food diary).

Participants estimated their food intake for the past three months. The correlation coefficient for the FFQ and food diaries was 0.74 for the percentage of calories from fat. Fiber estimates were not reported. In another comparison of a brief screener, FFQ, and dietary recalls, Neuhouser, Kristal, McLerran, Patterson, and Atkinson (1999) found a correlation of 0.71 between FFQs and dietary recalls. As reported by Thompson and Byers (1994), food frequency questionnaires in general are useful for estimating subject's nutrient intakes.

Participants were asked to rate their food habits for the past month at both the baseline and post-intervention phase. The FFQs were computer scored at the Fred Hutchinson Cancer 
Research Center with a scoring system derived from a large food and nutrient database (Schakel, Sievert, \& Buzzard, 1988). Nutrients used from this analysis were \% of calories from fat, and fiber $(\mathrm{gm})$.

Decisional balance measures. There are many variations on rating the pros and cons of change to a healthier diet (i.e., decisional balance). Steptoe, Wijetunge, Doherty, and Wardle (1996) developed the items for their decisional balance measure from previous research on attitudes about healthy eating. After factor analysis and varimax rotation, the final scale had six pro items with an internal consistency of 0.77 and six con items with an internal consistency of 0.64. Steptoe et al. did find the expected pattern of lower pros and higher cons in the earlier stages and a shift to higher pros and lower cons at the action stage. The final measure included pro and con items such as "What I eat is one of the most important things for my health." and "It is not easy to buy healthy food." This decisional balance questionnaire was used for comparison with the gender-based decisional balance used in this study. Items for the gender-based decisional balance questionnaire were developed from available research. Most of the research from which items were derived is epidemiological, because of the time course of chronic health problems. Some items focused on differences in bloodwork factors based on dietary differences, some items related to symptoms of chronic illnesses such as non-insulin dependent diabetes, and some items related to the side effects of drugs used to treat chronic diseases such as hypertension.

The Decisional Balance Measure for males (see Appendix E) and females (see Appendix F) contains pro items for males and females respectively. The following men's health problems are included: prostate cancer (Giles \& Ireland, 1997; Tominaga \& Kurioshi, 1997), normal testosterone levels (Katznelson, Rosenthal, Rosol, Anderson, Hayden, Schoenfeld, \& Klibanski, 
1998), and impotence (Hackett, 1996; Perera \& Hill, 1998). Similarly, pro items were developed for females as follows: breast cancer (Boyd, Lockwood, Greenberg, Martin, \& Tritchler, 1997), fatigue (Bowen, Kestin, McTiernan, Carrell, \& Green, 1995), gynecological problems (Jones, 1987), and weight loss (Kraemer et al., 1997). Some items are contained on both gender-based questionnaires but may have increased importance because of current attention by news media and public health educational efforts. Common items for pros include: physical ability or mobility (Visser et al., 1998), urinary problems (Lee et al., 1997), side effects of medicines (Crenshaw \& Goldberg, 1996), cognitive abilities (Draelos, Jacobsen, Weinger, Widom, Ryan, Finkelstein, \& Simonson, 1995), and heart attack (McCarron et al. 1997). The con items are the same on both gender measures but generally reflect current advertising strategies for American men. These items include: image of youth and invulnerability (Gleason, 1996), time constraints (Rubel, 1995), real men eat real foods (Smith, 1998), cost (Rubel), deserving preferred foods as a treat (Rubel), and perceived autonomy (Rubel). The fat and protein combinations item is based on research (Drewnowski, Kurth, Holden-Wiltse, \& Saari, 1992). The item on a heart attack versus nursing home avoidance reflects a personal observation by the author's husband that seems to resonate with male friends and acquaintances. Although items for the male and female version of the decisional balance scales were conceptually based upon epidemiological findings, they have not been validated.

One female and two male participants returned the wrong gender type of decisional balance measure. One male and one female participant skipped the gender type of decisional balance measure and it was not completed. One female participant in the preparation stage for fat and for fiber was a low outlier for the pro items. Data for these six participants were not included in the analysis of decisional balance. 


\section{Design and Procedure}

Recruitment. The initial plan for participant recruitment called for an announcement in the wellness newsletter for the West Virginia Public Employees Insurance Association (PEIA). The newsletter offer was replaced with an offer of a link on the PEIA webpage with over 9,000 hits per month. There were problems with the ease of use for the webpage and the location of data on the server. After several months of recruiting, there were only 9 women enrollees. Several methods were used to expand recruiting. A major hospital agreed to send a mass email to all employees. This required a second Institutional Review Board review and a separate consent form on hospital letterhead. Posters with tear-off strips were sent to 427 gyms and fitness centers in the nearby states (see Appendix G). Posters were also placed at the Health Sciences Center and the Department of Psychology's research recruitment bulletin board. A major city newspaper in the surrounding area placed a notice in the health section of the events calendar (see Appendix G). All newspapers in West Virginia and Pennsylvania towns close to Morgantown received a mailing asking them to place the announcement in the events or health calendar. Attempts were made to have the announcement placed in the calendar section of other major city newspapers but without a local connection to the distribution area, these requests were all denied. One paid ad was placed in the health section of a major city newspaper (see Appendix G). Another advertising route was made through a webpage on the University server. The webpage displayed the announcement with a link to the author's email and contained information similar to the notice used in other recruiting efforts. Various attempts were made to distribute the webpage including: advertising the study's webpage with banner ads placed on other websites, placing the webpage in major search engines such as Yahoo and AOL, and setting links from other webpages. Friends, family, and associates either participated or recruited for the study. 
Participants were asked to mention the study to anyone that might be interested, especially men. New women participants were particularly effective recruiters. Attempts were also made to place a poster of announcement with several major employers in West Virginia but these were unsuccessful because of existing wellness programs, recent mergers, looming layoffs, and other administrative uncertainties. Several hospitals were contacted about a possible recruiting table located at a convenient location such as the entrance to the cafeteria. The hospitals declined recruiting requests generally stating either an unwillingness to have an outside person recruiting customers and staff or an overlap with their existing wellness programs. In one case, the hospital dietitian rejected the study because of concern the cons listed on the decisional balance measure would encourage unhealthy eating behavior. The extended recruiting efforts continued for three years and two months

Baseline Data Collection. Men and women responding to various ads and announcements received a packet containing the following: two copies of the consent form (see Appendix $\mathrm{H}$ ), a recruiting announcement (see Appendix B) with description of the research and background information form, an FFQ, the Health Behaviors Questionnaire with gender appropriate decisional balance measures. The FFQ included instructions with a blank line for the time frame for usual food intake. The time frame of "the past month" was written in this line on all FFQs before mailing the packets to the participants. Each section of the Health Behaviors Questionnaire also included instructions for the participants. A stamped addressed envelope was included for returning the forms and measures. The estimated completion time for the initial packets was approximately 1.25 hours. Enrollment continued until there were sufficient men for approximately 75 men and 75 women at completion of the study. Inducements for participation included individual dietary feedback and entries for a drawing of $\$ 250.00$. Because women were 
effective recruiters for male participants, women were enrolled beyond the originally planned 125 limit. For this reason, there were two cash prizes of $\$ 250$. Also, men recruited from undergraduate Psychology courses received extra credit points for their class.

Intervention. Upon return of the completed enrollment surveys, participants were assigned to stages for low-fat eating. Participants were then assigned to one of three intervention groups: delayed feedback control, dietary feedback, and enhanced dietary feedback. Participants in each group were matched for gender and stage of change for dietary fat. Intervention group assignment was made by use of random number tables. Initially, assignment to group and receipt of feedback materials were delayed to allow for additional recruiting. This would have allowed participants in different groups to receive their materials during the same season. The planned equalization of timing for the groups became extensive because of recruiting difficulties. The timing strategy was abandoned in favor of assigning participants to stage as their materials arrived.

The Fred Hutchinson Cancer Research Center provided a nutrient analysis for the participants' FFQs. Major nutrients were processed into dietary feedback reports (see Appendix I). Grams of fat were multiplied by 9 to obtain calories from fat and then divided by total calories and multiplied by 100 to obtain the percentage of calories from fat. The same process was used to determine percentage of calories from saturated fat. For enhanced feedback, a set of 29 messages were developed from the following sources: American Heart Association Eating Plan for Healthy Americans (n.d.), Dietary Guidelines for Americans (USDA, 2000a), and the National Cholesterol Education Program report on cholesterol detection and treatment (NCEP, 1994; 2000). These messages provided suggestions for replacing or reducing high-fat foods and increasing high-fiber foods (see Appendix J). For the enhanced feedback group, individual FFQs 
were examined for responses indicating high-fat and low-fiber intake sources. Up to three messages to reduce or replace high-fat choices and three messages to increase fiber choices were developed into an enhanced feedback report (see Appendix K).

Packets were prepared for each group. All packets contained the staging questions from the Health Behaviors Questionnaire and a return envelope. Packets varied by group according to the intervention level. The control group received a general brochure on healthy diets (USDA, 2000b). The individual feedback group received the brochure plus the feedback report based on the FFQ analysis (see Appendix I). Finally, the enhanced feedback group received the enhanced message report (see Appendix K) plus the brochure and the dietary feedback report. Participants were asked to review the enclosed materials and complete the second staging algorithm. Participants returning the second survey received a second entry for the drawing. The extensive recruiting efforts interfered with original plans to match participants for gender and stages and led to an extended delay of up to one year before receiving feedback for initial participants. By the end of the study, participants were receiving feedback in two to four weeks. A reminder was mailed to non-responders. Several participants reported they had not received the second mailing or had misplaced it. A duplicate second mailing was then sent to all non-responders.

Post-Intervention Data Collection. After five months to adapt to the feedback, participants received the final packet containing the staging questions, second FFQ, and return envelope. Those who received second mailings for the second phase feedback had at least six weeks to adapt to feedback. Those who returned their measures received their third entry in the drawing. Approximately two months after receiving the post-intervention packets, those who had not returned the measures received a duplicate third packet. FFQs were again computer scored. 
Final feedback reports were sent to all participants completing the last phase of the study.

Members of the control group received their baseline report at this time.

Results

Baseline Characteristics and Health Behaviors. In the baseline sample, there were 171 women (63\%) and 102 men (37\%). Most of the participants had some college education (35\%) or had completed college degrees (53\%). Age and educational level did not vary significantly between men and women. The participants were primarily from Pennsylvania (30\%) or West Virginia (28\%). Another 19\% were from the surrounding states (Maryland, Ohio, Virginia, North Carolina, District of Columbia) with 22\% scattered across the remaining states or Canada.

Eighty-seven percent of participants indicated some type of previous diet or nutrition training. In a duplicated count, training methods included the following: school $63 \%$, seeking advice $25 \%$, national weight loss program $20 \%$, consultation with dietitian or nutritionist $15 \%$, workplace wellness program $14 \%$ and other $7 \%$. Two types of dietary training, national weight loss program and no training varied by gender (see Table 1). More women (28\%) than men (7\%) reported attending a national weight loss program $\left(\chi^{2}=17.6, p<.001\right)$. Fewer women $(8 \%)$ than men $(23 \%)$ reported no dietary training $\left(\chi^{2}=12.2, p<.001\right)$.

The majority of the participants reported current non-smoking (63\%) or ex-smoker (30\%) status. The 20 current smokers (7\%) reported a median intake of 12.5 cigarettes per day although the distribution was nearly bi-modal at 5 and 20 (1 pack) cigarettes. Because of the low number of current smokers, analysis of differences by stage and gender was not conducted. Smoking status did not vary by gender.

A slim plurality of the participants reported aerobic activities three times a week or more (44\%). Another 43\% reported low-energy activities with the remaining $13 \%$ reporting only 
activities of daily living. Chi square analysis was also used to examine gender issues relating to exercise levels [gender (male, female) x exercise level (non-active, minimally active, meets fitness guidelines)] (see Table 2). Men and women differed by activity level $\left(\chi^{2}=9.7, p<.01\right)$ with fewer men $(5 \%)$ than women (18\%) reporting only daily living activity levels compared to the combined low-energy/aerobic levels $\left(\chi^{2}=9.1, p<.01\right)$.

The participants reported generally low levels of alcohol consumption with $70 \%$ light or non-drinkers, 19\% moderate drinkers, and 3\% heavy drinkers. Men consumed significantly more alcohol than women $(\mathrm{M}=.23 \mathrm{oz}, .10 \mathrm{oz} ; t=2.85, p<.01)$. More men $(29 \%)$ compared to women $(10 \%)$ were assigned to the combined moderate to heavy alcohol intake category $\left(\chi^{2}=5.8, p<\right.$ $.05)$.

At baseline, the mean daily energy intake for the participants was $1700 \mathrm{kcal}(\mathrm{SD}=913)$ with men at $1925 \mathrm{kcal}(\mathrm{SD}=1064)$ and women at $1566 \mathrm{kcal}(\mathrm{SD}=782)$. Calorie intakes below $1200 \mathrm{kcal} /$ day were reported by $32 \%$ of the participants. The mean "\% of calories from fat" was $34.2 \%(\mathrm{SD}=9.5)$ for all participants, $34.2 \%(\mathrm{SD}=8.3)$ for men and $34.2 \%(\mathrm{SD}=10.2)$ for women. The mean daily fiber intake reported was $15.7 \mathrm{~g}(\mathrm{SD}=7.9)$, with men at $16.4 \mathrm{~g}(\mathrm{SD}=$ 8.6) and women at $15.4 \mathrm{~g}(\mathrm{SD}=7.5)$. Additional findings regarding dietary intake are reported in several of the following sections.

\section{Baseline SOC Differences.}

For the low-fat SOC algorithm, Table 3 lists the participant assignment percentages (see Table 3). Chi square analysis was used to examine the effect of gender on assignment to stage for dietary fat behavior. Stage for low-fat dietary behaviors did not vary by gender. The mean ages for individuals in the various low-fat stages were significantly different $(F(4,267)=6.5, p<$ .001) (see Table 4 and Appendix L: Summary Tables). Based on post hoc analysis, the 
maintenance stage members were older than the action members $(p<.001)$, the preparation members $(p<.05)$, and the contemplation members $(p<.05)$. The remaining stages did not differ on age. Intake levels measured as percentage of calories from fat based on the initial FFQ were compared to stage assignment for low-fat dietary behaviors. Dietary fat intake was examined by 2 x 3 [Gender (male, female) x Stage (early, action, maintenance)] analyses of variance. Stages were combined because of the low number of men in the contemplation and preparation stages and the low number of women in the precontemplation stage.

Precontemplation, contemplation, and preparation were combined into the early stages. Although older participant age was related to the maintenance stage for low-fat SOC, age was not related to fat intake and did not co-vary with fat intake. For this reason, age was not included in the baseline analysis of fat intake. No significant Gender by Stage interaction or main effect for Gender was found. Dietary intakes did vary by stage (see Table 5 and Appendix L: Summary Tables). For fat intake measured as "\% of daily calories from fat", there was a main effect for Stage $(F(3,264)=22.1, p<.001)$. Post hoc analysis revealed the early stage members consumed a higher " $\%$ of calories from fat" than those in the action stage $(p<.001)$ or maintenance stage $(p<.001)$.

Table 3 also lists the participant assignment percentages for high-fiber SOC (see Table 3). Chi square analyses were used to examine the effect of gender on assignment to dietary stage of change for fiber behaviors. Gender did vary with SOC fiber $\left(\chi^{2}=22.5, p<.001\right)$ as indicated in Table 3. Subgroup comparisons indicated more men than women were assigned to the precontemplation stage $\left(\chi^{2}=10.18, p<.001\right)$. Similarly, fewer men than women were assigned to the action stage $\left(\chi^{2}=13.5, p<.001\right)$. Age varied by stage $(F(4,268)=9.6, p<.001)($ see Table 4 and Appendix L: Summary Tables). Participants in the maintenance stage were older 
than those in the precontemplation $(p<.001)$ or action $(p<.01)$ stages. Daily fiber intake levels were also examined by 2 × 2 [Gender (male, female) x Stage (early, late)] analyses of variance. Stages were combined because of small sample size in some cells. Precontemplation, contemplation, and preparation were combined into the early stages. Action and maintenance were combined into the late stages. Age was not a significant co-variate in the analysis of baseline fiber intake and was not included in the final analysis. There were significant main effects for both Gender and Stage (See Table 5 and Appendix L: Summary Tables). Women consumed slightly more fiber than men $(F(1,269)=3.9, p<.05)$. The late stages consumed more fiber than the early stages $(F(1,269)=28.2, p<.001)$. Participants in the late stages had fiber intakes 5 grams higher than those in the early stages. The Gender by Stage interaction for fiber intake was not significant.

Low-fat SOC was moderately correlated with high-fiber SOC $\left(r_{s}=.40, p<.001\right)$. For low-fat SOC, $76 \%$ of participants in the early stages were in the early stages for high-fiber SOC and $57 \%$ of those in the late stages for low-fat SOC were also in the late stages for high-fiber SOC. Similarly, $81 \%$ of those in the late stages for high-fiber SOC were also in the late stages for low-fat SOC compared to $49 \%$ of those in the early stages for high-fiber SOC also in the early stages for low-fat SOC.

\section{Stage Differences in Study Completion Rates}

Participant study completion rates were examined for their relation to age, feedback status, stage, and gender. Age group was significantly related to completion rates $\left(X^{2}=6.8, p<\right.$ $.01)$. Participants 30 years or older had higher completion rates $(76 \%)$ than younger participants $(59 \%)$. There was no significant difference for feedback status on completion rates. 
Completion rates differed significantly for low-fat SOC $\left(X^{2}=13.5, p<.01\right)$ (see Table 6$)$. The maintenance stage had higher completion rates $(83 \%)$ than the other stages combined $(64 \%)$ $\left(X^{2}=11.5, p<.01\right)$. Women accounted for the difference in completion rates in low-fat SOC $\left(X^{2}\right.$ $=13.4, p<.01)$. Completion rates were higher for women in the maintenance stages $(86 \%)$ compared to the other stages combined $(65 \%)\left(X^{2}=9.6, p<.01\right)$. The remaining stages did not differ significantly in completion rates, nor did completion rates differ by stage for males.

For high-fiber SOC, the difference in completion rates for the maintenance stage did approach significance (see Table 6). Women did have a significant difference in completion rates for high-fiber SOC for different stages $\left(X^{2}=8.0, p<.05\right)$. Again the completion rates were higher for maintenance stage $(89 \%)$ than the other stages $(68 \%)\left(X^{2}=6.8, p<.01\right)$.

\section{Gender Differences in Decisional Balance.}

Ratings on both types (general and specific) of decisional balance measures (DB) at pretreatment (pros, cons, pro/con ratio) were analyzed using a series of 2 × 2 [Gender (male, female) $\mathrm{x}$ Low-fat Stage (early, late)] factorial analyses of variance. Stages were combined because of low numbers of men and women in some of the earlier stages. There was no Gender by Stage interaction for either the general or specific mean pro ratings (see Table 7 and Appendix L: Summary Tables for Table 7). There was a significant main effect for Gender on the general pro ratings $(F(1,262)=17.0, p<.001)$. Women rated the DB general pros higher than men. There was also a significant main effect for Stage on the general pro ratings $(F(1,262)=18.1, p<$ .001). Participants in the later stages rated the general pros higher than those in the early stages. There was no main effect for Gender for the DB specific pro ratings but there was a significant main effect for Stage on the specific pro ratings $(F(1,262)=22.1, p<.001)$. Those in the later stages rated the DB specific pros higher than those in the early stages. 
Participant DB con ratings (see Table 7 and Appendix L: Summary Tables for Table 7) followed a different pattern than the pro ratings described above. There was no main effect for Gender or interaction for Gender by Stage on the general DB con ratings, but there was a significant main effect for Stage $(F(1,262)=12.2, p<.001)$. Participants in the early stages indicated higher agreement with the general DB con items than those in the later stages. For the specific DB con ratings, there was a significant Gender by Stage interaction $(F(1,262)=8.6, p$ $<.01)$. Simple effects tests for the early stages indicated men rated the specific cons higher than women $(t=2.9, \mathrm{df}=91, p<.01$, two-tailed $)$ but men and women in the later stages did not differ on the specific con ratings. Simple effects tests for Gender indicated men in the early stages reported higher agreement with the specific cons against healthy eating than men in the later stages $(t=5.2, \mathrm{df}=97, p<.001$, two-tailed). Similarly, women in the early stages reported greater agreement with the specific cons against healthy eating than women in the later stages $(t$ $=2.2, \mathrm{df}=165, p<.05$, two-tailed).

For low-fat SOC, the pro/con ratios followed a similar pattern to the DB con ratings (see Table 7 and Appendix L: Summary Tables for Table 7). For the general DB measure, there was a significant main effect for Stage $(F(1,262)=14.4, p<.001)$. Those in the later stages for lowfat SOC had a higher ratio than those in the early stages. There was a significant Gender by Stage interaction for the specific DB measure $(F(1,262)=6.8, p<.01)$. Simple effects tests for the early stages indicated men had lower specific pro/con ratios than women $(t=-3.0, \mathrm{df}=91, p$ $<.01$, two-tailed) but men and women in the later stages did not differ on the specific pro/con ratios. Simple effects tests for Gender indicated pro/con ratios were higher for men in the late stages compared to men in the early stages $(t=-6.9, \mathrm{df}=87.2, p<.001$, two-tailed $)$ and for 
women in the later stages compared to women in the early stages $(t=-2.9, \mathrm{df}=165, p<.01$, two-tailed).

A similar analysis of ratings on both types (general and specific) of decisional balance measures was conducted for gender and high-fiber SOC using a series of 2 × 2 [Gender (male, female) x High-fiber Stage (early, late)] factorial analyses of variance. Stages were again combined because of low numbers in the contemplation, preparation, and action stages for high fiber SOC. For the DB general mean pro ratings (see Table 8 and Appendix L: Summary Tables for Table 8), there was a main effect for Gender with women rating the pros slightly higher than men $(F(1,263)=10.0, p<.01)$. There was a main effect for Stage on the general mean pro ratings $(F(1,263)=9.9, p<.01)$ with later stage members rating the pros higher than the cons. For the specific pro ratings, there was a main effect for Stage $(F(1,263)=9.1, p<.01)$ with later stage members rating the pros higher than early stage members. There was no main effect for Gender or interaction for Gender by Stage on the DB specific pro ratings.

For the general con ratings, there were no significant main effects for Gender or Stage or interaction for Gender by Stage although the differences for Stage did approach significance with those in the early stages for high-fiber SOC rating the cons slightly higher than those in the later stages (see Table 8). A significant Gender by Stage interaction for high-fiber SOC was found for the specific con ratings $(F(1,263)=7.8, p<.01)$. Simple effects tests for the early stages of high-fiber behavior indicated men rated the specific cons higher than women $(t=2.3, \mathrm{df}=116.2$, $p<.05$, two-tailed) but men and women in the later stages did not differ on the specific con ratings. Simple effects tests on men indicated men in the early stages rated the specific cons higher than men in the later stages $(t=3.6, \mathrm{df}=97, p<.01$, two-tailed). Women in the early or late stages did not differ in their ratings of the specific cons. 
There were significant main effects for Stage for the two types of pro/con ratios (see Table 8 and Appendix L: Summary Tables for Table 8). Late stage members scored higher for the general pro/con ratio than early stage members. $(F(1,263)=5.8, p<.05)$. Similarly, late stage members had higher specific pro/con ratios than those in the early stages $(F(1,263)=$ $19.1, p<.001)$. Main effects for Gender and interactions for Gender by Stage were not significant for either the general or the specific pro/con ratio.

Post-Feedback Change in Stage Assignment.

This analysis focused on change in self-reported stage assignment following feedback on dietary intake for fat and fiber. Both low-fat and high-fiber SOCs were examined for change immediately following feedback (change from enrollment to stage 2) and change after time to act on the feedback (change from phase 2 to phase 3 ). Stages were combined to early (precontemplation, contemplation, and preparation) and late (action and maintenance) because of small cell sizes, particularly in the early categories. In the early stages, change was categorized as remaining in the early stages or advancing to the later stages. For the later stages, change was coded as regressing to the earlier stages or remaining in the late stages. Both feedback groups (feedback and tailored message) were combined and compared to the wait-list control group for this analysis. Intake levels were added as a separate component to the analysis. For these comparisons, cutpoints were set at 30\% of calories from fat or less (Krauss et al., 2000) and 20g/dy of fiber or more (Marlett, McBurney, \& Slavin, 2002). Chi square analyses were employed [Stage (early, late) x Feedback (no feedback, feedback)].

There were significant differences in stage change $\left(X^{2}=3.8, p=.05\right)$ for those participants initially categorized as being in one of the late stages for low-fat SOC but consuming $>30 \%$ of calories from fat (see Table 9). For late stage members who had high 
dietary fat intakes at baseline, regression to earlier stages was more likely among those receiving feedback (24\%) when compared to those receiving no feedback (7\%). Comparisons among other stages and fat intake levels were not significantly different; however, there were insufficient numbers for analysis in the early stages with intakes below 30\%. Likewise, no significant differences in SOC change were observed among stage or fat intake levels between Phase 2 and Phase 3 of the study (see Table 10). The category for those in the early stage with intakes below $30 \%$ of calories from fat was again too small for analysis.

Change in high-fiber SOC at baseline varied with feedback on low dietary fiber intakes (see Table 11). For late stage members, those receiving feedback on fiber intakes below $20 \mathrm{~g} /$ day were more likely to regress to an earlier stage (33\%) compared to $9 \%$ for those who did not receive this feedback $\left(X^{2}=4.9, p<.05\right)$. There were no differences for the early stages. Low cell sizes in the categories for fiber intake above $20 \mathrm{~g} /$ day precluded analysis of these data. A similar pattern was seen for late stage change from Phase 2 to Phase 3 (see Table 12). For the late stages, $34 \%$ of those receiving feedback on low dietary fiber intake regressed to the early stages compared with $12 \%$ of those receiving no feedback $\left(X^{2}=4.7, p<.05\right)$. The early stages with intakes below 20g/day did not vary in terms of stage change based on feedback. Phase 2 to 3 change contained low cell sizes for the categories with fiber intakes above $20 \mathrm{~g} / \mathrm{day}$.

\section{Dietary Intervention.}

An examination was conducted of the effects of treatment condition, (at baseline, phase 2, and phase 3), and gender on pre-post change in dietary intakes of fat and fiber. The change in fat intake was calculated by subtracting the baseline fat intake level from final fat intake level. Fiber intake change was calculated by subtracting the baseline fiber intakes from the final fiber intake level. One extreme outlier was removed from each intake type. A positive pre-post change 
score indicated an increase in intake from the baseline to the final FFQ. Negative change scores indicated a lower intake level at the final FFQ than during the initial FFQ. Lower fat intakes at post-intervention than at pre-intervention resulted in a negative change score. Conversely, higher fiber intakes at post-intervention compared to pre-intervention resulted in a positive change score. Because of the small number of men in the early stages for low-fat SOC and in the late stages for high-fiber SOC, three-way analyses were not conducted. Pre, post change for fat and for fiber were examined using 2 × 3 [Gender (male, female) x Treatment Group (wait list, feedback, message)] analyses of variance. Stages were combined into early and late for the SOC analyses because of small numbers in some of the cells. The influence of stage on change in fat and fiber intake was examined using 2 x 3 [Stage (early, late) x Treatment Group (wait list, feedback, message)] analyses of variance.

For change in fat intake (see Table 13 and Appendix L: Summary Tables for Table 13), there was a significant interaction for Gender and Treatment $\operatorname{Group}(F(2,190)=3.9, p<.05)$. Simple effects tests for the wait list group indicated men reported lower levels of fat postintervention while women reported higher levels of fat $(t=-2.2, \mathrm{df}=67, p<.05$, two-tailed). Gender differences approached significance with the tailored message group for men reporting lower levels of fat intake post-intervention and women reporting higher post-intervention dietary fat levels $(p<.07)$ but the difference was not significant. There was also a slight difference approaching significance for women in the feedback group who reported lower post-intervention fat intake compared to women in the wait list group. There were no significant main effects for Stage and Treatment Group or interaction for Stage by Treatment Group related to change in fat intake for baseline staging or phase 2 staging (see Table 14 and Appendix L: Summary Tables for Table 14). Pre-post change in "\% of calories from fat" at phase 3 was associated with a 
significant main effect for Stage $(F(1,189)=4.5, p<.05)$. Participants in the later stages reported lower levels of fat intake than participants in the early stages.

The same types of analyses were conducted on the pre-post change in fiber intake. There were no main effects for Gender and Treatment Group or interaction for Gender by Treatment Group for fiber intake (see Table 13 and Appendix L: Summary Tables for Table 13). Similarly, there were no significant findings for high-fiber SOC and Treatment Group or Stage at baseline, phase 2, or phase 3 (see Table 14 and Appendix L: Summary Tables for Table 14).

\section{Discussion}

This study examined three questions related to the application of stage of change theory to dietary intake behavior. The first question addressed whether men really have lower interest in healthy behaviors or whether standard approaches to measuring healthy behaviors fail to address men's specific health interests. The second question addressed the effect of feedback on staging for SOC on hidden nutrients that people cannot adequately judge. The final question examined the use of tailored dietary messages on changes in dietary intake.

\section{Gender Differences.}

As hypothesized, the type of items used in decisional balance ratings for dietary change differentially affected the results for men and women. The findings support the importance of cultural role expectations in creating measures relating to health promoting behaviors. Items involving either general or gender-specific health issues appeared equally effective in addressing cultural expectations for the women's role in health maintenance (Addis \& Mahalik, 2003; Courtenay, 2000) and body appearance (Garner et al., 1980). Based on gender role socialization theory, cultural expectations for men to be strong and independent explained men's tendency to highly endorse items that focus on preventing common men's maladies, avoiding the doctor, and 
improving physical ability. For men, performance issues relating to toughness, stoicism, and avoiding the appearance of weakness meets the cultural expectation for males.

In this study, general pro ratings were higher for women than for men. Men and women did not differ in ratings for pro items based on specific health issues. The items used in the specific DB measure for men and for women were generally comparable, with the exception being one item on healthy eating reducing fatigue on the women's specific DB. The comparable men's specific DB item asked about keeping testosterone levels normal, and was not highly endorsed by men. Because gender differences were only observed on the general DB measure and not the specific measure, this suggests that previous gender differences that have been observed (McDonnell, Roberts, \& Lee, 1998; Steptoe et al., 1996) may be linked to the items contained in general DB scales. Perhaps if items focused on important health attributes for both genders, both males and females would endorse health behaviors comparably.

This study found no significant gender differences for the DB general con ratings but lower con ratings in the later stages for low-fat SOC than the early stages. For the DB specific con ratings, men in the early stages endorsed the cons at higher levels than men in the later stages and women in early stages. Men and women in the later stages did not differ in their DB specific con ratings. Specific con items fit well with cultural expectations for independence such as "not liking to be told what to eat" or invulnerability/strength expectations such as "worry is for old people." Use of specific con items addressing gender role socialization issues may more accurately determine men's progress through the various stages of change and indicate barriers to overcome in changing health behaviors. Because of the significant Gender by Stage interaction, it appears that the gender difference was observed among persons in the early stages. 
Once behavior change efforts are underway in the late stages, there is no difference in con ratings among males and females.

The pro/con ratio reflected the patterns found in the pro and the con ratings. As predicted by Prochaska's examination of decisional balance in health behaviors (Prochaska, 1994; Prochaska, Norcross, et al., 1994), members of the later stages for low-fat SOC had higher ratios than members in earlier stages for the DB general measure. For the pro/con ratings on the DB specific measure, a comparable effect was found for both men and women. Again, a gender difference was only observed among those participants in the early stages of change.

The patterns for ratings and ratios using high-fiber SOC were similar to those found for low-fat SOC. Women rated the general pros higher than men and both men and women in the early stages rated pros lower than men and women in the later stages. General con ratings did not differ for men and women or for early and late stages. Men in the early stages rated specific cons higher than men in the late stages or women in the early stages. Men and women in the late stages gave similar ratings to the specific cons. For high-fiber SOC, these differences in the DB specific con ratings, however, did not correspond to gender differences in the pro/con ratios. There was a significant overlap in the membership for the early and late stages for the two types of SOCs. This overlap may have accounted for the similarity in the findings.

Prochaska and his colleagues (Prochaska, 1994; Prochaska, Norcross, et al., 1994) described the relation between pro and con ratings and stage membership for 12 health behaviors including low-fat dietary behavior and weight loss. They noted a distinct increase in pro ratings and decrease in con ratings as people moved to the action stage for these behaviors. Improving the design of decisional balance measures by accounting for gender differences in selected items may improve the value of decisional balance in promoting healthy behaviors. Steptoe, 
Wijetunge, Doherty, and Wardle (1996) reported differences in pro and con ratings by stage but found no differences by gender. McDonnell, Roberts, and Lee (1998) reported women rated the pros significantly higher and the cons significantly lower than men. Horacek et al. (2002) reported men's pro-scores but not women's pro-scores predicted stage assignment for SOC on fruit and vegetable intake. Other studies have not examined the issue of gender in ratings for decisional balance (Herrick, Stone, \& Mettler, 1997; O’Connell \& Velicer, 1988; Rossi, 1993), the related benefits and barriers (Campbell, Symon, et al., 1998), or have included only women (Ounpuu et al., 2000) and the influence of item choice remains unknown. The exact relation of decisional balance to stage has not been completely determined. Clearly, pro and con items can be designed to enhance or minimize gender differences. General measures of decisional balance that have been developed in the literature (McDonnell et al.; Rossi; Steptoe et al.) reflect the gender differences on health behaviors seen in society. If items are written to reflect gender specific concerns for both men and women, these gender differences become less apparent. There is also a remaining question of the effect of designing education strategies to increase the likelihood of men moving from the early to the later stages which may require a better understanding of the pros and cons that concern men.

Effects of Feedback on Stages of Change

The results of the present study suggest negative dietary feedback during the later stages of either low-fat or high-fiber SOC is associated with higher rates of regression to earlier stages. Many participants in the maintenance stage thought they were doing well on their dietary control of fat and fiber intake but found they were wrong. Bad news on their dietary efforts may have led to some discouragement over the difficulty of changing dietary behavior and return to an earlier stage. Recommendations for utilizing feedback in dietary behavior change include efforts to 
minimize any discouraging effect. Another possible explanation for movement to an earlier stage based on feedback is accurate classification after feedback. Rather than becoming discouraged, some participants may have used the feedback to more accurately describe their intention to make no further changes. Regardless, the majority of those participants in the late stages remained in the late stages whether they received feedback or not and this pattern remained at the final staging opportunity for Phase 3 as well. Over time, there was a tendency for those in the early stages for low-fat dietary behavior to advance to later stages. This finding supports stage of change theory for the somewhat dynamic flow between stages (DiClemente \& Prochaska, 1982; Prochaska \& DiClemente, 1983). Previous research (Rossi, 1993) counted "pseudo-maintainers," who had not met dietary guidelines, as members of the precomtemplation stage because they were not currently trying to change. Reassigning people to "pseudo-maintainer" status may miss appropriate interventions for people who are willing to renew change efforts when given appropriate and accurate feedback regarding their current dietary habits. Another possible explanation for changes in stage derives from motivational interviewing derived originally for addictive behaviors (Miller \& Rollnick, 1991; Rollnick \& Miller, 1995). This technique views readiness to change as a fluid condition subject to many influences, both internal and external (Resnicow et al., 2002). In this model, opportunities to promote change develop rapidly during counseling sessions. In the current study, receiving feedback that the dietary fat and fiber may not be as they desired may have provided sufficient motivation for rapid behavioral change.

The algorithm for staging used in this study did not specify fat or fiber intake levels. This approach solves some of the problem of self-assessment for hidden nutrients but adds a new problem of disparity between individual goals for behavior change and recognized healthy eating behavior guidelines. This study found little impact for feedback on poor dietary behavior 
regarding recommended macronutrient intake for fat and fiber. Larger samples would be needed to more adequately determine improvements in accuracy of self-reported stage based on feedback. An alternative approach to staging for dietary behaviors utilizes dietary goals based on observable behaviors. Recent research has found some observable behaviors were associated with improved nutrient intakes such as "eating two or more servings of fruit per day" related to higher intakes for fiber and Vitamin C (Boury, Krummel, \& Semmons, 2003).

\section{Intervention Effects.}

Several factors were examined regarding change in fat and fiber intakes from baseline to post-intervention. At baseline and at phase 2, there were no significant effects of stage and treatment condition for changes in either fat or fiber intake. At phase 3 (follow-up), the later stages reported lower intakes of fat compared to higher intakes of fat for the early stages. This finding was not influenced by the intervention but may reflect increasing sophistication in staging or completing the FFQ by those in the later stages. In this study, the tailored message was individually tailored but was not stage tailored. Based on stage of change theory (DiClemente \& Prochaska, 1982; Prochaska \& DiClemente, 1983), members of the action stages would have responded to suggestions for dietary change while those in the early stages would not have responded to the tailored message. Also, those in the early stages may have demonstrated some resistance to directed change as described in the motivational interviewing model (Resnicow et al., 2002). However, this resistance could not be adequately addressed by mailed feedback. The exact nature of resistance is difficult to determine because motivational interviewing relies on direct contact by a therapist and the technique involves considerable social support for change, both of which were not used in the current study. This study employed a single intervention that may not have provided sufficient contact to adequately promote change 
in a complex behavior such as dietary intake. Another potential problem was the large number of people in the maintenance stage defined as having made changes and no longer seeking new behaviors to incorporate into their repertoire. Obviously, this group of people was characterized by already "changed" and further intervention may appear unnecessary to these participants.

There were significant findings for the effects of gender and treatment condition on fat intake but they were difficult to interpret. Gender differences among those in the wait list control group and the tailored message intervention groups were not consistent with expectations. The second FFQ may have been subject to demand characteristics. Depending on the participant's bias, "healthier" responses could have been provided by respondents in order to obtain a "better dietary report" showing lower fat intake or to seek a more accurate report with realistic energy intake. It is possible that males were more likely motivated by these demand characteristics than females.

The lack of change in fiber intake suggests people did not follow the tailored messages to increase their intakes for vegetables and whole grains. Part of the problem may have rested with the nature of the FFQ as it does not distinguish really high-fiber foods such as $100 \%$ whole wheat bread from whole wheat breads that consist mostly of white flour. Changing fiber consumption requires perseverance in a marketplace full of refined carbohydrates. Generally, it appeared the group had less interest in dietary fiber goals than dietary fat goals. Some previous studies have also found more people in the later stages for fat than for fiber (Auld et al., 1996; Povey, Conner, Sparks, James, \& Shepherd, 1999). One study with older participants found similar rates with most people assigned to the maintenance stage for fat and fiber (Nigg et al., 1999). Obviously, continuing efforts to educate the population about the importance of fiber is recommended. 


\section{Limitations}

As is common in volunteer study populations, there was some bias in the sample. A large percentage of participants were in the maintenance stage based on self-report. In other samples, such as attendees at a folk music concert (Bowen et al., 1994) or family practice patients (Campbell et al., 1994), more people were assigned in the precontemplation stage than the current study. This study began with an adequate number of people in each stage for low-fat SOC and with similar rates of men and women in each stage. Dropout rates disproportionately affected the earlier stages and insufficient numbers, particularly for men in the early stages, required some combining of categories to proceed with analysis. These sample characteristics are unique to this study and clearly limit its generalizability.

In this study, a majority of the participants were women and had some college education. Other studies involving SOC for dietary behavior have reported a majority of women participants when drawing from volunteer populations (Auld, et al., 1998; Beresford, et al., 1997; Bowen, Meische, \& Tomoyasu, 1994; Brug, Glance, \& Kok, 1997; Campbell et al., 1998; Cowan, Britton, Logue, Smucker, and Milo, 1995; Delaney \& Miggs, 2002; Kreuter, \& Stretcher, 1996; Patterson, Kristal, Shannon, Hunt, \& White, 1997; Povey, Conner, Sparks, James, \& Shepherd, 1999; Sporny \& Contento, 1995). The finding of high rates of college education for participants in SOC studies is also common, even when the sample is drawn from non-college sources such as HMOs or government employees (Auld, et al.; Beresford, et al.; Bowen, Meische, \& Tomoyasu, 1994; Boyle, O’Conner, Pronk, \& Tan, 1998; Campbell et al., 1994; Greene, Rossi, Reed, Willey, \& Prochaska, 1994; Herrick, Stone, \& Mettler, 1997; Prochaska, Norcross, Fowler, Follick, \& Abrams, 1992). This study’s population may be 
representative of SOC studies generally, but may not be representative of the general population in need of improved dietary behaviors.

Gender role socialization theory explains the relative disparity between male and female participation in this study, based on cultural expectations for health seeking and promoting behaviors as feminine pursuits (Addis \& Mahalik, 2003; Courtenay, 2000) and cultural expectations for body appearance (Garner et al., 1980). Indeed, this study continued enrolling women beyond the needed number because the women were enthusiastic about recruiting men to participate. Enrolling men did not respond to requests to mention the study to others.

Another limitation of this study applies to the measures used. The specific decisional balance measure created for this study was exploratory in nature. The limited number of items used here may not adequately cover the full range of pro and con issues affecting people's decisions regarding dietary change. While men and women rated the pros in the specific DB in a similar fashion, the cons on the specific DB magnified gender differences for men in the early stages. Clarifying gender issues remains a problem area for promoting healthy behavior and further refinement of specific DB scales may be warranted.

This study's volunteer population had prior training or interest in diet and nutrition, with a large majority reporting some type of training. Only $8 \%$ of women reported "no training" while $23 \%$ of men reported "no training," a finding that was also consistent with gender role socialization theory. The percentage of men with "no training" will likely decline because the school system has included some nutrition training in high school for both men and women over the past several years. While data on overweight and obesity were not collected because of problems with self-reported weight and height, $20 \%$ of the participants reported training in weight loss programs or groups. Other types of training such as consulting with a dietitian may 
have been for problems relating to weight concerns as well, indicating a large proportion may have an obesity problem, or at least being overweight. Participants' health status or doctor's orders may also have prompted attempts at dietary change.

Sample characteristics may have limited the effect of dietary feedback in this study. The health status of this sample is unknown. Many of the intervention studies use populations with known disease risk factors (Beresford et al., 1997; Campbell et al., 1994; Greene \& Rossi, 1998; McCann et al., 1996; Prochaska et al., 1992; Siero et al., 2000; Steptoe et al., 2001). These at risk populations used in previous work may have more incentives and support for making dietary changes. In the current study, the participants had high rates of previous exposure to dietary information. Even though this was primarily through classes, the tailored messages may have had a lesser impact because of similarity to previously received messages regarding dietary intake of fat and fiber.

The energy intake derived from the FFQ as reported in this study was low compared to the general population (USDA, Agricultural Research Service, 1999; Wright, Wang, KennedyStephenson, \& Ervin, 2003). Thompson and Byers (1994) report both underreporting and overreporting have been common on FFQs, although they note overreporting is more common on longer food lists such as the one used in this study. A variety of factors may have been involved in the finding of low energy intake, including lack of awareness of eating patterns, unwillingness to admit to dietary patterns, caloric restriction associated with weight loss, difficulty with estimating usual portion size, and food choices or preparation behaviors not available on the FFQ. For example, several participants indicated they did not eat egg yolks and their nutrient intakes had to be manually adjusted to correct for a substantial amount of fat and cholesterol in egg yolks. Systematic underestimation of energy intake has been noted in 
overweight persons (Lichtman et al., 1992) and in college-educated women with high scores on social desirability and approval (Hebert et al., 2002). Despite the low energy intake reported for participants in this study, dietary fat for this population was measured as $34 \%$ of calories from fat, slightly higher than current populations estimates from national surveys (USDA, Agricultural Research Service; Wright et al.). Dietary fiber intake was low in the study population at $15.7 \mathrm{~g}$ but similar to the levels reported in the USDA Agricultural Research Service data tables. As mentioned previously, participant completion of the second FFQ may have been influenced by the results of their first FFQ. Underestimation or overestimation on the second FFQ may have increased as participants sought a more desirable (e.g., lower fat) or more accurate feedback report.

Another source of variation in nutrient intakes may have arisen from seasonal or regional differences in food choices. One study with New Jersey men found increased fruit and vegetable consumption in the summer (Ziegler, Wilcox, Mason, Bill, \& Virgo, 1987). In the most recent report from a large national survey, seasonal variations were found for 22 foods (Subar, Frey, Harlan, \& Kahle, 1994). Regional differences in fruit and vegetable intake have also been found in the United States (Thompson et al., 1999). These studies have generally been cross-sectional or epidemiological. In one comparison study, season had little effect on nutrient rankings except for fiber intake (Hartman et al., 1996). The influence of seasonal differences in food intakes for this study is unknown.

Because the SOC algorithm used in this study did not employ a question focused on actual dietary intake levels of fat and fiber, the accuracy of self-report for limiting fat or increasing fiber in the diet is difficult to determine. The majority of those in the maintenance stage for low-fat SOC at baseline remained in the maintenance stage at phase 2 despite receiving 
feedback on fat intake above recommended levels. They may indeed be accurate because they had previously lowered their fat intake from $35 \%$ of calories to $31 \%$ of calories. Another problem with stage assignment was the small number of people in the early stages indicating they had no interest in change but who actually met dietary recommendations for fat or fiber. These participants may have been more correctly assigned to the maintenance stage because they were engaging in healthy dietary behavior but were unaware of their behavior. Health professionals seem to have a choice between using a hidden nutrient people cannot accurately judge for SOC algorithms or using estimates of behaviors such as "limiting fat' that are open to interpretation. A better solution may involve staging people to desirable, observable goals like "eating 3 to 5 servings of dark green or yellow vegetables per day." Also, because the study attracted more participants in the later stages and slightly higher dropout rates occurred in the early stages, limited conclusions can be made about the effects of feedback on progression/regression through the early stages.

The tailored message strategy employed in this study had several potential problem areas. Single contact interventions may be insufficient for changing complex behaviors such as dietary behavior (Greene et al., 1998). Several contacts may be necessary to have the desired effect. Also, the intervention was individually tailored but not stage matched. According to Prochaska's theory, tailored dietary messages would be most appropriate for those in the action stage (Prochaska, DiClemente, et al., 1992). Those in the early stages may benefit more from messages designed to address their individual pros and cons for changing behavior. A longer list of potential pros and cons may be necessary to individualize tailored messages. Efforts to identify effective and available incentives may also enhance the impact of tailored messages. Finally, messages may need to include a greater degree of individualization such as the 223 computer- 
tailored messages developed by Brug and van Assema (2000). In addition to messages directed to specific dietary behaviors, Brug and van Assema addressed issues related to negative attitudes, low self-efficacy, social environment, comparisons to community norms and participant ratings of their own behavior. Although stage-matched messages have been previously associated with significant reductions in fat intake and increase in fiber intake (Campbell et al., 1994; Siero et al., 2000), the limitations of the current study design and problems with underestimating or overestimating food intakes on the FFQ may have combined to limit the effectiveness of the intervention.

\section{Conclusions}

The results of this investigation support the first hypothesis that gender effects in decisional balance measures can be influenced by the type of items included in the measure. In this case, men and women responded with similar patterns to pros items designed to address specific health issues common to men and women but responded differentially to the pros addressing general health issues. Consistent with gender role socialization theory, general health issues would match women's cultural role as caretakers. The use of specific health issues matches Addis and Mahalik's (2003) proposed strategy of normalizing healthy behavior to make it more acceptable for men.

The second hypothesis was partially supported by the available data. A larger percentage of those receiving negative dietary feedback at stage 2 of the study reported earlier stage assignment compared to those who did not receive feedback. However, the majority of those in the late stages remained in the late stages. Well-defined, observable dietary behaviors are recommended as an alternative to using hidden nutrients of fat and fiber in applying SOC to change in eating behaviors in further studies. 
Finally, there was no support for the use of tailored messages combined with feedback to improve dietary behavior in the current study. Reporting difficulties and response bias issues on FFQs may mask our ability to detect dietary behavior change. A one-time intervention may also be insufficient to influence complex dietary behaviors. Additionally, SOC theory suggests tailoring would have been more effective if the messages had been stage matched.

Americans continue eating diets high in low-nutrient density foods with resulting increases in obesity and diseases associated with obesity. Intakes for calories and refined carbohydrates continue to rise and fat consumption after falling for several years is again on the rise (Putnam, Allshouse, \& Kantor, 2002). Diseases associated with dietary behavior and obesity are also on the rise with expenditures now estimated at $\$ 93$ billion/year or $9 \%$ of U.S. health care expenditures (Finkelstein et al., 2003). Health professionals need to become more sophisticated in their approaches to helping people change their behavior and efforts, like those made in the current study should receive continued attention until more effective interventions are devised, evaluated, and disseminated. 


\section{References}

AbuSabha, R., \& Achterberg, C. (1997). Review of self-efficacy and locus of control for nutrition- and health- related behavior. Journal of the American Dietetic Association, 97, 11221132.

Addis, M. E., \& Mahalik, J. R. (2003). Men, masculinity, and the contexts of help seeking. American Psychologist, 58, 5-14.

Albala, C., Vio, F., Kain, J., \& Uauy, R. (2002) Nutrition transition in Chile: determinants and consequences. Public Health Nutrition, 5, 123-128.

Alexander, H., Lockwood, L. P., Harris, M. A., \& Melby, C. L. (1999) Risk factors for cardiovascular disease and diabetes in two groups of Hispanic Americans with differing dietary habits. Journal of the American College of Nutrition, 18, 127-136.

Alpert, J. S., Goldberg, R., Ockene, I. S., \& Taylor, P. (1991) Heart disease in native Americans. Cardiology, 78, 3-12.

American Heart Association. (AHA, n.d.). Basic food groups. Retrieved January 12, 2002, from http://www.americanheart.org/presenter.jhtml?identifier=779

American Heart Association. (AHA, n.d.). Goals of the American Heart Association Eating Plan. Retrieved January 12, 2002, from http://www.americanheart.org/presenter.jhtml?identifier $=9203$

Armitage, C. J., \& Conner, M. (2001). Efficacy of a minimal intervention to reduce fat intake. Social Science \& Medicine, 52, 1517-1524.

*Auld, G. W., Nitzke, S. A., McNulty, J., Bock, M. A., Bruhn, C. M., Gabel, K., et al. (1998). A stage-of-change classification system based on actions and beliefs regarding dietary fat and fiber. American Journal of Health Promotion, 12, 192-201.

Baer, J. T. (1993). Improved plasma cholesterol levels in men after a nutrition education program at the worksite. Journal of the American Dietetic Association, 93, 658-663. Co.

Bandura, A. (1997). Self-efficacy: The exercise of control. New York: W H Freeman \&

Bemelmans, W. J., Broer, J., Feskens, E. J., Smit, A. J., Muskiet, F. A., Lefrandt, J. D., et al. (2002). Effect of an increased intake of alpha-linolenic acid and group nutritional education on cardiovascular risk factors: the Mediterranean Alpha-linolenic Enriched Groningen Dietary Intervention (MARGARIN) study. American Journal of Clinical Nutrition, 75, 221-227.

*Beresford, S. A., Curry, S. J., Kristal, A. R., Lazovich, D., Feng, Z., \& Wagner, E. H. (1997). A dietary intervention in primary care practice: The Eating Patterns Study. American Journal of Public Health, 87, 610-616. 
Björntorp, P. (1985). Regional patterns of fat distribution. Annals of Internal Medicine, 103, 994-995.

Bourne, L. T., Lambert, E.V., \& Steyn, K. (2002) Where does the black population of South Africa stand on the nutrition transition? Public Health Nutrition, 5, 157-162.

Boury, J. (1998). The influence of dietary experience on the taste preference for fatreduced foods. Unpublished thesis, West Virginia University, Morgantown.

Boury, J., Krummel, D.A. \& Semmons, E.L. Self-reported stages of change for weight management behaviors as compared with actual nutrients. (October, 2003). Poster Session accepted for the 2003 Food \& Nutrition Conference and Expo of the American Dietetic Association, San Antonio, TX

Bowen, D. J., Kestin, M., McTiernan, A., Carrell, D., \& Green, P. (1995). Effects of dietary fat intervention on mental health in women. Cancer Epidemiology, Biomarkers, and Prevention, 4, 555-559.

*Bowen, D. J., Meischke, H., \& Tomoyasu, N. (1994). Preliminary evaluation of the processes of changing to a low-fat diet. Health Education Research, 9, 85-94.

Bowman, S. A. (1999). Diets of individuals based on energy intakes from added sugars. Family economics and nutrition Review, 12, 31-38.

Boyd, N. F., Lockwood, G. A., Greenberg, C. V., Martin, L. J., \& Tritchler, D. L. (1997). Effects of a low-fat high-carbohydrate diet on plasma sex hormones in premenopausal women: results from a randomized controlled trial. Canadian Diet and Breast Cancer Prevention Study Group. British Journal of Cancer, 76, 127-135.

*Boyle, R. G., O'Connor, P. J., Pronk, N. P., \& Tan A. (1998). Stages of change for physical activity, diet, and smoking among HMO members with chronic conditions. American Journal of Health Promotion, 12, 170-175.

*Brug, J., Glanz, K., \& Kok, G. (1997). The relationship between self-efficacy, attitudes, intake compared to others, consumption, and stages of change related to fruit and vegetables. American Journal of Health Promotion, 12, 25-30.

*Brug, J., Hospers, H. J., \& Kok, G. (1997). Differences in psychosocial factors and fat consumption between stages of change for fat reduction. Psychology and Health, 12, 719-727.

*Brug, J., \& van Assema, P. (2000). Differences in use and impact of computer-tailored dietary fat-feedback according to stage of change and education. Appetite, 34, 285-293.

Brunner, E., White, I., Thorogood, M., Bristow, A., Curle, D., \& Marmot, M. (1997). Can dietary interventions change diet and cardiovascular risk factors? A meta-analysis of randomized controlled trials. American Journal of Public Health, 87, 1415-1422. 
Buzzard, I. M., Asp, E. H., Chlebowski, R. T., Boyar, A. P., Jeffery, R. W., Nixon, D. W., et al. (1990). Diet intervention methods to reduce fat intake: nutrient and food group composition of self-selected low-fat diets. Journal of the American Dietetic Association, 90, 42$50,53$.

Caldwell, M. B., Brownell, K., \& Wifley, D. E. (1997). Relationship of weight, body dissatisfaction, and self-esteem in African-American and white female dieters. International Journal of Eating Disorders, 22, 127-130.

Calfas, K. J., Sallis, J. F., Zabinski, M. F., Wilfley, D. E., Rupp, J., et al. (2002). Preliminary evaluation of a multicomponent program for nutrition and physical activity change in primary care: PACE+ for adults. Preventive Medicine, 34, 153-161.

*Campbell, M. K., DeVellis, B. M., Strecher, V. J., Ammerman, A. S., DeVellis, R. F., \& Sandler, R. S. (1994). Improving dietary behavior: The effectiveness of tailored messages in primary care settings. American Journal of Public Health, 84, 783-787.

*Campbell, M. K., Reynolds, K. D., Havas, S., Curry, S., Bishop, D., Nicklas, T., et al. (1999). Stages of change for increasing fruit and vegetable consumption among adults and young adults participating in the national 5-a-Day for Better Health community studies. Health Education \& Behavior, 26, 513-534.

*Campbell, M. K., Symons, M., Demark-Wahnefried, W., Polhamus, B., Bernhardt, J. M., McClelland, J. W., \& Washington, C. (1998). Stages of change and psychosocial correlates of fruit and vegetable consumption among rural African-American church members. American Journal of Health Promotion, 12, 185-191.

*Campbell, M. K., Tessaro, I., DeVellis, B., Benedict, S., Kelsey, K., Belton, L., \& Henriquez-Roldan, C. (2000). Tailoring and targeting a worksite health promotion program to address multiple health behaviors among blue-collar women. American Journal of Health Promotion, 14, 306-313.

Centers for Disease Control and Prevention, National Center for Chronic Disease Prevention and Health Promotion (CDC-NCCDPHP). (2002). 2000 BRFSS summary prevalence report. Atlanta, GA: CDC

Centers for Disease Control and Prevention, National Center for Chronic Disease Prevention and Health Promotion (CDC-NCCDPHP). (2002). The burden of chronic diseases and their risk factors. Atlanta, GA: CDC

Centers for Disease Control and Prevention, National Center for Health Statistics. (CDCNCHS). (2002). Health, United States. Chartbook on trends in the health of Americans 2002. Atlanta, GA: CDC

Conlin, P. R., Chow, D., Miller, E. R. 3rd, Svetkey, L. P., Lin, P. H., Harsha, D. W., et al. (2000). The effect of dietary patterns on blood pressure control in hypertensive patients: results from the Dietary Approaches to Stop Hypertension (DASH) trial. American Journal of Hypertension, 13, 949-955. 
Courtenay, W. H. (1999). Better to die than cry? A longitudinal and constructionist study of masculinity and the health risk behavior of young American men. Dissertation Abstracts International Section A: Humanities and Social Sciences, 59, 3207

Courtenay, W. H. (2000). Constructions of masculinity and their influence on men's wellbeing: a theory of gender and health. Social Science \& Medicine, 50, 1385-1401.

Courtenay, W. H., McCreary, D. R., \& Merighi, J. R. (2002). Gender and ethnic differences in health beliefs and behaviors. Journal of Health Psychology, 7, 219-231.

*Cowan, R., Britton, P. J., Logue, E., Smucker, W., \& Milo, L. (1995). The relationship among the transtheoretical model of behavioral change, psychological distress, and diet attitudes in obesity: Implications for primary care intervention. Journal of Clinical Psychology in Medical Settings, 2, 249-267.

Crenshaw, T. L., \& Goldberg, J. P. (1996). Sexual Pharmacology: Drugs that affect sexual functioning. New York: W. W. Norton and Co., Inc.

Cronin, K. A., Krebs-Smith, S. M., Feuer, E. J., Troiano, R. P., \& Ballard-Barbash, R. (2001) Evaluating the impact of population changes in diet, physical activity, and weight status on population risk for colon cancer (United States). Cancer Causes \& Control, 12, 305-316.

*Cullen, K. W., Bartholomew, L. K., Parcel, G.S., \& Koehly, L. (1998). Measuring stage of change for fruit and vegetable consumption in 9- to 12-year-old girls. Journal of Behavioral Medicine, 21, 241-254.

*Curry, S. J., Kristal, A. R., \& Bowen, D. J. (1992). An application of the stage model of behavior change to dietary fat reduction. Health Education Research, 7, 97-105.

Davies, J., McCrae, B. P., Frank, J., Dochnahl, A., Pickering, T., Harrison, B., Zakrzewski, M., \& Wilson, K. (2000). Identifying male college students' perceived health needs, barriers to seeking help, and recommendations to help men adopt healthier lifestyles. Journal of the American College Health, 48, 259-267.

*de Graaf, C., Van der Gaag, M., Kafatos, A., Lennernas, M., \& Kearney, J.M. (1997). Stages of dietary change among nationally-representative samples of adults in the European Union. European Journal of Clinical Nutrition, 51 Suppl 2, S47-56.

*Delahanty, L. M., Meigs, J. B., Hayden, D., Williamson, D. A., \& Nathan, D. M. (2002). Psychological and behavioral correlates of baseline BMI in the diabetes prevention program (DPP). Diabetes Care, 25, 1992-1998.

Delichatsios, H. K., Hunt, M. K., Lobb, R., Emmons, K., \& Gillman, M. W. (2001). EatSmart: efficacy of a multifaceted preventive nutrition intervention in clinical practice. Preventive Medicine, 33, 91-98. 
DiClemente, C. C., \& Prochaska, J. O. (1982) Self-change and therapy change of smoking behavior: A comparison of processes of change in cessation and maintenance. Addictive Behaviors, 7, 133-142.

Diehl, H. A. (1998). Coronary risk reduction through intensive community-based lifestyle intervention: the Coronary Health Improvement Project (CHIP) experience. American Journal of Cardiology, 82, 83T-87T.

Dixon, L. B., \& Ernst, N. D. (2001). Choose a diet that is low in saturated fat and cholesterol and moderate in total fat: subtle changes to a familiar message. Journal of Nutrition, $131,510 \mathrm{~S}-526 \mathrm{~S}$.

*Domel, S. B., Baranowski, T., Davis, H. C., Thompson, W. O., Leonard, S. B., \& Baranowski, J. (1996). A measure of stages of change in fruit and vegetable consumption among fourth- and fifth-grade school children: Reliability and validity. Journal of the American College of Nutrition, 15, 56-64.

Draelos, M. T., Jacobsen, A. M., Weinger, K., Widom, B., Ryan, C. M., Finkelstein, D. M., \& Simonson, D. C. (1995). Cognitive function inpatients with insulin-dependent diabetes mellitus during hyperglycemia and hypoglycemia. American Journal of Medicine, 98, 135-144.

Drewnowski, A., Kurth, C., Holden-Wiltse, J., \& Saari, J. (1992). Food preferences in human obesity: Carbohydrates versus fats. Appetite, 18, 207-221.

Eden, I., Kamath, S. K., Kohrs, M. B., \& Olson, R. E. (1984). Perceived control of nutrition behavior: a study of the locus of control theory among healthy subjects. Journal of the American Dietetic Association, 84, 1334-1339.

Ernst, N. D., Sempos, C. T., Briefel, R. R., \& Clark, M. B. (1997). Consistency between US dietary fat intake and serum total cholesterol concentrations: The National Health and Nutrition Examination Surveys. American Journal of Clinical Nutrition, 66 (Suppl.), 965S-972S.

*Finckenor, M., \& Byrd-Bredbenner, C. (2000). Nutrition intervention group program based on preaction-stage-oriented change processes of the Transtheoretical Model promotes long-term reduction in dietary fat intake. Journal of the American Dietetic Association, 100, $335-$ 342 .

Finkelstein, E. A., Fiebelkorn, I. C., \& Wang, G., (2003). National medical expenses attributable to overweight and obesity: How much, and who's paying? Health Affaires, $22,8$.

Fraser, G. E. (1999) Associations between diet and cancer, ischemic heart disease, and all- cause mortality in non-Hispanic white California Seventh-day Adventists. American Journal of Clinical Nutrition, 70, 532S-538S.

Fraser, G. E., \& Shavlik, D. J. (2001) Ten years of life: Is it a matter of choice? Archives of Internal Medicine, 161, 1645-1652. 
Fung, T. T., Rimm, E. B., Spiegelman, D., Rifai, N., Tofler, G. H., Willett, W. C., \& Hu, F. B. (2001) Association between dietary patterns and plasma biomarkers of obesity and cardiovascular disease risk. American Journal of Clinical Nutrition, 73, 61-67.

Garner, D. M., Garfinkel, P. E., Schwartz, D., \& Thompson, M. (1980). Cultural expectations of thinness in women. Psychological Reports, 47, 483-491.

Garrow, J. S. (1992). Obesity in man. In E. M. Widdowson \& J, C. Mathers (Eds.), The contribution of nutrition to animal and human health (pp. 53-62). Cambridge, England: Cambridge University Press.

Giles, G., \& Ireland, P. (1997). Diet, nutrition, and prostate cancer. International Journal of Cancer. 10 (Suppl). 13-17.

Gillman, M. W., Cupples, L. A., Millen, B. E., Ellison, R. C., \& Wolf, P. A. (1997) Inverse association of dietary fat with development of ischemic stroke in men. JAMA, 278, 21452150.

*Glanz, K., Kristal, A. R., Tilley, B. C., \& Hirst, K. (1998). Psychosocial correlates of healthful diets among male auto workers. Cancer Epidemiol Biomarkers Prev, 7, 119-126.

*Glanz, K., Patterson, R. E., Kristal, A. R., DiClemente, C. C., Heimendinger, J., Linnan, L., et al. (1994). Stages of change in adopting healthy diets: Fat, fiber, and correlates of nutrient intake. Health Education Quarterly, 21, 499-519.

Gleason, M. (1996). Men are newest targets for 'milk mustache ' ads. Advertising Age, 67 (27), 10-16.

Gleason, J. A., Bourdet, K. L., Koehn, K., Holay, S. Y., \& Schaefer, E. J. (2002). Cardiovascular risk reduction and dietary compliance with a home- delivered diet and lifestyle modification program. Journal of the American Dietetic Association, 102, 1445-1451.

Gould, K. L., Ornish, D., Kirkeeide, R., Brown, S., Stuart, Y., Buchi, M., et al. (1992). Improved stenosis geometry by quantitative coronary arteriography after vigorous risk factor modification. American Journal of Cardiology, 69, 845-853.

Gould, K. L., Ornish, D., Scherwitz, L., Brown, S., Edens, R. P., Hess, M. J., et al. (1995). Changes in myocardial perfusion abnormalities by positron emission tomography after long-term, intense risk factor modification. JAMA, 274, 894-901.

*Gracey, D., Stanley, N., Burke, V., Corti, B., \& Beilin, L.J. (1996). Nutritional knowledge, beliefs and behaviours in teenage school students. Health Education Research, 11, 187-204.

*Greene, G. W., \& Rossi, S. R. (1998). Stages of change for reducing dietary fat intake over 18 months. Journal of the American Dietetic Association, 98, 529-534; quiz 535-6.

*Greene, G. W., Rossi, S. R., Reed, G. R., Willey, C., \& Prochaska, J. O. (1994). Stages 
of change for reducing dietary fat to $30 \%$ of energy or less. Journal of the American Dietetic Association, 94, 1105-1110; quiz 1111-2.

Hackett, G. I. (1996). The treatment of patients with diabetes. International Journal of Sexually Transmitted Diseases and Aids, 7 (Suppl 3), 24-26.

*Hargreaves, M. K., Schlundt, D. G., Buchowski, M. S., Hardy, R. E., Rossi, S. R., \& Rossi, J. S. (1999). Stages of change and the intake of dietary fat in African-American women: Improving stage assignment using the Eating Styles Questionnaire. Journal of the American Dietetic Association, 99, 1392-1399.

Hartman, A. M., Block, G., Chan, W., Williams, J., McAdams, M., Banks, W. L. Jr., \& Robbins A. (1996). Reproducibility of a self-administered diet history questionnaire administered three items over three different seasons. Nutrition and Cancer, 25, 305-315.

Henderson, W. H., Ross, R. H., \& Pike, M. C. (1991). Toward the primary prevention of cancer. Science, 254, 1131-1138.

*Herrick, A. B., Stone, W. J., \& Mettler, M. M. (1997). Stages of change, decisional balance, and self-efficacy across four health behaviors in a worksite environment. American Journal of Health Promotion, 12, 49-56.

Holtzman, D., Powell-Griner, E., Bolen, J.C., \& Rhodes, L. (2000). State and Sex Specific Prevalence of Selected Characteristics: Behavioral Risk Factor Surveillance System, 1996 and 1997. Morbidity and Mortality Weekly Report (MMWR), 49, 1-39.

Horacek, T. M., White, A., Betts, N. M., Hoerr, S., Georgiou, C., Nitzke, S., et al. (2002). Self-efficacy, perceived benefits, and weight satisfaction discriminate among stages of change for fruit and vegetable intakes for young men and women. Journal of the American Dietetic Association, 102, 1466-1470.

Howard, B. V., Abbott, W. G., \& Swinburn, B. A. (1991) Evaluation of metabolic effects of substitution of complex carbohydrates for saturated fat in individuals with obesity and NIDDM. Diabetes Care, 14, 786-795.

Hu, F. B., Rimm, E., Smith-Warner, S. A., Feskanich, D., Stampfer, M.J., Ascherio, A., Sampson, L., \& Willett, W. C. (1999) Reproducibility and validity of dietary patterns assessed with a food- frequency questionnaire. American Journal of Clinical Nutrition, 69, 243-249.

Hu, F. B., van Dam, R. M., \& Liu, S. (2001). Diet and risk of Type II diabetes: the role of types of fat and carbohydrate. Diabetologia, 44, 805-817.

Hu, F. B. \& Willett, W. C. (2003). Optimal diets for prevention of coronary heart disease. JAMA, 288(20), 2569-2578.

Jacobs, D. R. Jr, Marquart, L., Slavin, J., \& Kushi, L. H. (1998). Whole-grain intake and cancer: an expanded review and meta-analysis. Nutrition and Cancer, 30, 85-96. 
Janis, I. L., \& Mann, L. (1977). Decision making: A psychological analysis of conflict, choice, and commitment. New York: Free Press.

Jenkins, D.J., Wesson, V., Wolever, T.M., Jenkins, A.L., Kalmusky, J., Guidici, S., Csima, A., Josse, R.G., \& Wong, G.S. (1988). Wholemeal versus wholegrain breads: proportion of whole or cracked grain and the glycaemic response. British Medical Journal, 297, 958-960.

Jones, D. V. (1987). Influence of dietary fat on self-reported menstrual symptoms. Physiological Behavior, 40, 483-487.

Jones-Putnam, J., \& Duewer, L. (1995). U.S. per capita food consumption: Record high meat and sugars in 1994. U.S. Department of Agriculture Food Review, 18 (2), 2-11.

Joshipura, K. J., Ascherio, A., Manson, J. E., Stampfer, M. J., Rimm, E. B., Speizer, F. E., et al. (1999) Fruit and vegetable intake in relation to risk of ischemic stroke. JAMA, 282, 1233-1239.

Kabir, M., Oppert, J.M., Vidal, H., Bruzzo, F., Fiquet, C., Wursch, P., Slama, G., \& Rizkalla, S.W. (2002). Four-week low-glycemic index breakfast with a modest amount of soluble fibers in type 2 diabetic men. Metabolism, 51, 819-826.

Katznelson, L., Rosenthal, D. I., Rosol, M. S., Anderson, E. J., Hayden, D. L., Schoenfeld, D. A., \& Klibanski, A. (1998). Using quantitative CT to assess adipose distribution in adult men with acquired hypogonadism. American Journal of Roentgenology, 170, 423-427.

Kraemer, W. J., Volek, J. S., Clark, K. L., Gordon, S. E., Incledon, T., Puhl, S. M., et al. (1997). Physiological adaptations to a weight-loss dietary regimen and exercise programs in women. Journal of Applied Physiology, 83, 270-279.

Krauss, R. M., Deckelbaum, R. J., Ernst, N., Fisher, E., Howard, B. V., Knopp, R. H., et al. (1996). Dietary guidelines for healthy American adults: A statement for health professionals from the Nutrition Committee, American Heart Association. Circulation, 94, 1795-1800.

Krauss, R. M., Eckel, R.H., Howard, B. V., Appel, L. J., Daniels, S. R., Deckelbaum, R. J., et al. (2000). Revision 2000: AHA dietary guidelines: A statement for health professionals from the Nutrition Committee, American Heart Association. Circulation, 102, 2296-2311.

Krebs-Smith, S. M. (2001). Choose beverages and foods to moderate your intake of sugars: measurement requires quantification. Journal of Nutrition, 131, 527S-535S.

*Kreuter, M. W., \& Strecher, V. J. (1996). Do tailored behavior change messages enhance the effectiveness of health risk appraisal? Results from a randomized trial. Health Education Research, 11, 97-105.

Kristal, A.R., Beresford, S.A., \& Lazovich, D. (1994). Assessing change in dietintervention research. American Journal of Clinical Nutrition, 59, 185S-189S. 
Kristal, A. R., Curry, S. J., Shattuck, A. L., Feng, Z., \& Li, S. (2000). A randomized trial of a tailored, self-help dietary intervention: the Puget Sound Eating Patterns study. Preventive Medicine, 31, 380-389.

*Kristal, A. R., Glanz, K., Tilley, B. C., \& Li, S. (2000). Mediating factors in dietary change: Understanding the impact of a worksite nutrition intervention. Health Education \& Behavior, 27, 112-125.

Kristal, A. R., Shattuck, A. L., Henry, H. J., \& Fowler, A. S. (1990). Rapid assessment of Dietary Group, fiber, and saturated fat: Validity of an instrument suitable for community intervention research and nutritional surveillance. American Journal of Health Promotion, 4, 288-295.

Kristal, A.R., Vizenor, N.C., Patterson, R.E., Neuhouser, M.L., Shattuck, A.L., \& McLerran, D. (2000). Precision and bias of food frequency-based measures of fruit and vegetable intakes. Cancer Epidemiology, Biomarkers \& Prevention, 9, 939-944.

*Laforge, R. G., Greene, G. W., \& Prochaska, J. O. (1994). Psychosocial factors influencing low fruit and vegetable consumption. Journal of Behavioral Medicine, 17, 361-374.

*Lamb, R., \& Joshi, M. S. (1996). The stage model and processes of change in dietary fat reduction. Journal of Human Nutrition and Dietetics, 9, 43-51.

Lee, E., Park, M. S., Shin, C., Lee, H., Yoo, K., Kim, Y., et al. (1997). A high-risk group for prostatism: A population-based epidemiological study in Korea. British Journal of Urology, 79, 736-741.

Lichtman, S.W., Pisarska, K., Berman, E.R., Pestone, M., Dowling, H., Offenbacher, E., et al. (1992). Discrepancy between self-reported and actual caloric intake and exercise in obese subjects. New England Journal of Medicine, 327, 1893-1898.

Lubin, J. H., Blot, W. J., Berrino, F., Flamant, R., Gillis, C. R., Kunze, M., et al. (1984). Patterns of lung cancer risk according to type of cigarette smoked. International Journal of Cancer, 33, 569-576.

Lutz, S. F., Ammerman, A. S., Atwood, J. R., Campbell, M. K., DeVellis, R. F., \& Rosamond, W. D. (1999). Innovative newsletter interventions improve fruit and vegetable consumption in healthy adults. Journal of the American Dietetic Association, 99, 705-709.

Margetts, B. M., Little, P., \& Warm, D. (1999). Interaction between physical activity and diet: implications for blood pressure management in primary care. Public Health Nutrition, 2, $377-382$.

Marlett, J. A., McBurney, M. I., \& Slavin, J. L. Position of the American Dietetic association: Health implications of dietary fiber. (2002). Journal of the American Dietetic Association, 102, 993-1000. 
Marmot, M. G., \& Syme, S. L. (1976) Acculturation and coronary heart disease in Japanese-Americans. American Journal of Epidemiology, 104, 225-247.

Martin, L. J., Lockwood, G. A., Kristal, A. R., Kriukov, V., Greenberg, C., Shattuck, A. L., Boyd, N. F. (1997). Assessment of a food frequency questionnaire as a screening tool for low fat intakes. Controlled Clinical Trials, 18, 241-250.

*McCann, B. S., Bovbjerg, V. E., Curry, S. J., Retzlaff, B. M., Walden, C. E., \& Knopp, R. H. (1996). Predicting participation in a dietary intervention to lower cholesterol among individuals with hyperlipidemia. Health Psychology, 15, 61-64.

McCarron, D. A., Oparil, S., Chait, A., Haynes, R. B., Kris-Etherton, P., Stern, J. S., et al. (1997). Nutritional management of cardiovascular risk factors: A randomized clinical trial. Archives of Internal Medicine, 157, 169-177.

*McDonell, G. E., Roberts, D. C. K., \& Lee, C. (1998). Stages of change and reduction of dietary fat: Effect of knowledge and attitudes in an Australian university population. Journal of Nutrition Education, 30, 37-44.

McGinnis, J. M., \& Foege, W. H. (1993). Actual causes of death in the United States. Journal of the American Medical Association, 270, 2207-2212.

Miller, W., \& Rollnick, S. (1991). Motivational interviewing: Preparing people to change addictive behavior. New York: Guilford Press.

Mills, P. K., Beeson, W. L., Phillips, R. L., \& Fraser, G. E. (1989) Cohort study of diet, lifestyle, and prostate cancer in Adventist men. Cancer, 64, 598-604.

Moore, M. H., \& Gernstein, D. R., eds. (1981). Alcohol and Public Policy: Beyond the shadow of prohibition. Washington, DC: National Academy Press.

Moore, T. J., Conlin, P. R., Ard, J., \& Svetkey, L. P. (2001). DASH (Dietary Approaches to Stop Hypertension) diet is effective treatment for stage 1 isolated systolic hypertension. Hypertension, 38, 155-158.

Morganti, J. B., Nehrke, M. F., Hulicka, I. M., \& Cataldo, J. F. (1988). Life-span differences in life satisfaction, self-concept, and locus of control. International Journal of Aging \& Human Development, 26, 45-56.

National Cancer Institute. (1986). Cancer Control Objectives for the Nation: 1985-2000. Washington, DC: U.S. Government

National Cholesterol Education Program (NCEP). Second report of the expert panel on detection, evaluation, and treatment of high blood cholesterol in adults. (Adult Treatment Panel II, 1994). Circulation, 89, 1333-1445. 
National Health and Nutrition Examination Survey III (NHANES III). (1994). Daily Dietary fat and total food energy intakes: Third National Health and Nutrition Survey Phase 1, 1988-1991. Morbidity and Mortality Weekly Report, 43, 116-125.

National Institutes of Health, National Heart, Lung, and Blood Institute, National Cholesterol Education Program (NCEP), Adult Treatment Panel III. (2002) Detection, evaluation, and treatment of high blood cholesterol in adults. Third Report (NIH Publication No. 02-5215). Washington, DC: U.S. Government

National Research Council (NRC), National Academy of Sciences. (1989a). Diet and Health: Implications for reducing chronic disease risk. Washington, DC: National Academy Press.

National Research Council (NRC), National Academy of Sciences. (1989b). Recommended Dietary Allowances $\left(10^{\text {th }}\right.$ ed.). Report on the Committee of Dietary Allowances. Washington, DC: National Academy Press.

Ness, A. R., \& Powles, J. W. (1997). Fruit and vegetables, and cardiovascular disease: a review. International Journal of Epidemiology, 26, 1-13.

Neuhouser, M. L., Kristal, A. R., McLerran, D., Patterson, R. E., \& Atkinson, J. (1999). Validity of short food frequency questionnaires used in cancer chemoprevention trials: results from the Prostate Cancer Prevention Trial. Cancer Epidemiology, Biomarkers \& Prevention, 8, 721-725.

Ni Mhurchu, C., Margetts, B. M., \& Speller, V. M. (1997). Applying the stages of change model to dietary change. Nutrition Reviews, 55, 10-16.

*Nigg, C. R., Burbank, P. M., Padula, C., Dufresne, R., Rossi, J. S., Velicer, W. F., et al. (1999). Stages of change across ten health risk behaviors for older adults. Gerontologist, 39, 473482.

*O'Connell, D., \& Velicer, W. F. (1988). A decisional balance measure and the stages of change model for weight loss. International Journal of Addictions, 23, 729-750.

O'Dea, K. (1991) Cardiovascular disease risk factors in Australian aborigines. Clinical and experimental pharmacology \& physiology, 18, 85-88.

Ogden, J., (2003). Some problems with social cognition models: A pragmatic and conceptual analysis. Health Psychology, 22, 424-428.

Ornish, D., Scherwitz, L.W., Billings, J.H., Brown, S.E., Gould, K.L., Merritt, T.A., et al. (1998). Intensive lifestyle changes for reversal of coronary heart disease. JAMA, 280, 2001-2007.

*Ounpuu, S., Woolcott, D. M., \& Greene, G. W. (2000). Defining stage of change for lower-fat eating. Journal of the American Dietetic Association, 100, 674-679. 
Page, I. H., Stare, F. J., Corcoran, A. C., Pollack, H., \& Wilkerson, C. F. (1957). Atherosclerosis and the fat content of the diet. Journal of the American Medical Association, 164, 2048-2051.

*Patterson, R. E., Kristal, A. R., Shannon, J., Hunt, J. R., \& White, E. (1997). Using a brief household food inventory as an environmental indicator of individual dietary practices. American Journal of Public Health, 87, 272-275.

Perera, N. D., \& Hill, J. T. (1998). Erectile and ejaculatory failure after transurethral prostectomy. Ceylon Medical Journal, 43 (2), 74-77.

Perez-Jimenez, F., Lopez-Miranda, J., Pinillos, M.D., Gomez, P., Paz-Rojas, E., Montilla, P., Marin, C., Velasco, M.J., Blanco-Molina, A., Jimenez Pereperez, J.A., \& Ordovas, J.M. (2001). A Mediterranean and a high-carbohydrate diet improve glucose metabolism in healthy young persons. Diabetologia, 44, 2038-2043.

Pingitore, R., Spring, B., \& Garfield, D. (1997). Gender differences in body satisfaction. Obesity Research, 5, 402-409.

Pliner, P., Chaiken, S., \& Flett, G. L (1990). Gender differences in concern with body weight and physical appearance over the life span. Personality \& Social Psychology Bulletin, 16, 263-273.

Pollock, M. L. (1978). How much exercise is enough? The Physician and Sportsmedicine, 6 (6), 50-64.

*Povey, R., Conner, M., Sparks, P., James, R., \& Shepherd, R. (1999). A critical examination of the application of the Transtheoretical Model's stages of change to dietary behaviours. Health Education Research, 14, 641-651.

Prochaska, J. O. (1994). Strong and weak principles for progressing from precontemplation to action on the basis of twelve problem behaviors. Health Psychology, 13, 4751.

Prochaska, J. O., \& DiClemente, C. C. (1983). Stages and processes of self-change of smoking: Toward an integrative model of change. Journal of Consulting and Clinical Psychology, 51, 390-395.

Prochaska, J. O., DiClemente, C. C., \& Norcross, J. C. (1992). In search of how people change: Applications to addictive behaviors. American Psychologist, 47, 1102-1114.

Prochaska, J. O., DiClemente, C. C., Velicer, W. F., Ginpil, S., \& Norcross, J. C. (1985) Predicting change for smoking status for self- changers. Addictive Behaviors, 10, 395-406.

Prochaska, J. O., Norcross, J. C., and DiClemente, C. C. (1994). Changing for Good. New York: William Morrow and Company, Inc. 
*Prochaska, J. O., Norcross, J. C., Fowler, J. L., Follick, M. J., Abrams, D. B. (1992). Attendance and outcome in a work site weight control program: Processes and stages of change as process and predictor variables. Addictive Behaviors, 17, 35-45.

Prochaska, J. O., \& Velicer, W. F., (1997). The transtheoretical model of health behavior change. American Journal of Health Promotion, 12, 38-48.

Prochaska, J. O., Velicer, W. F., Rossi, J. S., Goldstein, M. G., Marcus, B. H., Rakowski, W., et al. (1994). Stage of change and decisional balance for 12 problem behaviors. Health Psychology, 13, 39-46.

Putnam, J., Allshouse, J., \& Kantor, L.S., (2002). U.S. per capita food supply trends: More calories, refined carbohydrates, and fats. Food Review, 25, 2-15.

Raats, M. M., Sparks, P., Geekie, M. A. \& Shepherd, R. (1999). The effects of providing personalized dietary feedback: A semi-computerized approach. Patient Education Counseling, 37, 177-189.

Read, M. H., Auld, G. W., Bock, M. A., Bruhn, C. M., Gabel, K., Lauritzen, G., et al. (1996). Age dietary behaviors, and the stages of change model. American Journal of Health Behavior, 20, 417-424.

Reboussin, B. A., Rejeski, W. J., Martin, K. A., Callahan, K., Dunn, A. L., King, A. C., \& Sallis, J. F. (2000). Correlates of satisfaction with body function and body appearance in middle and older aged adults: The Activity Counseling Trial (ACT). Psychology \& Health, 15, 239-254.

*Reed, G. R., Velicer, W. F., Prochaska, J. O., Rossi, J. S., \& Marcus, B. H. (1997). What makes a good staging algorithm: Examples from regular exercise. American Journal of Health Promotion, 12, 57-66.

Resnicow, K., DiIorio, C., Soet, J.E., Borrelli, B., Hecht, J., Ernst, D. (2002). Motivational interviewing in health promotion: It sounds like something is changing. Health Psychology, 21, 444-451.

Rivera, J. A., Barquera, S., Campirano, F., Campos, I., Safdie, M., \& Tovar, V. (2002) Epidemiological and nutritional transition in Mexico: rapid increase of non-communicable chronic diseases and obesity. Public Health Nutrition, 5, 113-122.

Rollnick, S., \& Miller, W. (1995). What is motivational interviewing? Behavioural and Cognitive Psychotherapy, 23, 225-234.

*Rossi, S. R. (1994). Application of the Transtheoretical Model of Behavior Change to dietary fat reduction in a naturalistic environment. Dissertation Abstracts International, SectionB: The Sciences and Engineering., 55 (4B), 1386.

Rotter, J. B. (1966). Generalized expectancies for internal versus external control of reinforcement. Psychological Monographs: General and Applied, 80, 1-28. (abstract) 
Rowley, K.G., Su, Q., Cincotta, M., Skinner, M., Skinner, K., Pindan, B., White, G.A., \& O'Dea, K. (2001). Improvements in circulating cholesterol, antioxidants, and homocysteine after dietary intervention in an Australian Aboriginal community. American Journal of Clinical Nutrition, 74, 442-448.

Rubel, C. (1995). Rising up angry, white, and male. Marketing News, 29 (5), 4-5.

Rutledge, J.C., Hyson, D.A., Garduno, D., Cort, D.A., Paumer, L., \& Kappagoda, C.T. (1999). Lifestyle modification program in management of patients with coronary artery disease: the clinical experience in a tertiary care hospital. Journal of Cardiopulmonary Rehabilitation, 19, 226-234.

Salmeron, J., Ascherio, A., Rimm, E. B., Colditz, G. A., Spiegelman, D., Jenkins, D. J., et al. (1997) Dietary fiber, glycemic load, and risk of NIDDM in men. Diabetes Care, 20, 545-550.

Salmeron, J., Manson, J. E., Stampfer, M. J., Colditz, G. A., Wing, A. L., \& Willett, W. C. (1997) Dietary fiber, glycemic load, and risk of non-insulin-dependent diabetes mellitus in women. JAMA, 277, 472-477.

Sandstrom, B., Marckmann, P., \& Bindslev, N. (1992). An eight-month controlled study of a low-fat high-fibre diet: effects on blood lipids and blood pressure in healthy young subjects. European Journal of Clinical Nutrition, 46, 95-109.

Schakel, S. F., Sievert, Y. A., \& Buzzard, I. M. (1988). Sources of data for developing and maintaining a nutrient database. Journal of the American Dietetic Association, 88, 12681271.

*Siero, F. W., Broer, J., Bemelmans, W. J., \& Meyboom-de Jong, B. M. (2000). Impact of group nutrition education and surplus value of Prochaska- based stage-matched information on health-related cognitions and on Mediterranean nutrition behavior. Health Education Research, 15, 635-647.

Smith, A. (1998). A few good men. Progressive Grocer, 77 (8), 17.

*Sporny, L. A., \& Contento, I. R. (1995). Stages of change in dietary fat reduction: Social psychological correlates. Journal of Nutrition Education, 27, 191-199.

Stemmermann, G., Nomura, A.M., Heilbrun, L.K., Mower, H., \& Hayashi, T. (1985) Colorectal cancer in Hawaiian Japanese men: a progress report. Journal of the National Cancer Institute. Monographs, 69, 125-131.

*Steptoe, A., Kerry, S., Rink, E., \& Hilton, S. (2001). The impact of behavioral counseling on stage of change in fat intake, physical activity, and cigarette smoking in adults at increased risk of coronary heart disease. American Journal of Public Health, 91, 265-269.

*Steptoe, A., Wijetunge, S., Doherty, S., \& Wardle, J. (1996). Stages of change for dietary fat reduction: Associations with food intake, decisional balance and motives for food choice. Health Education Journal, 55, 108-122. 
Subar, A. F., Frey, C. M., Harlan, L. C., Kahle, L. (1994). Differences in reported food frequency by season of questionnaire administration: The 1987 National Health Interview survey. Epidemiology, 5, 226-233.

Thompson, B., Demark-Wahnefried, W., Taylor, G., McClelland, J. W., Stables, G., Havas, S., Feng, Z., Topor, M., Heimendinger, J., Reynolds, K. D., \& Cohen, N. (1999). Baseline fruit and vegetable intake among adults in seven "5 a day" study center located in diverse geographic areas. Journal of the American Dietetic Association., 99, 1241-1248.

Thompson, F. E., \& Byers, T. (1994). Dietary Assessment Resource Manual. The Journal of Nutrition, 124 (No. 11 Suppl.), 2245S-2317S.

Tominaga, S., \& Kuroishi, T. (1997) An ecological study on diet/nutrition and cancer in Japan. International Journal of Cancer, 10(Suppl.), 2-6.

Toohey, M. L., Harris, M. A., DeWitt, W., Foster, G., Schmidt, W. D., \& Melby, C. L. (1998) Cardiovascular disease risk factors are lower in African-American vegans compared to lacto-ovo-vegetarians. Journal of the American College of Nutrition, 17, 425-434.

U.S. Department of Agriculture. (USDA, 2000a). Nutrition and your health: Dietary guidelines for Americans. 5th ed. (USDA: Home and garden bulletin; no. 232). Washington, DC: U.S. Government Printing Office.

U.S. Department of Agriculture. (USDA, 2000b). Using the dietary guidelines for Americans. (USDA: Program Aid 1676). Washington, DC: U.S. Government Printing Office.

U.S. Department of Agriculture, Agriculture Research Service. (USDA, 1999). Data tables: Food and nutrient intakes by income, 1994-1996. Retrieved August 3, 2003, from the "products" page at $<$ http://www.barc.usda.gov/bhnrc/foodsurvey/home.htm>

U.S. Department of Health and Human Services. (USDHHS, 1988). The Surgeon General's report on nutrition and health (DHHS Publication No. 88-50210). Washington, DC: U.S. Government Printing Office.

U.S. Department of Health and Human Services. (USDHHS, 1989). The Surgeon General's report: Reducing the health consequences of smoking. (DHHS Publication [CDC] No. 89-8411). Washington, DC: U.S. Government Printing Office.

U.S. Department of Health and Human Services. (USDHHS, 1990). Healthy people 2000: National health promotion and prevention objectives (PHS Publication No. 91-50212). Washington, DC: U.S. Government Printing Office.

U.S. Department of Health and Human Services. (USDHHS, 2000). Healthy people 2010: With understanding and improving health and objectives for improving health. 2 vols. Washington, DC: U.S. Government Printing Office. 
Visser, M., Langlois, J., Guralnik, J. M., Cauley, J. A., Kronmal, R. A., Robbins, J., et al. (1998). High body fatness but not fat-free mass, predicts disability in older men and women: The Cardiovascular Health Study. American Journal of Clinical Nutrition, 68, 584-590.

Vorster, H. H. (2002) The emergence of cardiovascular disease during urbanisation of Africans Public Health Nutrition, 5, 239-243.

Wang, M. Q., Eddy, J. M., \& Fitzhugh, E. C. (1992). Towards standard measures in health assessments. Health Values, 16, 52-56.

Wardlaw, G. M., Snook, J. T., Lin, M. C., Puangco, M. A., \& Kwon, J. S. (1991). Serum lipid and apolipoprotein concentrations in healthy men on diets enriched in either canola oil or safflower oil. American Journal of Clinical Nutrition, 54, 104-110.

*Watt, R. G. (1997). Stages of change for sugar and fat reduction in an adolescent sample. Community Dental Health, 14, 102-107.

Willett, W.C. (1997). Dietary fat intake and cancer risk: A controversial and instructive story. Seminars in Cancer Biology, 66, 1557S-1563S.

Willett, W.C. (2001). Diet and breast cancer. Journal of Internal Medicine, 249, 395-411.

Willett, W.C., Stampfer, M.J., Manson, J.E., Colditz, G.A., Speizer, F.E., Rosner, B.A., et al. (1993) Intake of trans fatty acids and risk of coronary heart disease among women. Lancet, $341,581-585$.

Williamson, D. F., Forman, M. R., Binkin, N. J., Gentry, E. M., Remington, P. 1., \& Trowbridge, F. L., (1987). Alcohol and body weight in United States adults. American Journal of Public Health, 77, 1324-1330.

Winett, R. A. (1995). A framework for health promotion and disease prevention programs. American Psychologist, 50, 341-350.

Winett, R. A., Moore, J. F., Wagner, J. L., Hite, L. A., Leahy, M., Neubauer, T. E., et al. (1991). Altering shopper's food purchases to meet nutritional guidelines: Interactive system. Journal of Applied Behavior Analysis, 24, 95-105

Wright, J. D., Wang, C. Y., Kennedy-Stephenson, J., Ervin, R. B. (2003). Dietary intake of ten key nutrients for public health, Unites States: 1999-2000. Advance data from vital and health statistics; no. 334. Hyattsville, MD: National Center for Health Statistics.

Ziegler, R. G., Wilcox, H. B. $3^{\text {rd }}$, Mason, T. J., Bill, J. S., \& Virgo, P. W. (1987). Seasonal variation in intake of carotenoids and vegetables and fruits among white men in New Jersey. American Journal of Clinical Nutrition, 45, 107-114.

* indicates the reference is cited in Review Table A1 or A2 (see Appendix A) 
Table 1

Gender Differences in Reported Dietary Training

\begin{tabular}{lccr}
\hline \multicolumn{1}{c}{ Training } & Male & Female & Total \\
\hline Classes in school & $59(58.4 \%)$ & $109(65.3 \%)$ & $168(62.7 \%)$ \\
Workplace wellness program & $12(11.9 \%)$ & $26(15.6 \%)$ & $38(14.2 \%)$ \\
Dietitian consultation & $12(11.9 \%)$ & $29(17.4 \%)$ & $41(15.3 \%)$ \\
National weight loss program & $7(6.9 \%)^{*}$ & $47(28.1 \%)^{*}$ & $54(20.1 \%)$ \\
Advice from media \& others & $25(24.8 \%)$ & $41(24.6 \%)$ & $66(24.6 \%)$ \\
Other & $4(4.0 \%)$ & $14(8.4 \%)$ & $18(6.7 \%)$ \\
None & $23(22.8 \%)^{*}$ & $13(7.8 \%)^{*}$ & $36(13.4 \%)$ \\
\hline
\end{tabular}

Note: Dietary training was a multiple response item with duplicate count

$*$ indicates significant gender differences based on separate $\chi^{2}, p<.05$ 
Table 2

Gender Differences for Other Health Behaviors

\begin{tabular}{cccc}
\hline & \multicolumn{2}{c}{ Gender } & \\
\cline { 2 - 3 } & Male & Female & Total \\
\cline { 2 - 3 } Smoking Status & $68(66.7 \%)$ & $103(60.6 \%)$ & $171(62.9 \%)$ \\
Non-Smoker & $7(6.9 \%)$ & $13(7.6 \%)$ & $20(7.4 \%)$ \\
Current Smoker & $27(26.5 \%)$ & $54(31.8 \%)$ & $81(29.8 \%)$ \\
Ex-Smoker & 102 & 170 & 272 \\
Total & $5(4.9 \%)^{*}$ & $30(17.5 \%)^{*}$ & $35(12.8 \%)$ \\
Activity Level & $45(44.1 \%)$ & $72(42.1 \%)$ & $117(42.9 \%)$ \\
Daily Living Activities & $52(51.0 \%)$ & $69(40.4 \%)$ & $121(44.3 \%)$ \\
Low Energy & 102 & 171 & 273 \\
Aerobic 3 or more weekly & & \\
Total & $6(5.9 \%)$ & $18(10.5 \%)$ & $24(8.8 \%)$ \\
Alcohol Intake Level & $66(64.7 \%)$ & $124(72.5 \%)$ & $190(69.6 \%)$ \\
None $\quad 24(23.5 \%)^{*}$ & $28(16.4 \%)^{*}$ & $52(19.0 \%)$ \\
Light $\leq 1.5$ oz/week & $6(5.9 \%)^{*}$ & $1(0.6 \%)^{*}$ & $7(2.6 \%)$ \\
Moderate $\leq 1$ oz/day & 102 & 171 & 273 \\
Heavy $\geq 1$ oz/day & Total & &
\end{tabular}

* indicates significant gender difference based on $\chi^{2}, p<.05$ 
Table 3

Number (Percentage) of Male and Female Participants Assigned to SOC for Low-Fat or HighFiber Dietary Behaviors

\begin{tabular}{crrr}
\hline \multicolumn{1}{c}{ Stages } & \multicolumn{1}{c}{ Male } & \multicolumn{1}{c}{ Female } & \multicolumn{1}{c}{ Total } \\
\hline SOC low-fat & & & \\
Precontemplation & $16(15.7)^{*}$ & $14(8.2)^{*}$ & $30(11.0)$ \\
Contemplation & $10(9.8)^{*}$ & $17(10.0)^{*}$ & $27(9.9)$ \\
Preparation & $13(12.7)^{*}$ & $26(15.3)^{*}$ & $39(14.3)$ \\
Action & $18(17.6)^{*}$ & $42(24.7)^{*}$ & $60(22.1)$ \\
Maintenance & $45(44.1)^{*}$ & $71(41.8)^{*}$ & $116(42.6)$ \\
SOC high-fiber & & & \\
Precontemplation & $54(52.9)^{*}$ & $57(33.3)^{*}$ & $111(40.7)$ \\
Contemplation & $7(6.9)^{*}$ & $13(7.6)^{*}$ & $20(7.3)$ \\
Preparation & $5(4.9)^{*}$ & $14(8.2)^{*}$ & $19(7.0)$ \\
Action & $5(4.9)^{*}$ & $43(25.1)^{*}$ & $48(17.6)$ \\
Maintenance & $31(30.4)^{*}$ & $44(25.7)^{*}$ & $75(27.5)$ \\
\hline
\end{tabular}

$*$ indicates significant gender differences based on $\chi^{2}, p<.05$ 
Table 4

Differences in Mean Age for SOC for Low-Fat and High Fiber Dietary Behavior

\begin{tabular}{lll}
\hline Stage & Age & SD \\
\hline SOC Low-Fat & & \\
Precontemplation & 41.0 & 10.0 \\
Contemplation & $39.2^{\mathrm{a}}$ & 14.1 \\
Preparation & $39.4^{\mathrm{b}}$ & 13.6 \\
Action & $38.2^{\mathrm{c}}$ & 13.3 \\
Maintenance & $47.8^{\mathrm{a}, \mathrm{b}, \mathrm{c}}$ & 14.9 \\
Total & 42.9 & 14.4 \\
SOC High-Fiber & & \\
Precontemplation & $38.1^{\mathrm{d}}$ & 13.9 \\
Contemplation & 42.3 & 11.7 \\
Preparation & 46.3 & 13.8 \\
Action & $40.9^{\mathrm{e}}$ & 15.3 \\
Maintenance & $50.3^{\mathrm{d}, \mathrm{e}}$ & 12.1 \\
Total & 42.8 & 14.4 \\
\hline
\end{tabular}

Superscript indicates significant differences between stages, $p<.05$

${ }^{a}$ low-fat SOC, contemplation stage members younger than maintenance stage members

${ }^{b}$ low-fat SOC, preparation stage members younger than maintenance stage members

${ }^{c}$ low-fat SOC, action stage members younger than maintenance stage members

${ }^{\mathrm{d}}$ high-fiber SOC, precontemplation members younger than maintenance stage members

${ }^{\mathrm{e}}$ high-fiber SOC, action members younger than maintenance stage members 
Table 5

Dietary Intake Compared to Gender and Low-Fat or High-Fiber SOCs

\begin{tabular}{|c|c|c|c|}
\hline & \multicolumn{3}{|c|}{ Mean Intake (SD) } \\
\hline & Male & Female & Total \\
\hline \multicolumn{4}{|c|}{$\%$ of Calories from Fat for Low-Fat SOC } \\
\hline Early & $37.5(8.3)$ & $40.4(9.4)$ & $39.2(9.0)^{\mathrm{a}, \mathrm{b}}$ \\
\hline Action & $35.0(7.3)$ & $32.1(8.7)$ & $33.0(8.4)^{\mathrm{a}}$ \\
\hline \multirow{2}{*}{$\begin{array}{l}\text { Action } \\
\text { Maintenance }\end{array}$} & $31.2(7.7)$ & $30.4(9.2)$ & $30.7(8.6)^{b}$ \\
\hline & $34.3(8.3)$ & $34.1(10.2)$ & $34.2(9.5)$ \\
\hline \multicolumn{4}{|c|}{ Fiber (gm) for High-Fiber SOC } \\
\hline Early & $14.3(8.0)$ & $13.1(6.2)$ & $13.6(7.0)^{\mathrm{c}}$ \\
\hline \multirow[t]{2}{*}{ Late } & $20.1(8.1)$ & $17.6(8.0)$ & $18.3(8.1)^{\mathrm{c}}$ \\
\hline & $16.4(8.6)^{*}$ & $15.4(7.5) *$ & $15.7(7.9)^{\mathrm{a}}$ \\
\hline
\end{tabular}

Superscript indicates significant differences between stages, $p<.05$

${ }^{a}$ fat intake higher for early stage members than action members

${ }^{b}$ fat intake higher for early members than maintenance members

${ }^{\mathrm{c}}$ fiber intake lower for early stage members than late stage members

* Significant gender difference for fiber intake 
Table 6

Effects of Stage Assignment on Completion Rates for Males and Females

\begin{tabular}{|c|c|c|c|c|c|c|}
\hline \multirow[b]{2}{*}{ Stage at Baseline } & \multicolumn{2}{|c|}{ Male } & \multicolumn{2}{|c|}{ Female } & \multicolumn{2}{|c|}{ Total } \\
\hline & $\mathrm{N}$ & Rate & $\mathrm{N}$ & & $\mathrm{N}$ & Rate \\
\hline \multicolumn{7}{|l|}{ Low-fat SOC } \\
\hline Precontemplation & 11 & $69 \%$ & 8 & $57 \%$ & 19 & $63 \%$ \\
\hline Contemplation/Preparation & 14 & $61 \%$ & 32 & $74 \%$ & 46 & $70 \%$ \\
\hline Action & 11 & $61 \%$ & 24 & $57 \%$ & 35 & $58 \%$ \\
\hline Maintenance & 35 & $78 \%$ & 61 & $86 \%{ }^{\mathrm{a}}$ & 96 & $83 \%^{\mathrm{c}}$ \\
\hline \multicolumn{7}{|l|}{ High-fiber SOC } \\
\hline Precontemplation & 35 & $65 \%$ & 37 & $65 \%$ & 72 & $65 \%$ \\
\hline Contemplation/Preparation & 9 & $75 \%$ & 18 & $67 \%$ & 27 & $69 \%$ \\
\hline Action & 4 & $80 \%$ & 32 & $74 \%$ & 36 & $75 \%$ \\
\hline Maintenance & 23 & $74 \%$ & 39 & $89 \%{ }^{\mathrm{b}}$ & 62 & $83 \%$ \\
\hline
\end{tabular}

${ }^{a}$ Significantly higher completion rate for maintenance stage women than other low-fat stages

${ }^{\mathrm{b}}$ Significantly higher completion rate for maintenance stage women than other high-fiber stages

${ }^{c}$ Significantly higher completion rate for maintenance stage members than other low-fat stages 
Table 7

Mean Pro and Con Ratings for General or Gender-Specific Decisional Balance (DB) Measures by Gender and Low-Fat SOC

\begin{tabular}{|c|c|c|c|c|c|c|}
\hline & \multicolumn{3}{|c|}{ General } & \multicolumn{3}{|c|}{ Specific } \\
\hline & Male & Female & Total & Male & Female & Total \\
\hline \multicolumn{7}{|l|}{ Pros } \\
\hline Early stages & $4.10(.61)$ & $4.47(.45)$ & $4.32(.55)^{b}$ & $3.30(.66)$ & $3.50(.74)$ & $3.42(.71)^{\mathrm{c}}$ \\
\hline Late stages & $4.48(.46)$ & $4.62(.42)$ & $4.57(.44)^{\mathrm{b}}$ & $3.80(.60)$ & $3.79(.59)$ & $3.80(.59)^{\mathrm{c}}$ \\
\hline Total & $4.34(.55)^{\mathrm{a}}$ & $4.57(.43)^{\mathrm{a}}$ & $4.48(.49)$ & $3.61(.67)$ & $3.70(.66)$ & $3.66(.66)$ \\
\hline \multicolumn{7}{|l|}{ Cons } \\
\hline Early stages & $3.38(.76)$ & $3.38(.82)$ & $3.38(.79)^{\mathrm{d}}$ & $2.83(.64)^{f, g}$ & $2.47(.57)^{\mathrm{f}, \mathrm{h}}$ & $2.62(.62)$ \\
\hline Late stages & $2.90(.78)$ & $3.10(.87)$ & $3.03(.84)^{\mathrm{d}}$ & $2.16(.62)^{\mathrm{g}}$ & $2.26(.59)^{\mathrm{h}}$ & $2.22(.60)$ \\
\hline Total & $3.09(.80)$ & $3.19(.86)$ & $3.15(.84)$ & $2.42(.71)$ & $2.33(.59)$ & $2.36(.64)$ \\
\hline \multicolumn{7}{|l|}{ Pro/Con Ratio } \\
\hline Early stages & $1.29(.44)$ & $1.44(.57)$ & $1.38(.53)^{\mathrm{e}}$ & $1.21(.31)^{\mathrm{i}, \mathrm{j}}$ & $1.52(.58)^{\mathrm{i}, \mathrm{k}}$ & $1.39(.51)$ \\
\hline Late stages & $1.70(.70)$ & $1.66(.65)$ & $1.67(.67)^{\mathrm{e}}$ & $1.94(.73)^{\mathrm{j}}$ & $1.82(.66)^{\mathrm{k}}$ & $1.85(.69)$ \\
\hline Total & $1.54(.64)$ & $1.58(.63)$ & $1.57(.64)$ & $1.66(.70)$ & $1.72(.65)$ & $1.70(.67)$ \\
\hline
\end{tabular}

Note: Higher ratings indicate higher agreement with either pro or con position

${ }^{a}$ difference in gender for general pro mean rating

${ }^{b}$ difference in low-fat SOC for general pro mean rating

${ }^{c}$ difference in low-fat SOC for gender-specific pro mean rating

${ }^{\mathrm{d}}$ difference in low-fat SOC for general con mean rating

${ }^{\mathrm{e}}$ difference in low-fat SOC for general pro/con ratio

Gender by Stage Interaction for Specific Con Ratings

${ }^{f}$ for early stages, simple effect of males rating cons higher than females

$\mathrm{g}$ for males, simple effect of early stages rating cons higher than later stages

${ }^{\mathrm{h}}$ for females, simple effect of early stages rating cons higher than later stages

Gender by Stage Interaction for Specific Pro/Con Ratio

${ }^{i}$ for early stages, simple effect of males having lower pro/con ratios than females

${ }^{\mathrm{j}}$ for males, simple effect of early stages having lower pro/con ratio than later stages

${ }^{\mathrm{k}}$ for females, simple effect of early stages having lower pro/con ratio than later stages 
Table 8

Mean Pro and Con Ratings for General or Gender-Specific Decisional Balance (DB) Measures by Gender and High-Fiber SOC

\begin{tabular}{|c|c|c|c|c|c|c|}
\hline & \multicolumn{3}{|c|}{ General } & \multicolumn{3}{|c|}{ Specific } \\
\hline & Male & Female & Total & Male & Female & Total \\
\hline \multicolumn{7}{|l|}{ Pros } \\
\hline Early stages & $4.24(.61)$ & $4.51(.44)$ & $4.39(.54)^{b}$ & $3.56(.67)$ & $3.51(.70)$ & $3.53(.68)^{\mathrm{c}}$ \\
\hline Late stages & $4.51(.38)$ & $4.63(.41)$ & $4.59(.41)^{b}$ & $3.70(.67)$ & $3.88(.56)$ & $3.83(.60)^{\mathrm{c}}$ \\
\hline Total & $4.34(.55)^{\mathrm{a}}$ & $4.57(.43)^{\mathrm{a}}$ & $4.48(.49)$ & $3.61(.67)$ & $3.70(.66)$ & $3.67(.66)$ \\
\hline \multicolumn{7}{|l|}{ Cons } \\
\hline Early stages & $3.17(.83)$ & $3.29(.80$ & $3.23(.82)$ & $2.59(.69)^{\mathrm{f}, \mathrm{g}}$ & $2.36(.53)^{\mathrm{f}}$ & $2.46(.62)$ \\
\hline Late stages & $2.94(.73)$ & $3.09(.90)$ & $3.05(.86)$ & $2.10(.63)^{\mathrm{g}}$ & $2.31(.64)$ & $2.25(.64)$ \\
\hline Total & $3.09(.80)$ & $3.19(.86)$ & $3.15(.84)$ & $2.41(.71)$ & $2.33(.59)$ & $2.36(.64)$ \\
\hline \multicolumn{7}{|l|}{ Pro/Con Ratio } \\
\hline Early stages & $1.47(.59)$ & $1.49(.59)$ & $1.48(.59)^{\mathrm{d}}$ & $1.49(.58)$ & $1.58(.53)$ & $1.54(.55)^{\mathrm{e}}$ \\
\hline Late stages & $1.68(.72)$ & $1.67(.66)$ & $1.68(.67)^{\mathrm{d}}$ & $1.96(.80)$ & $1.85(.71)$ & $1.88(.74)^{\mathrm{e}}$ \\
\hline Total & $1.54(.64)$ & $1.59(.63)$ & $1.57(.64)$ & $1.66(.70)$ & $1.72(.65)$ & $1.70(.67)$ \\
\hline
\end{tabular}

Note: Higher ratings indicate higher agreement with either pro or con position

${ }^{a}$ difference in gender for general pro mean rating

${ }^{\mathrm{b}}$ difference in High-Fiber SOC for general pro mean rating

${ }^{c}$ difference in High-Fiber SOC for specific pro mean rating

d difference in High-Fiber SOC for general pro/con ratio

${ }^{\mathrm{e}}$ difference in High-Fiber SOC for specific pro/con ratio

Gender by Stage Interaction for Specific Con Ratings

${ }^{\mathrm{f}}$ for early stages, simple effect of males rating cons higher than females

$\mathrm{g}$ for males, simple effect of early stages rating cons higher than later stages 
Table 9

Baseline to Phase 2 Change of Low-Fat Stage Based on Feedback Type

\begin{tabular}{|c|c|c|c|c|c|c|}
\hline \multirow[t]{2}{*}{ Change at Phase 2} & \multirow[b]{2}{*}{$\mathrm{N}$} & \multicolumn{2}{|c|}{ Fat Intake $\leq 30 \%$} & \multirow[b]{2}{*}{$\mathrm{N}$} & \multicolumn{2}{|c|}{ Fat Intake $>30 \%$} \\
\hline & & No feedback & Feedback & & No feedback & Feedback \\
\hline Early Stage at Baselin & & & & & & \\
\hline Remain Early & 5 & $2(40 \%)$ & $3(60 \%)$ & 32 & $9(41 \%)$ & $23(49 \%)$ \\
\hline Advance & 5 & $3(60 \%)$ & $2(40 \%)$ & 37 & $13(59 \%)$ & $24(51 \%)$ \\
\hline Late Stage at Baseline & & & & & & \\
\hline Regress & 12 & $3(14 \%)$ & $9(20 \%)$ & 16 & $2(7 \%)^{a}$ & $14(24 \%)^{\mathrm{a}}$ \\
\hline Remain Late & 56 & $19(86 \%)$ & $37(80 \%)$ & 71 & $27(93 \%)$ & $44(76 \%)$ \\
\hline
\end{tabular}

${ }^{\mathrm{a}}$ Significant difference in stage change at Phase 2 for late stage at baseline 
Table 10

Phase 2 to Phase 3 Change of Low-Fat Stage Based on Feedback Type

\begin{tabular}{|c|c|c|c|c|c|c|}
\hline \multirow[t]{2}{*}{ Change at Phase 3} & \multirow[b]{2}{*}{$\mathrm{N}$} & \multicolumn{2}{|c|}{ Fat Intake $\leq 30 \%$} & \multirow[b]{2}{*}{$\mathrm{N}$} & \multicolumn{2}{|c|}{ Fat Intake $>30 \%$} \\
\hline & & No feedback & Feedback & & No feedback & Feedback \\
\hline Early Stage at Phase 2 & & & & & & \\
\hline Remain Early & 5 & $2(40 \%)$ & $3(38 \%)$ & 24 & $7(78 \%)$ & $17(61 \%)$ \\
\hline Advance & 8 & $3(60 \%)$ & $5(62 \%)$ & 13 & $2(22 \%)$ & $11(39 \%)$ \\
\hline Late Stage at Phase 2 & & & & & & \\
\hline Regress & 5 & $2(10 \%)$ & $3(10 \%)$ & 15 & $8(23 \%)$ & $7(12 \%)$ \\
\hline Remain Late & 46 & $18(90 \%)$ & $28(90 \%)$ & 80 & $27(77 \%)$ & $53(88 \%)$ \\
\hline
\end{tabular}


Table 11

Baseline to Phase 2 Change of High-Fiber Stage Based on Feedback Type

\begin{tabular}{|c|c|c|c|c|c|c|}
\hline \multirow[t]{2}{*}{ Change at Phase 2} & \multirow[b]{2}{*}{$\mathrm{N}$} & \multicolumn{2}{|c|}{ Fiber Intake $\leq 20 \mathrm{~g}$} & \multirow[b]{2}{*}{$\mathrm{N}$} & \multicolumn{2}{|c|}{ Fiber Intake $>20 \mathrm{~g}$} \\
\hline & & No feedback & Feedback & & No feedback & Feedback \\
\hline Early Stage at Baseline & & & & & & \\
\hline Remain Early & 62 & $17(53 \%)$ & $45(67 \%)$ & 13 & $3(43 \%)$ & $10(67 \%)$ \\
\hline Advance & 37 & $15(47 \%)$ & $22(33 \%)$ & 9 & $4(57 \%)$ & $5(33 \%)$ \\
\hline Late Stage at Baseline & & & & & & \\
\hline Regress & 17 & $2(9 \%)^{\mathrm{a}}$ & $15(33 \%)^{\mathrm{a}}$ & 7 & $1(7 \%)$ & $6(21 \%)$ \\
\hline Remain Late & 51 & $21(91 \%)$ & $30(67 \%)$ & 37 & $14(93 \%)$ & $23(79 \%)$ \\
\hline
\end{tabular}

${ }^{a}$ Significant difference in stage change at Phase 2 for late stage at baseline 
Table 12

Phase 2 to Phase 3 Change of High-Fiber Stage Based on Feedback Type

\begin{tabular}{lrrrrrr}
\hline Change at Phase 3 & & \multicolumn{2}{c}{ Fiber Intake $\leq 20 \mathrm{~g}$} & & \multicolumn{2}{c}{ Fiber Intake $>20 \mathrm{~g}$} \\
\cline { 3 - 4 } & & No feedback & Feedback & & No feedback & Feedback \\
\hline Early Stage at Phase 2 & & & & & & \\
$\quad$ Remain Early & 42 & $11(73 \%)$ & $31(66 \%)$ & 12 & $4(100 \%)$ & $8(80 \%)$ \\
$\quad$ Advance & 20 & $4(27 \%)$ & $16(34 \%)$ & 2 & & $2(20 \%)$ \\
Late Stage at Phase 2 & & & & & & \\
$\quad$ Regress & 20 & $4(12 \%)^{\mathrm{a}}$ & $16(34 \%)^{\mathrm{a}}$ & 6 & $1(6 \%)$ & $5(23 \%)$ \\
$\quad$ Remain Late & 59 & $28(88 \%)$ & $31(66 \%)$ & 33 & $16(94 \%)$ & $17(77 \%)$ \\
\hline
\end{tabular}

${ }^{a}$ Significant difference in stage change at Phase 3 for late stage at Phase 2 
Table 13

Effects of Gender and Treatment Condition on Pre-post change in \% of Calories from Fat and in Fiber (g/day)

\begin{tabular}{|c|c|c|c|}
\hline Treatment Group & Male & Female & Total \\
\hline \multicolumn{4}{|l|}{ Change in $\%$ of calories from fat } \\
\hline Wait list & $-1.0(5.9)^{\mathrm{a}}$ & $2.1(5.7)^{\mathrm{a}}$ & $1.0(5.9)$ \\
\hline Feedback & $1.2(7.0)$ & $-1.9(9.3)$ & $-0.8(8.6)$ \\
\hline Message & $-3.0(7.5)$ & $1.0(8.7)$ & $-0.4(8.5)$ \\
\hline Totals & $-0.9(6.9)$ & $0.5(8.1)$ & $-0.0(7.7)$ \\
\hline \multicolumn{4}{|l|}{ Change in Fiber (g/day) } \\
\hline Wait list & $1.0(8.0)$ & $-0.8(6.2)$ & $-0.1(6.9)$ \\
\hline Feedback & $-0.3(6.2)$ & $-1.0(6.7)$ & $-0.8(6.5)$ \\
\hline Message & $1.1(7.0)$ & $0.6(7.8)$ & $0.8(7.5)$ \\
\hline Totals & $0.6(7.1)$ & $-0.4(6.9)$ & $-0.0(7.0)$ \\
\hline
\end{tabular}

Significant interaction in pre-post change in \% of calories from fat for gender by treatment group ${ }^{a}$ Simple effect for Wait List Group, males reporting lower fat intake and females reporting higher fat intake 
Table 14

Effects of Stage and Treatment Group on Pre-Post Change in \% of Calories from Fat and in Fiber (g/day)

\begin{tabular}{|c|c|c|c|c|c|c|}
\hline \multirow[b]{3}{*}{ Phase } & \multicolumn{3}{|c|}{ Change in $\%$ of calories from fat } & \multicolumn{3}{|c|}{ Change in Fiber $(\mathrm{g} / \mathrm{dy})$} \\
\hline & \multicolumn{2}{|c|}{ Low-Fat SOC } & \multirow[t]{2}{*}{ Total } & \multicolumn{2}{|c|}{ High-Fiber SOC } & \multirow[t]{2}{*}{ Total } \\
\hline & Early & Late & & Early & Late & \\
\hline \multicolumn{7}{|l|}{ Baseline } \\
\hline Wait list & $0.6(6.1)$ & $1.2(5.9)$ & $1.0(5.9)$ & $-1.0(6.0)$ & $0.7(7.6)$ & $-0.1(6.9)$ \\
\hline Feedback & $-1.5(9.0)$ & $-0.4(8.5)$ & $-0.8(8.6)$ & $-0.8(6.7)$ & $-0.8(6.4)$ & $-0.8(6.5)$ \\
\hline Message & $-1.7(9.2)$ & $0.2(8.3)$ & $-0.4(8.5)$ & $1.5(8.0)$ & $-0.0(6.8)$ & $0.8(7.5)$ \\
\hline Total & $-0.8(8.1)$ & $0.4(7.6)$ & $-0.0(7.7)$ & $-0.0(7.0)$ & $0.0(7.0)$ & $-0.0(7.0)$ \\
\hline \multicolumn{7}{|l|}{ Phase 2} \\
\hline Wait list & $1.9(6.3)$ & $0.8(5.9)$ & $1.0(5.9)$ & $-0.6(6.3)$ & $-0.2(7.0)$ & $-0.3(6.8)$ \\
\hline Feedback & $2.4(3.9)$ & $-2.1(9.7)$ & $-0.8(8.6)$ & $-0.6(5.7)$ & $-0.8(7.1)$ & $-0.7(6.5)$ \\
\hline Message & $0.0(9.9)$ & $-0.6(8.0)$ & $-0.4(8.5)$ & $0.2(7.8)$ & $1.3(7.1)$ & $0.8(7.5)$ \\
\hline Total & $1.4(7.1)$ & $-0.5(7.9)$ & $0.0(7.7)$ & $-0.3(6.7)$ & $0.0(7.1)$ & $-0.1(6.9)$ \\
\hline \multicolumn{7}{|l|}{ Follow-up } \\
\hline Wait list & $0.4(4.9)$ & $1.2(6.3)$ & $1.0(5.9)$ & $-0.2(6.6)$ & $-0.1(7.1)$ & $-0.1(6.9)$ \\
\hline Feedback & $2.1(5.6)$ & $-1.1(8.6)$ & $-0.4(8.1)$ & $-1.0(6.1)$ & $0.0(6.4)$ & $-0.5(6.2)$ \\
\hline Message & $3.6(8.6)$ & $-1.7(8.1)$ & $-0.4(8.5)$ & $1.4(6.8)$ & $0.2(8.0)$ & $0.8(7.4)$ \\
\hline Total & $2.0(6.5)^{\mathrm{a}}$ & $-0.5(7.8)^{\mathrm{a}}$ & $0.1(7.5)$ & $0.2(6.5)$ & $0.0(7.2)$ & $0.1(6.9)$ \\
\hline
\end{tabular}

\footnotetext{
${ }^{a}$ Significant difference in pre, post- change in \% of calories from fat with late stages reporting lower levels of fat and early stage reporting higher levels of fat at follow-up
} 
Appendix A: Review Tables for Stage of Change 


\section{SOC Review Table A1}

Summary of Studies on the Stages of Change Model Applied to Dietary Behavior Model Testing Studies

\begin{tabular}{|c|c|c|c|c|c|c|c|c|}
\hline \multirow{2}{*}{ Authors } & \multirow[b]{2}{*}{ Participants } & \multirow[b]{2}{*}{ Measures } & \multirow[b]{2}{*}{ Type } & \multicolumn{5}{|c|}{ SOC percents, Other scores } \\
\hline & & & & $\mathrm{Pc}$ & $\mathrm{C}$ & $\mathrm{Pp}$ & A & $\mathrm{M}$ \\
\hline \multicolumn{9}{|c|}{ Classification methods for SOC } \\
\hline \multirow{6}{*}{$\begin{array}{l}\text { Auld, et al. } \\
\text { (1998) and } \\
\text { Read, et al. } \\
\text { 1996) }\end{array}$} & mailed survey in & low-fat \& high-fiber & SOC Low-Fat & & & & & \\
\hline & 11 states and $\mathrm{DC}$ & SOCs & Male & 9 & 16 & 40 & 35 & $\mathrm{~A} / \mathrm{M}$ \\
\hline & with $\sim 2000$ & & Female & 7 & 10 & 32 & 51 & $\mathrm{~A} / \mathrm{M}$ \\
\hline & unambiguously & & SOC High-Fiber & & & & & \\
\hline & assigned to stage & & Male & 9 & 13 & 47 & 31 & $\mathrm{~A} / \mathrm{M}$ \\
\hline & & & Female & 7 & 9 & 43 & 42 & $\mathrm{~A} / \mathrm{M}$ \\
\hline \multirow{2}{*}{$\begin{array}{l}\text { Boyle, et al. } \\
\text { (1998) }\end{array}$} & $6152 \mathrm{HMO}$ & SOC for dietary fat & Low-fat & 8 & 5 & 4 & 21 & 62 \\
\hline & $\begin{array}{l}\text { members age } 40 \\
\text { or older }\end{array}$ & and $F \& V$ intake & $\mathrm{F} \& \mathrm{~V}$ & 6 & 4 & 4 & 19 & 67 \\
\hline \multirow{2}{*}{$\begin{array}{l}\text { Brug, Glanz, } \\
\text { et al. (1997) }\end{array}$} & 739 Dutch & 4 item SOC for fruit & Vegies & 6 & 8 & 33 & 5 & 48 \\
\hline & $\begin{array}{l}\text { respondents to a } \\
\text { newspaper ad }\end{array}$ & and for vegetables & Fruit & 9 & 8 & 36 & 5 & 40 \\
\hline \multirow{6}{*}{$\begin{array}{l}\text { Curry, et al. } \\
\text { (1992) }\end{array}$} & 158 adult $\mathrm{HMO}$ & SOC for limiting fat & HMO Sample & & & & & \\
\hline & enrollees and & & Male & 36 & 8 & 4 & 16 & 36 \\
\hline & 1053 adults from & & Female & 9 & 8 & 9 & 19 & 55 \\
\hline & phone survey & & Phone Sample & & & & & \\
\hline & & & Male & 29 & 7 & 7 & 6 & 50 \\
\hline & & & Female & 17 & 6 & 11 & 8 & 59 \\
\hline \multirow[t]{5}{*}{$\begin{array}{l}\text { Glanz, et al. } \\
\text { (1994) }\end{array}$} & $\begin{array}{l}17,121 \\
\text { employees of }\end{array}$ & $\begin{array}{l}\text { SOC for fat and } \\
\text { fiber intake }\end{array}$ & $\begin{array}{l}\text { SOC Fat Intake } \\
\text { Male }\end{array}$ & 16 & 20 & 4 & 43 & 16 \\
\hline & several & & Female & 8 & 15 & 5 & 52 & 20 \\
\hline & companies in the & & SOC Fiber Intake & & & & & \\
\hline & Working Well & & Male & 14 & 30 & 8 & 31 & 18 \\
\hline & Trial & & Female & 7 & 24 & 11 & 39 & 18 \\
\hline \multirow[t]{3}{*}{$\begin{array}{l}\text { Greene, et } \\
\text { al. (1994) }\end{array}$} & $\begin{array}{l}614 \text { from mail } \\
\text { survey }(481 \text { at }\end{array}$ & $\begin{array}{l}\text { SOC for avoiding } \\
\text { fat }\end{array}$ & $\begin{array}{l}\text { SOC avoid fat } \\
\text { Fat intake }\end{array}$ & 18 & 14 & 8 & 12 & 48 \\
\hline & $>30 \%$ fat intake & & $>30 \%$ & 22 & 17 & 9 & 12 & 40 \\
\hline & $\begin{array}{l}\text { and } 133 \text { at } \\
<30 \%)\end{array}$ & & $<30 \%$ & 2 & 4 & 4 & 14 & 77 \\
\hline \multirow{5}{*}{$\begin{array}{l}\text { Hargreaves } \\
\text { and Schlundt } \\
\text { (1999) }\end{array}$} & African- & SOC fat intake & Local Sample & & & & & \\
\hline & $\begin{array}{l}\text { American } \\
\text { women; } 174\end{array}$ & $\begin{array}{l}\text { based on 3-step } \\
\text { algorithm, first step }\end{array}$ & $\begin{array}{r}\text { SOC fat } \\
\text { Actual \% of cal }\end{array}$ & 13 & 16 & 12 & 24 & 35 \\
\hline & $\begin{array}{l}\text { from churches, } \\
\text { universities, and }\end{array}$ & traditional algorithm & $\begin{array}{l}\text { from fat } \\
\text { Worksite Sample }\end{array}$ & 41 & 39 & 40 & 35 & 33 \\
\hline & senior programs & & Step 1 & 14 & 16 & 16 & 27 & 27 \\
\hline & $\begin{array}{l}\text { and } 208 \text { from } \\
\text { worksites }\end{array}$ & & After Step 2\&3 & 13 & 22 & 34 & 14 & 18 \\
\hline $\begin{array}{l}\text { Laforge, et } \\
\text { al. (1994) }\end{array}$ & $\begin{array}{l}405 \text { adult from } \\
\text { telephone survey }\end{array}$ & SOC F\&V items & Fruit/veg & 38 & 29 & 18 & 2 & 13 \\
\hline
\end{tabular}




\begin{tabular}{|c|c|c|c|c|c|c|c|c|}
\hline \multirow[b]{2}{*}{ Authors } & \multirow[b]{2}{*}{ Participants } & \multirow[b]{2}{*}{ Measures } & \multirow[b]{2}{*}{ Type } & \multicolumn{5}{|c|}{ SOC percents, Other scores } \\
\hline & & & & $\mathrm{Pc}$ & $\mathrm{C}$ & $\mathrm{Pp}$ & A & $\mathrm{M}$ \\
\hline $\begin{array}{l}\text { Patterson, et } \\
\text { al. (1997) }\end{array}$ & $\begin{array}{l}1002 \text { cancer risk } \\
\text { phone survey }\end{array}$ & $\begin{array}{l}\text { SOC for reducing } \\
\text { fat intake }\end{array}$ & Fat & 22 & 7 & 6 & 18 & 48 \\
\hline $\begin{array}{l}\text { Povey, et al. } \\
\text { (1999) }\end{array}$ & $\begin{array}{l}541 \text { newspaper } \\
\text { ad respondents } \\
(242 \text { healthy } \\
\text { diet, } 148 \text { low-fat } \\
\text { diet, } 151 \mathrm{~F} \& \mathrm{~V})\end{array}$ & $\begin{array}{l}\text { SOC for healthy } \\
\text { eating, low-fat diet, } \\
\text { and F\&V; algorithm } \\
\text { did not use time to } \\
\text { distinguish stages }\end{array}$ & $\begin{array}{l}\text { SOC } \\
\text { Healthy eating } \\
\text { Low-Fat } \\
\text { F\&V }\end{array}$ & $\begin{array}{r}4 \\
15 \\
24\end{array}$ & $\begin{array}{r}6 \\
18 \\
21\end{array}$ & $\begin{array}{r}4 \\
8 \\
12\end{array}$ & $\begin{array}{l}32 \\
11 \\
15\end{array}$ & $\begin{array}{l}53 \\
41 \\
24\end{array}$ \\
\hline Rossi (1993) & $\begin{array}{l}180 \text { staff, } \\
\text { faculty, and } \\
\text { graduate } \\
\text { students, and } \\
201 \text { volunteers } \\
\text { responding to } \\
\text { mailed survey }\end{array}$ & $\begin{array}{l}\text { Study } 1,2-\text { SOC } \\
\text { algorithm for fat } \\
\text { reduction; } \\
\text { pseudo-maintenance } \\
\text { with fat intake } \\
>30 \% \text { calories }\end{array}$ & $\begin{array}{r}\text { University Sample } \\
\text { Male } \\
\text { Female } \\
\text { Volunteer Sample } \\
\text { Male } \\
\text { Fat Intake }<30 \% \\
\text { Fat Intake }>30 \% \\
\text { Female } \\
\text { Fat Intake }<30 \% \\
\text { Fat Intake }>30 \%\end{array}$ & $\begin{array}{l}29 \\
21\end{array}$ & $\begin{array}{l}14 \\
19\end{array}$ & & $\begin{array}{l}4 \\
2\end{array}$ & $\begin{array}{r}68 \\
(21) \\
(47) \\
66 \\
(28) \\
(37)\end{array}$ \\
\hline
\end{tabular}

\section{Comparing SOC to psycho-social factors}

Bowen, et 720 attendees at

al. (1994) music festival

Brug,

Hospers, et

al. (1997)

Campbell,

Tessaro et al. (2000)
507 Dutch oil

company

employees

859 women workers from 9 rural factory sites
Cowan, et al. (1995)
SOC low-fat diet

low-fat SOC

SOC low-fat, F\&V

Healthy Eating

Sample

$\begin{array}{rrrrrr}\text { Low-Fat } & 20 & 42 & 10 & 10 & 17 \\ \text { F\&V } & 14 & 53 & 26 & 1 & 6\end{array}$

Combined eating/exercise sample

$$
\text { Low-Fat }
$$

$\mathrm{F} \& \mathrm{~V}$

SOC for weight loss

454 urban family
practice patients,

197 obese and

257 non-obese

Delahanty, 274 participants et al. (2002) in the Diabetes

Prevention

Program in MA

Herrick, et 393 Municipal al. (1997)
SOC weight loss

SOC Weight-Loss

$\begin{array}{rrrrr}22 & 13 & 5 & 19 & 41 \\ 14 & 8 & 26 & 12 & 40\end{array}$

$\begin{array}{rrrrrrr}\text { Obese } & 12 & 11 & 23 & 47 & 8 \\ \text { Non-Obese } & \text { NR } & & & & \end{array}$

SOC Low-Fat employees, mail survey; wellness participants and non-participants
SOC for four health behaviors - dietary fat, smoking, sun exposure, exercise

\begin{tabular}{rrrrrr} 
Total Sample & 19 & 14 & 10 & 10 & 47 \\
Wellness Sample & 11 & 13 & 10 & 10 & 56 \\
Non-well-ness & 26 & 15 & 11 & 10 & 38 \\
Sample & & & & & \\
\hline
\end{tabular}




\begin{tabular}{|c|c|c|c|c|c|c|c|c|}
\hline \multirow[b]{2}{*}{ Authors } & \multirow[b]{2}{*}{ Participants } & \multirow[b]{2}{*}{ Measures } & \multirow[b]{2}{*}{ Type } & \multicolumn{5}{|c|}{ SOC percents, Other scores } \\
\hline & & & & $\mathrm{Pc}$ & $\mathrm{C}$ & $\mathrm{Pp}$ & A & $\mathrm{M}$ \\
\hline $\begin{array}{l}\text { Lamb and } \\
\text { Joshi (1996) }\end{array}$ & $\begin{array}{l}133 \text { young } \\
\text { English adults }\end{array}$ & SOC avoid fat & Avoid fat & 21 & 32 & 23 & 14 & 11 \\
\hline $\begin{array}{l}\text { McDonell, } \\
\text { et al. (1998) }\end{array}$ & $\begin{array}{l}1081 \text { Australian } \\
\text { university } \\
\text { employees, mail } \\
\text { survey }\end{array}$ & $\begin{array}{l}\text { SOC algorithm for } \\
\text { reducing fat }\end{array}$ & $\begin{array}{l}\text { Male } \\
\text { Female }\end{array}$ & $\begin{array}{l}43 \\
26\end{array}$ & $\begin{array}{l}5 \\
7\end{array}$ & $\begin{array}{r}8 \\
16\end{array}$ & $\begin{array}{l}20 \\
24\end{array}$ & $\begin{array}{l}25 \\
28\end{array}$ \\
\hline $\begin{array}{l}\text { O'Connell, } \\
\text { and Velicer } \\
\text { (1988) }\end{array}$ & $\begin{array}{l}123 \text { College } \\
\text { students }\end{array}$ & $\begin{array}{l}\text { SOC for self- } \\
\text { reported weight loss }\end{array}$ & Weight loss & 15 & 53 & & 18 & 15 \\
\hline $\begin{array}{l}\text { Ounpuu, et } \\
\text { al. }(2000)\end{array}$ & $\begin{array}{l}495 \text { women, } \\
\text { phone recruiting }\end{array}$ & $\begin{array}{l}\mathrm{SOC}<30 \% \text { of } \\
\text { calories from fat }\end{array}$ & $\begin{array}{r}\text { SOC fat } \\
\text { Actual Fat Intake } \\
<30 \% \text { Sample }\end{array}$ & 19 & 12 & 10 & 12 & 47 \\
\hline $\begin{array}{l}\text { Sporny and } \\
\text { Contento } \\
(1995)\end{array}$ & $\begin{array}{l}615 \text { government } \\
\text { employees, } \\
\text { suburban } \\
\text { northeast town }\end{array}$ & SOC for dietary fat & $\begin{array}{l}\text { Male } \\
\text { Female }\end{array}$ & $\begin{array}{r}14 \\
4\end{array}$ & $\begin{array}{r}14 \\
7\end{array}$ & & $\begin{array}{l}31 \\
42\end{array}$ & $\begin{array}{l}41 \\
47\end{array}$ \\
\hline
\end{tabular}

\section{Generalization of Model to other populations}

\begin{tabular}{|c|c|c|c|c|c|c|c|c|c|}
\hline $\begin{array}{l}\text { Campbell, et } \\
\text { al. (1998) }\end{array}$ & $\begin{array}{l}3,557 \text { adults } \\
\text { from African- } \\
\text { American rural } \\
\text { churches }\end{array}$ & SOC for \& V & & $\begin{array}{l}\text { Male } \\
\text { Female }\end{array}$ & $\begin{array}{l}30 \\
24\end{array}$ & $\begin{array}{l}4 \\
3\end{array}$ & $\begin{array}{l}66 \\
65\end{array}$ & $\begin{array}{l}6 \\
9\end{array}$ & $\begin{array}{l}\mathrm{A} / \mathrm{M} \\
\mathrm{A} / \mathrm{M}\end{array}$ \\
\hline $\begin{array}{l}\text { Campbell, et } \\
\text { al. (1999) }\end{array}$ & $\begin{array}{l}\text { Report from } 8 \\
\text { state consortium: } \\
\text { Alabama - } 1,292 \\
\text { parents of } 4^{\text {th }} \\
\text { grade students; } \\
\text { Arizona - } 2,069 \\
\text { public } \\
\text { employees; } \\
\text { Louisiana - } \\
2,2139^{\text {th }} \text { grade } \\
\text { students; } \\
\text { Massachusetts - } \\
1,359 \text { employees } \\
\text { of } 22 \text { community } \\
\text { health centers; } \\
\text { Maryland - } \\
3,119 \text { WIC } \\
\text { participants; } \\
\text { Minnesota - 384 } \\
\text { parents of grade } \\
\text { school students; } \\
\text { North Carolina - } \\
3,737 \text { members, } \\
50 \text { rural African- } \\
\text { American } \\
\text { churches; }\end{array}$ & $\begin{array}{l}\text { SOC for F\&V } \\
\text { intake }\end{array}$ & SOC F\&V & $\begin{array}{r}\text { AL } \\
\text { AZ } \\
\text { LA } \\
\text { MA } \\
\text { MD } \\
\text { MN } \\
\text { NC } \\
\text { WA } \\
\text { AL } \\
\text { AZ } \\
\text { LA } \\
\text { MA } \\
\text { MD } \\
\text { MN } \\
\text { NC } \\
\text { WA }\end{array}$ & $\begin{array}{r}84 \\
17 \\
41 \\
80 \\
100 \\
84 \\
70 \\
44\end{array}$ & $\begin{array}{r}91 \\
27 \\
66 \\
84 \\
100 \\
88 \\
70 \\
66\end{array}$ & $\begin{array}{r}59 \\
40 \\
51 \\
54 \\
65 \\
36 \\
62 \\
46 \\
\\
\mathrm{C} / \mathrm{Pp} \\
\mathrm{C} / \mathrm{Pp} \\
\mathrm{C} / \mathrm{Pp} \\
\mathrm{C} / \mathrm{Pp} \\
\mathrm{C} / \mathrm{Pp} \\
\mathrm{C} / \mathrm{Pp} \\
\mathrm{C} / \mathrm{Pp} \\
\mathrm{C} / \mathrm{Pp}\end{array}$ & $\begin{array}{r}88 \\
33 \\
51 \\
87 \\
100 \\
91 \\
79 \\
64\end{array}$ & $\begin{array}{r}12 \\
24 \\
9 \\
17 \\
15 \\
18 \\
6 \\
13 \\
\mathrm{~A} / \mathrm{M} \\
\mathrm{A} / \mathrm{M} \\
\mathrm{A} / \mathrm{M} \\
\mathrm{A} / \mathrm{M} \\
\mathrm{A} / \mathrm{M} \\
\mathrm{A} / \mathrm{M} \\
\mathrm{A} / \mathrm{M} \\
\mathrm{A} / \mathrm{M}\end{array}$ \\
\hline
\end{tabular}




\begin{tabular}{|c|c|c|c|c|c|c|c|c|}
\hline \multirow[b]{2}{*}{ Authors } & \multirow[b]{2}{*}{ Participants } & \multirow[b]{2}{*}{ Measures } & \multirow[b]{2}{*}{ Type } & \multicolumn{5}{|c|}{ SOC percents, Other scores } \\
\hline & & & & $\mathrm{Pc}$ & $\mathrm{C}$ & $\mathrm{Pp}$ & A & $\mathrm{M}$ \\
\hline & $\begin{array}{l}\text { Washington - } \\
3,097 \text { employees } \\
\text { from } 28 \text { sites }\end{array}$ & & & & & & & \\
\hline \multirow{2}{*}{$\begin{array}{l}\text { Cullen, et al. } \\
\text { (1998) }\end{array}$} & 259 Girl Scouts & SOC for $F \& V$ & Fruit & 14 & 28 & 14 & 45 & \\
\hline & $\begin{array}{l}\text { ages } 9-12 \\
\text { surveyed during } \\
\text { meetings }\end{array}$ & intake & Vegie & 25 & 24 & 7 & 44 & \\
\hline \multirow[t]{3}{*}{$\begin{array}{l}\text { DeGraaf, et } \\
\text { al. (1997) }\end{array}$} & $\begin{array}{l}14,331(15 \text { yrs or } \\
\text { older) from } 15\end{array}$ & $\begin{array}{l}\text { SOC healthy eating, } \\
\text { algorithm included }\end{array}$ & EU total & 52 & 2 & 1 & 7 & 31 \\
\hline & EU countries, & questions for relapse & Male & 59 & & & & 26 \\
\hline & $\begin{array}{l}\text { market research } \\
\text { interviews }\end{array}$ & ( $7 \%$ of total sample) & Female & 46 & & & & 36 \\
\hline $\begin{array}{l}\text { Domel, et al. } \\
\text { (1996) }\end{array}$ & $\begin{array}{l}386 \text { children } \\
\text { from } 4 \text { th and } 5 \text { th } \\
\text { grade; } 134 \text { pilot } \\
\text { testing, and } 252 \\
\text { field application }\end{array}$ & $\begin{array}{l}32 \text { item F\&V } \\
\text { questionnaire with } 8 \\
\text { items per stage and } \\
\text { two trials separated } \\
\text { by } 7 \text { weeks }\end{array}$ & NR & & & & & \\
\hline \multirow{2}{*}{$\begin{array}{l}\text { Glanz, et al. } \\
\text { (1998) }\end{array}$} & 2,764 male & SOC fat and fiber & SOC Low-Fat & 10 & 17 & 2 & 42 & 29 \\
\hline & $\begin{array}{l}\text { employees from } \\
28 \text { worksites }\end{array}$ & & SOC High-Fiber & 7 & 24 & 4 & 28 & 37 \\
\hline \multirow{2}{*}{$\begin{array}{l}\text { Gracey, et } \\
\text { al. }(1996)\end{array}$} & 480 Australian & SOC for healthy diet & Male & 70 & & & 16 & \\
\hline & $\begin{array}{l}\text { students, age 15- } \\
16\end{array}$ & & Female & 30 & & & 30 & \\
\hline \multirow[t]{14}{*}{$\begin{array}{l}\text { Nigg, et al, } \\
\text { (1999) }\end{array}$} & $\begin{array}{l}\text { 19,266 adults } \\
\text { screened from a }\end{array}$ & $\begin{array}{l}\text { SOC for ten health } \\
\text { behaviors, fat, fiber, }\end{array}$ & $\begin{array}{r}\text { SOC Low-Fat } \\
<55 \mathrm{yrs}\end{array}$ & 26 & 8 & 10 & 10 & 46 \\
\hline & managed care & losing weight, using & $55-64$ yrs & 14 & 5 & 8 & 9 & 64 \\
\hline & system; & seatbelts, exercising, & $65-74$ yrs & 12 & 4 & 6 & 8 & 71 \\
\hline & age groups: & avoiding sun, using & $75+y r s$ & 13 & 2 & 7 & 4 & 75 \\
\hline & $<55 \mathrm{~N}=14,972$ & sunscreen, reducing & SOC High-Fiber & & & & & \\
\hline & $55-64 \mathrm{~N}=1.924$ & stress, smoking, & $<55 \mathrm{yrs}$ & 29 & 7 & 7 & 9 & 47 \\
\hline & $65-74 \mathrm{~N}=1,194$ & self-exam & $55-64$ yrs & 15 & 6 & 7 & 8 & 64 \\
\hline & $75+N=421$ & & $65-74$ yrs & 13 & 3 & 6 & 7 & 70 \\
\hline & & & $75+\mathrm{yrs}$ & 16 & 3 & 6 & 5 & 70 \\
\hline & & & SOC Weight-Loss & & & & & \\
\hline & & & $<55$ yrs & 39 & 7 & 7 & 18 & 29 \\
\hline & & & $55-64$ yrs & 31 & 6 & 7 & 13 & 43 \\
\hline & & & $65-74$ yrs & 39 & 4 & 6 & 11 & 40 \\
\hline & & & $75+y r s$ & 61 & 6 & 5 & 7 & 21 \\
\hline \multirow{2}{*}{$\begin{array}{l}\text { Steptoe, et } \\
\text { al. (1996) }\end{array}$} & 366 from mail & SOC for dietary fat & Male & 43 & 12 & 6 & 5 & 33 \\
\hline & $\begin{array}{l}\text { survey in } \\
\text { London }\end{array}$ & & Female & 29 & 13 & 2 & 6 & 50 \\
\hline \multirow[t]{6}{*}{ Watt (1997) } & 479 English & SOC for reducing & SOC Low-Fat & & & & & \\
\hline & students $13-14$ & fat and for reducing & Male & 44 & 6 & 7 & 29 & 14 \\
\hline & yrs old & sugar intake & Female & 19 & 15 & 6 & 46 & 15 \\
\hline & & & SOC Low-Sugar & & & & & \\
\hline & & & Male & 47 & 6 & 4 & 29 & 16 \\
\hline & & & Female & 26 & 13 & 10 & 38 & 14 \\
\hline
\end{tabular}




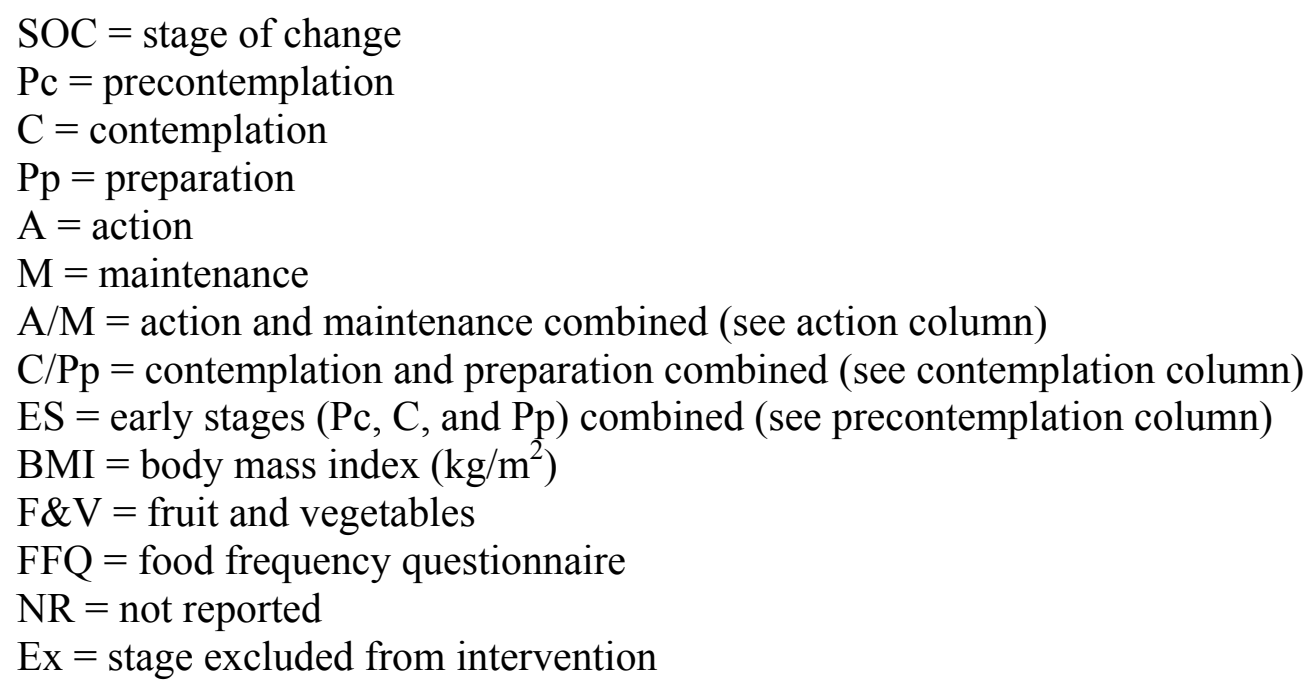




\section{SOC Review Table A2}

Summary of Studies on the Stages of Change Model Applied to Dietary Behavior Intervention Studies

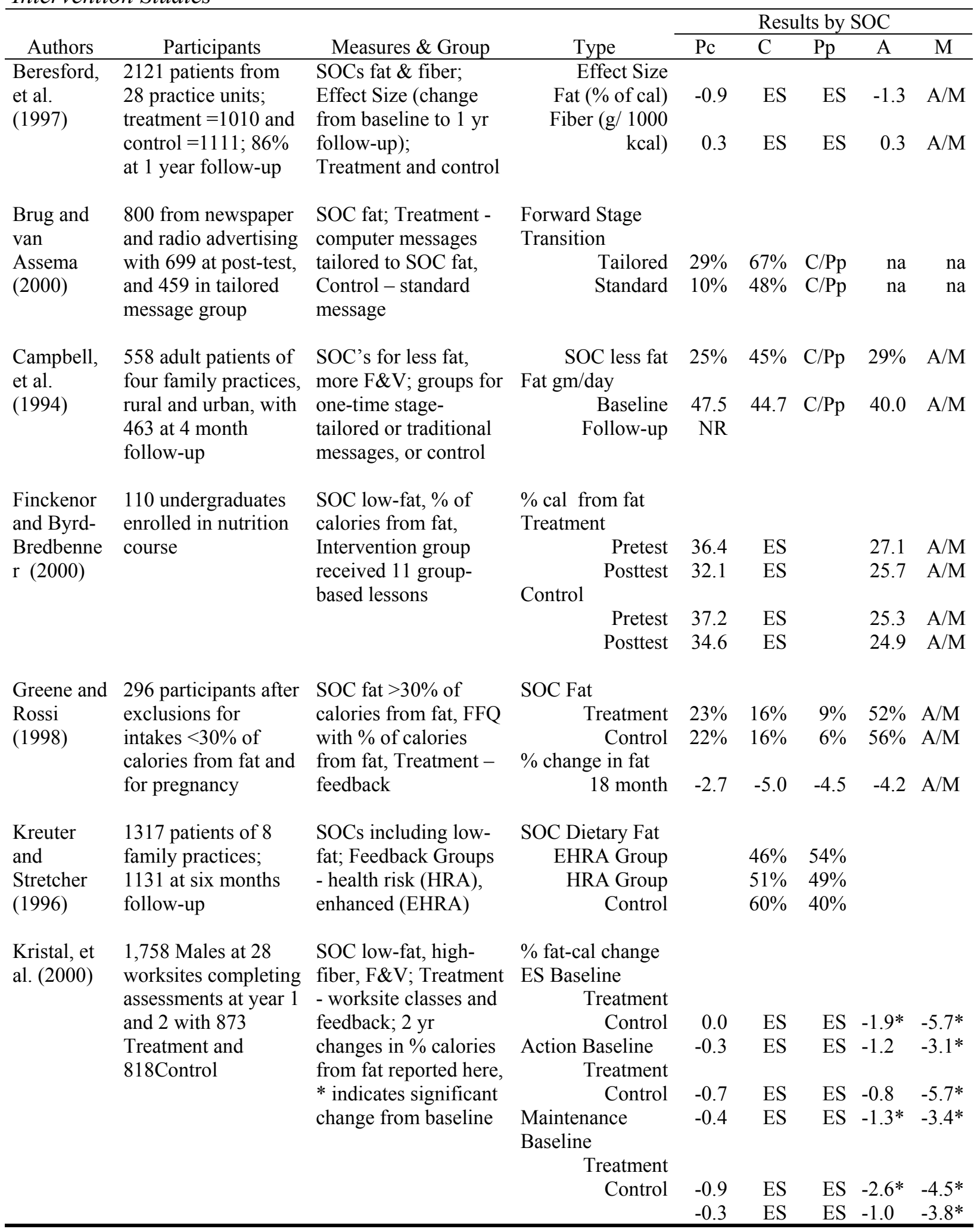




\begin{tabular}{|c|c|c|c|c|c|c|c|c|}
\hline \multirow[b]{2}{*}{ Authors } & \multirow[b]{2}{*}{ Participants } & \multirow[b]{2}{*}{ Measures \& Group } & \multirow[b]{2}{*}{ Type } & \multicolumn{5}{|c|}{ Results by SOC } \\
\hline & & & & Pc & $\mathrm{C}$ & $\mathrm{Pp}$ & A & $\mathrm{M}$ \\
\hline \multirow{2}{*}{$\begin{array}{l}\text { McCann, } \\
\text { et al. } \\
\text { (1996) }\end{array}$} & $\begin{array}{l}722 \text { industrial } \\
\text { workers with high }\end{array}$ & $\begin{array}{l}\text { SOC for lowering } \\
\text { cholesterol; Joiners }\end{array}$ & $\begin{array}{r}\% \text { Total Sample } \\
\text { Joiners }\end{array}$ & $66 \%$ & $74 \%$ & $78 \%$ & $61 \%$ & $67 \%$ \\
\hline & $\begin{array}{l}\text { cholesterol ( } 545 \\
\text { joiners, } 227 \text { non) }\end{array}$ & received 8 classes & Non-joiner & $34 \%$ & $26 \%$ & $22 \%$ & $39 \%$ & $33 \%$ \\
\hline \multirow{5}{*}{$\begin{array}{l}\text { Prochaska, } \\
\text { et al. } \\
\text { (1992) }\end{array}$} & 154 Pre-treatment & SOC 32 items for & Weight loss (lbs) & & & & & \\
\hline & and 72 Mid- & weight control; weight & Hospital 1 Group & 6.0 & 7.6 & & 10.7 & 7.4 \\
\hline & $\begin{array}{l}\text { treatment; staff with } \\
>10 \% \text { overweight, }\end{array}$ & loss & $\begin{array}{l}\text { Hospital } 2 \text { Group } \\
\text { Mean SOC score }\end{array}$ & 9.7 & 5.4 & & 8.9 & 9.2 \\
\hline & from two hospital & & Week 1 & 12.0 & 34.2 & & 32.2 & 30.4 \\
\hline & $\begin{array}{l}\text { workplace weight } \\
\text { loss programs }\end{array}$ & & Week 10 & 10.9 & 32.0 & & 33.8 & 29.9 \\
\hline \multirow{4}{*}{$\begin{array}{l}\text { Siero, et al. } \\
(2000)\end{array}$} & 262 participants with & SOC F\&V, fish; & Baseline & & & & & \\
\hline & $\begin{array}{l}\text { high CVD risk, } \\
\text { recruited by mas }\end{array}$ & Treatment $1-3 \mathrm{~g}$ & $\begin{array}{r}\text { SOC Fruit } \\
\text { SOC Vegies }\end{array}$ & $\begin{array}{l}18 \% \\
58 \%\end{array}$ & $2 \%$ & $\begin{array}{r}16 \% \\
9 \%\end{array}$ & $\begin{array}{l}4 \% \\
2 \%\end{array}$ & $\begin{array}{l}59 \% \\
30 \%\end{array}$ \\
\hline & mailing and radio in & - groups plus stage & SOC Fish & $76 \%$ & $2 \%$ & $10 \%$ & $4 \%$ & $9 \%$ \\
\hline & $\begin{array}{l}\text { CVD rates, and from } \\
\text { physicians or } \\
\text { pharmacies }\end{array}$ & $\begin{array}{l}\text { information, Control - } \\
\text { printed leaflet }\end{array}$ & & & & & & \\
\hline \multirow{5}{*}{$\begin{array}{l}\text { Steptoe, et } \\
\text { al. (2001) }\end{array}$} & $\begin{array}{l}883 \text { patients with } \\
\text { risk factors (e } \mathrm{g} \text { hioh }\end{array}$ & SOC for reducing fat, & $\begin{array}{l}\text { Treatment } \\
\text { Baseline }\end{array}$ & & & $29 \%$ & & \\
\hline & cholesterol) from 20 & exercise; Treatment - & 12 month & $14 \%$ & $6 \%$ & $12 \%$ & $68 \%$ & $\mathrm{~A} / \mathrm{M}$ \\
\hline & & 2 or 3 cour & Control & & & & & \\
\hline & Treatment $\mathrm{N}=316$ & sessions, Control - & & 25 & $14 \%$ & $19 \%$ & $42 \%$ & $\mathrm{~A} / \mathrm{M}$ \\
\hline & Control $\mathrm{N}=567$ & standard advice & 12 month & $16 \%$ & $8 \%$ & $17 \%$ & $59 \%$ & $\mathrm{~A} / \mathrm{M}$ \\
\hline
\end{tabular}

See abbreviations after Review Table A above

Note: References for Review Tables A \& B are marked with * in the Reference list above 
Appendix B: Recruiting Announcement and Background Information

Persons interested in receiving feedback on the amount of fat and fiber in their diets are being sought for a research project on dietary habits. If you are 18 years of age or older and would like to be considered for the project, please complete the form below and send it to the address provided.

All respondents to this notice will receive a packet with questionnaires that will take approximately 40 minutes to complete. The first 125 men and 125 women returning these packets will receive dietary feedback, and automatically be entered in a random drawing for a $\$ 250.00$ cash award.

Send this completed form to: Janis Boury, M.A.

WVU Psychology Department

P.O. Box 6040

Morgantown, WV 26506

e-mail: jboury@wvu.edu

Please provide the following information.

Name:

Address:

Phone \& e-mail:

(necessary for feedback, identifying information will be kept confidential)

Birthdate: Gender: M F

Education: less than high school high school graduate some college college graduate

Previous dietary training (please check all that apply):

Health classes in school Wellness program at work Individualized consultation by dietician or nutritionist National diet program e.g. Jenny Craig or Weightwatchers Other (please specify): 
Appendix C: Health Behaviors Questionnaire 


\section{Health Behaviors Questionnaire}

Please choose the items that best describe you.

\section{Dietary Fat Intake}

1. Have you ever changed your eating habits to decrease the amount of fat in your diet?

$$
\begin{array}{ll}
\text { Yes } & 1 \\
\text { No } & 2 \text { (Skip to \#2) }
\end{array}
$$

1A. IF YES, Are you currently limiting the amount of fat in your diet?

$$
\text { Yes } 1
$$

$$
\text { No } 2 \text { (Skip to \#2) }
$$

1B1. IF YES, How long have you been limiting the amount of fat in your diet?

Less than 30 days 1

1-6 months 2

7-12 months $\quad 3$

Over 1 year 4

2. In the past month, have you thought about changes you could make to decrease the amount of fat in your diet?

$$
\begin{array}{ll}
\text { Yes } & 1 \\
\text { No } & 2
\end{array}
$$

2A. How confident are you that you will make some of these changes during the next month?

$\begin{array}{ll}\text { Very confident } & 1 \\ \text { Somewhat confident } & 2 \\ \text { Mildly confident } & 3 \\ \text { Not at all confident } & 4\end{array}$

\section{Dietary Fiber Intake}

1. Have you ever changed your eating habits to increase the amount of fiber in your diet?

$$
\begin{array}{ll}
\text { Yes } & 1 \\
\text { No } & 2 \text { (Skip to \#2) }
\end{array}
$$

1A. IF YES, Are you currently eating an increased amount of fiber in your diet?

$$
\begin{array}{ll} 
& \text { Yes } 1 \\
\text { No } & 2 \text { (Skip to \#2) }
\end{array}
$$

1B1. IF YES, How long have you been increasing the amount of fiber in your diet? Less than 30 days 1 


$\begin{array}{ll}\text { 1-6 months } & 2 \\ 7-12 \text { months } & 3 \\ \text { Over 1 year } & 4\end{array}$

2. In the past month, have you thought about changes you could make to increase the amount of fiber in your diet?

$$
\begin{array}{ll}
\text { Yes } & 1 \\
\text { No } & 2
\end{array}
$$

2A. How confident are you that you will make some of these changes during the next month?

$\begin{array}{ll}\text { Very confident } & 1 \\ \text { Somewhat confident } & 2 \\ \text { Mildly confident } & 3 \\ \text { Not at all confident } & 4\end{array}$

\section{Cigarette Smoking}

How would you describe your cigarette smoking?

A. Never smoked

B. Used to smoke (Please indicate the following:) Years since stopped smoking

C. Still smoke (Please indicate the following:) Cigarettes per day

\section{Physical Activity}

How would you describe your current level of physical activity or exercise.

1. Daily living activities only e.g. cooking, shopping, driving the car.

2. Low energy activities (or aerobic exercise less than three times per week.)

- Low intensity activities e.g. golfing using a cart, bowling, stretching, gardening, slow walking, leisurely swimming

3. One or more aerobic activities using large muscle groups.

- at least 3 sessions per week

- exercise maintains heart rate in target zone (e.g. pulse 140 for 40 - 50 year olds in reasonably good health) continuously for at least thirty minutes

- examples include: running, fast walking, hiking, biking, soccer, dance-aerobics, cross-country skiing, swimming laps, and stairstepping 


\section{Staging Algorithm}

Stage Question(s) Answer(s)

Precontemplation

$\begin{array}{ll}1 \text { or } 1 \mathrm{~A} & \text { No } \\ 2 & \text { No }\end{array}$

Contemplation

$\begin{array}{ll}1 \text { or } 1 \mathrm{~A} & \text { No } \\ 2 & \text { Yes } \\ 2 \mathrm{~A} & \text { Mildly or not at all confident }\end{array}$

Decision/Preparation

1 or $1 \mathrm{~A}$

2

$2 \mathrm{~A}$

Action

1 and $1 \mathrm{~A}$

$1 \mathrm{~B}$

Maintenance
1 and $1 \mathrm{~A}$

$1 \mathrm{~B}$
No

Yes

Somewhat or very confident

Yes

12 months or less

Yes

more than one year 


\section{Appendix D: FFQ Contact Information}

Nutrition Assessment Shared Resource (NASR)

1100 Fairview Ave. N. MP-647

Seattle, WA 98109-1024

Phone: $800-460-7270$

206-667-4161

Fax: 206-667-7864

Email: ffq@fhcrc.org

Website: ffq.fhcrc.org 


\section{Appendix E: Decisional Balance Measure for Men}

\section{Decisional Balance 2}

Rate each item using the following scale: $1=$ strongly agree, $2=$ slightly agree, $3=$ neither agree or disagree, $4=$ slightly disagree, $5=$ strongly disagree

\begin{tabular}{|c|c|c|c|c|c|}
\hline $\begin{array}{l}\text { 1. Eating a low-fat, high-fiber diet reduces my chances of } \\
\text { getting prostate cancer. }\end{array}$ & 1 & 2 & 3 & 4 & 5 \\
\hline $\begin{array}{l}\text { 2. Eating a low-fat, high-fiber diet helps keep } \\
\text { testosterone levels normal. }\end{array}$ & 1 & 2 & 3 & 4 & 5 \\
\hline $\begin{array}{l}\text { 3. Eating a low-fat, high-fiber diet reduces my chances of } \\
\text { impotence. }\end{array}$ & 1 & 2 & 3 & 4 & 5 \\
\hline $\begin{array}{l}\text { 4. Eating a low-fat, high-fiber diet can give me more } \\
\text { physical ability (e.g. able to climb steps without } \\
\text { getting winded). }\end{array}$ & 1 & 2 & 3 & 4 & 5 \\
\hline $\begin{array}{l}\text { 5. I am less likely to have problems dribbling my urine if } \\
\text { I eat a low-fat, high-fiber diet. }\end{array}$ & 1 & 2 & 3 & 4 & 5 \\
\hline $\begin{array}{l}\text { 6. Eating a low-fat, high-fiber diet means fewer trips to } \\
\text { the doctor, fewer pills, and fewer side effects from } \\
\text { pills. }\end{array}$ & 1 & 2 & 3 & 4 & 5 \\
\hline $\begin{array}{l}\text { 7. Eating a low-fat, high-fiber diet will improve my } \\
\text { thinking and problem solving. }\end{array}$ & 1 & 2 & 3 & 4 & 5 \\
\hline $\begin{array}{l}\text { 8. Eating a low-fat, high-fiber diet will lower my chances } \\
\text { of having a heart attack in the next few years. }\end{array}$ & 1 & 2 & 3 & 4 & 5 \\
\hline 9. Worrying about healthy food is for old people. & 1 & 2 & 3 & 4 & 5 \\
\hline 10. I am too busy to eat healthy foods regularly. & 1 & 2 & 3 & 4 & 5 \\
\hline $\begin{array}{l}\text { 11. High-fat foods like hot dogs, burgers, and fried } \\
\text { chicken are some of the good things in life. }\end{array}$ & 1 & 2 & 3 & 4 & 5 \\
\hline 12. Real men eat whatever they want. & 1 & 2 & 3 & 4 & 5 \\
\hline $\begin{array}{l}\text { 13. A fatal heart attack a few years early is better than } \\
\text { ending up in some nursing home. }\end{array}$ & 1 & 2 & 3 & 4 & 5 \\
\hline 14. Healthy foods cost more. & 1 & 2 & 3 & 4 & 5 \\
\hline $\begin{array}{l}\text { 15. I work hard and deserve to treat myself with good } \\
\text { hearty food. }\end{array}$ & 1 & 2 & 3 & 4 & 5 \\
\hline 16. I don't like other people telling me what I can eat. & 1 & 2 & 3 & 4 & 5 \\
\hline
\end{tabular}




\section{Appendix F: Decisional Balance Measure for Women}

\section{Decisional Balance 2}

Rate each item using the following scale: $1=$ strongly agree, $2=$ slightly agree, $3=$ neither agree or disagree, 4 = slightly disagree, $5=$ strongly disagree

\begin{tabular}{|c|c|c|c|c|c|}
\hline $\begin{array}{l}\text { 1. Eating a low-fat, high-fiber diet reduces my chances of } \\
\text { getting breast cancer. }\end{array}$ & 1 & 2 & 3 & 4 & 5 \\
\hline $\begin{array}{l}\text { 2. Eating a low-fat, high-fiber diet will keep me from } \\
\text { feeling fatigued. }\end{array}$ & 1 & 2 & 3 & 4 & 5 \\
\hline $\begin{array}{l}\text { 3. Eating a low-fat, high-fiber diet means I am more } \\
\text { likely to keep my interest in sex. }\end{array}$ & 1 & 2 & 3 & 4 & 5 \\
\hline $\begin{array}{l}\text { 4. Eating a low-fat, high-fiber diet I will have more } \\
\text { physical ability (e.g. able to climb steps without } \\
\text { getting winded). }\end{array}$ & 1 & 2 & 3 & 4 & 5 \\
\hline $\begin{array}{l}\text { 5. I am less likely to have problems leaking my urine if I } \\
\text { eat a low-fat, high-fiber diet. }\end{array}$ & 1 & 2 & 3 & 4 & 5 \\
\hline $\begin{array}{l}\text { 6. Eating a low-fat, high-fiber diet means fewer trips to } \\
\text { the doctor, fewer pills, and fewer side effects from } \\
\text { pills. }\end{array}$ & 1 & 2 & 3 & 4 & 5 \\
\hline $\begin{array}{l}\text { 7. Eating a low-fat, high-fiber diet will improve my } \\
\text { thinking and problem solving. }\end{array}$ & 1 & 2 & 3 & 4 & 5 \\
\hline $\begin{array}{l}\text { 8. Eating a low-fat, high-fiber diet will lower my chances } \\
\text { of having a heart attack in the next few years. }\end{array}$ & 1 & 2 & 3 & 4 & 5 \\
\hline 9. Worrying about healthy food is for old people. & 1 & 2 & 3 & 4 & 5 \\
\hline 10. I am too busy to eat healthy foods regularly. & 1 & 2 & 3 & 4 & 5 \\
\hline $\begin{array}{l}\text { 11. High-fat foods like hot dogs, burgers, and fried } \\
\text { chicken are some of the good things in life. }\end{array}$ & 1 & 2 & 3 & 4 & 5 \\
\hline 12. Real women eat whatever they want. & 1 & 2 & 3 & 4 & 5 \\
\hline $\begin{array}{l}\text { 13. A fatal heart attack a few years early is better than } \\
\text { ending up in some nursing home. }\end{array}$ & 1 & 2 & 3 & 4 & 5 \\
\hline 14. Healthy foods cost more. & 1 & 2 & 3 & 4 & 5 \\
\hline $\begin{array}{l}\text { 15. I work hard and deserve to treat myself with good } \\
\text { hearty food. }\end{array}$ & 1 & 2 & 3 & 4 & 5 \\
\hline 16. I don't like other people telling me what I can eat. & 1 & 2 & 3 & 4 & 5 \\
\hline
\end{tabular}


Appendix G: Samples of Advertisements, Notices, Posters

Sample ad

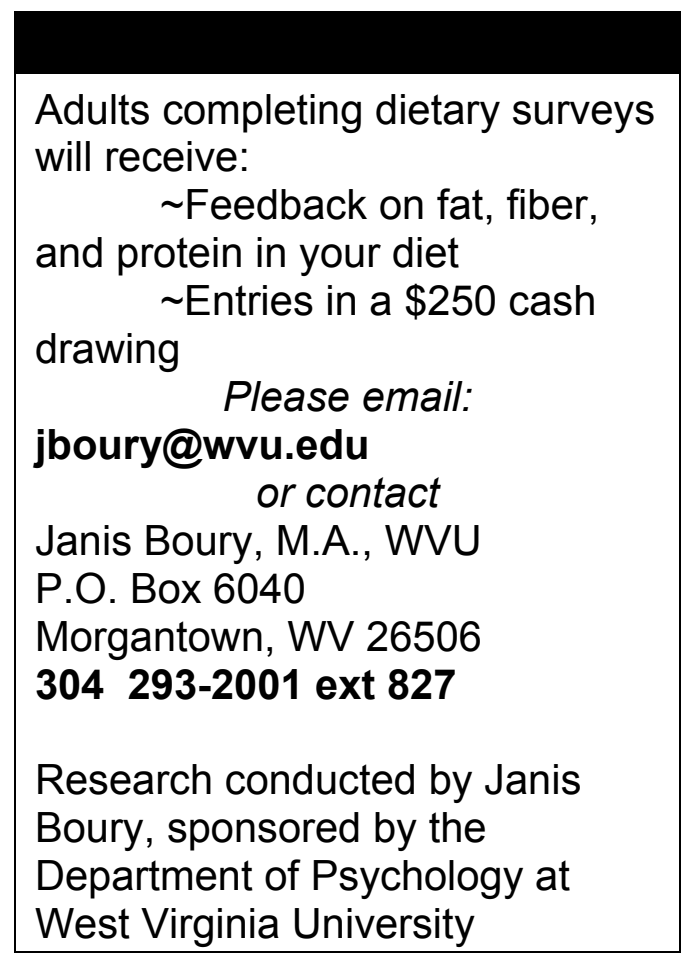

Sample Press Release to Newspapers

\section{PRESS RELEASE}

\section{University Research on Dietary Habits}

Persons interested in receiving feedback on the amount of fat and fiber in their diets are being sought for a research project about dietary habits. Research conducted by Janis Boury, M.A., sponsored by the Dept. of Psychology at West Virginia University.

The first 125 men and 125 women returning the survey packets will receive feedback on the fat, carbohydrates, protein, and fiber in their diets. Please contact: Janis Boury, M.A., phone 304-293-2001 x827, write WVU Psychology Department, P.O. Box 6040, Morgantown, WV 26506, or e-mail: jboury@wvu.edu. 
Poster for Bulletin Boards
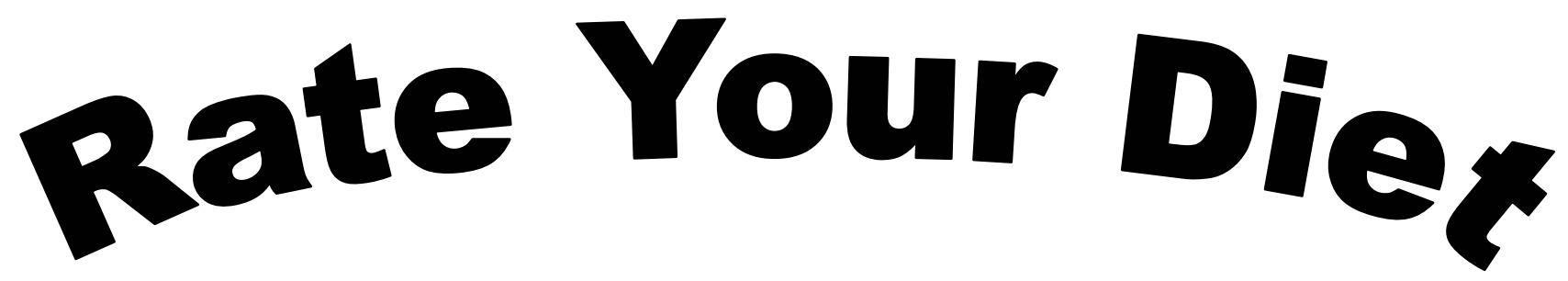

Complete dietary habits and diet opinion surveys and receive:

\section{- The fat level in your diet \\ - Your protein, fiber, \& carbohydrate intake}

\section{Plus}

\section{- Chances for $\$ 250$ cash drawing}

A research project by Janis Boury, M.A. and Kevin Larkin, Ph.D. of the Department of Psychology at West Virginia University. Contact Janis Boury at 304-293-2001, or jboury@wvu.edu , or on the web at http://wvnvm.wvnet.edu/ JBOURY/ratediet.htm 


\section{Appendix H: Participant Consent Form}

Dietary Feedback and Changing Fat and Fiber Intake

\section{Consent Form}

Introduction. I, , have been asked to participate in this research study, based on a written explanation provided to me by Janis Boury, M.A. Janis Boury is conducting this research to fulfill the requirements for a dissertation in Psychology at West Virginia University.

Purpose of the Study. The purpose of this study is to examine the effects of dietary feedback on adopting healthy diets.

Description of Procedures. I understand I will be asked to respond to three packets that will be mailed to me. In the first one I will complete three questionnaires and a diet survey on my current dietary and health habits. In the second packet, I will complete two of the questionnaires again. In the third packet, I will complete one of the questionnaires and the diet survey again. I will also receive information that may be useful for eating a healthy diet and will accept phone calls to clarify dietary feedback received previously. Approximately 250 people will participate in this study.

By signing this form, I understand I may be placed in a delayed feedback group. This means I will not receive any feedback regarding the fat and fiber content of my diet for approximately four months. This does not affect my entries into the drawing.

Risks and Discomforts. There are no known or expected risks from participating in this study.

Alternatives. I understand I have the option of not participating in this study.

Benefits. I understand I may learn something about my current dietary habits. Also, the knowledge gained from the research may be of benefit to others. I understand I will also receive entries into a drawing for a cash award of $\$ 250.00$ for each phase of the research. 
Dietary Feedback and Changing Fat and Fiber Intake (continued)

Contact Persons . For more information about this research, I can contact Janis Boury (ext. 827) or Kevin Larkin, Ph.D. (ext. 668) at the Department of Psychology at West Virginia University (293-2001). For information regarding my rights as a research subject, I may contact the Executive Secretary of the Institutional Review Board at 293-7073.

Confidentiality. I understand any information about me obtained as a result of my participation in this research will be kept as confidential as legally possible. I understand also that my research records, just like hospital records, may be subpoenaed by court order or may be inspected by federal regulatory authorities. In any publications that result from this research, neither my name nor any information from which I might be identified will be published without my consent.

Voluntary Participation. Participation in this study is voluntary. I understand I am free to withdraw my consent at any time. Refusal to participate or withdrawal will involve no penalty. I understand I do not have to answer all questions I am asked if I do not prefer. I have been given the opportunity to ask questions about the research, and I have received satisfactory answers concerning areas I did not understand.

Upon signing this form, I will receive a copy.

I willingly consent to participate in this study.

Signature of Participant

Signature of Investigator
Date

Date
Time

Time

Page 2 of 2

Version 3/27/01 
Appendix I: Sample Dietary Feedback Report

\section{Food Frequency Questionnaire: Feedback Report 1}

\begin{tabular}{|c|c|c|}
\hline \multicolumn{3}{|l|}{ Participant Name ID\# 789} \\
\hline Category & Your Daily Intake & USDA Dietary Guidelines \\
\hline \multicolumn{3}{|l|}{ Basic Nutrients } \\
\hline Total Calories* & 2458 & \\
\hline Fat (saturated and unsaturated) & $116.2 \mathrm{gm}$ & \\
\hline Saturated Fat & $47.3 \mathrm{gm}$ & \\
\hline Protein & $83.9 \mathrm{gm}$ & \\
\hline Carbohydrates & $259.6 \mathrm{gm}$ & \\
\hline \multicolumn{3}{|l|}{ More on Fat } \\
\hline $\begin{array}{l}\text { \% of total calories from fat } \\
\text { (saturated and unsaturated) }\end{array}$ & $42.5 \%$ & less than $30 \%$ of calories \\
\hline $\begin{array}{r}\% \text { of total calories from } \\
\text { saturated fat }\end{array}$ & $17.3 \%$ & less than $10 \%$ of calories \\
\hline Cholesterol & $226.4 \mathrm{mg}$ & less than $300 \mathrm{mg}$ \\
\hline \multicolumn{3}{|l|}{ Other } \\
\hline Water & $34.5 \mathrm{oz}$ & $\begin{array}{l}\text { at least } 64 \mathrm{oz} \text { ( } 8 \text { glasses) daily. Does } \\
\text { NOT include soda, flavored drinks, or } \\
\text { caffeine beverages such as coffee or tea. }\end{array}$ \\
\hline Fiber & $21.2 \mathrm{gm}$ & $\begin{array}{l}\text { Includes fiber from several servings of } \\
\text { whole grains and starchy vegetables } \\
\text { such as } 100 \% \text { whole wheat bread, brown } \\
\text { rice, oatmeal, potatoes, peas, and corn. }\end{array}$ \\
\hline Fruits & .5 servings & $\begin{array}{l}\text { at least } 2 \text { servings ( } 1 \text { medium piece or } \\
1 / 2 \text { cup) daily preferably fresh, frozen, } \\
\text { or canned without syrup }\end{array}$ \\
\hline Vegetables & 2.0 servings & $\begin{array}{l}\text { at least } 3 \text { servings ( } 1 \text { cup raw or } 1 / 2 \text { cup } \\
\text { cooked) daily of leafy green or orange } \\
\text { vegetables such as kale, brussel sprouts, } \\
\text { squash or carrots. }\end{array}$ \\
\hline
\end{tabular}

* $\quad$ The enclosed "dietary guidelines" brochure lists basic caloric needs in chart 1. Individual caloric intakes will vary with factors related to sex, age, activity level, and weight goals.

$* * \quad$ See the enclosed brochure for serving sizes

Converting grams (on food labels) to calories

grams $\times 9$ = calories of fat

grams $\times 4=$ calories of protein, carbohydrates, or sugars 
Appendix J: Enhanced Feedback Messages

\begin{tabular}{|c|c|c|c|c|}
\hline & Source & Type & & Message \\
\hline & & & & Vegetables and Fruits \\
\hline 1 & DGA & fiber & + & $\begin{array}{l}\text { Eat } 3 \text { to } 5 \text { servings daily of vegetables such as broccoli, spinach, } \\
\text { green salad, cooked greens, squash, carrots, orange yams/sweet } \\
\text { potatoes ( } 1 / 2 \text { cup cooked or } 1 \text { cup raw }=\text { one serving). }\end{array}$ \\
\hline \multirow[t]{2}{*}{2} & DGA & fiber & + & $\begin{array}{l}\text { Eat } 2 \text { to } 3 \text { servings of fruit per day ( } 1 \text { medium piece fresh or } 1 / 2 \\
\text { cup frozen or canned preferably without syrup). }\end{array}$ \\
\hline & & & & Milk Products \\
\hline 3 & DGA & FAT & + & $\begin{array}{l}\text { Eat or drink skim to } 1 \% \text { milk, yogurt, or buttermilk or soy } \\
\text { beverage with calcium. }\end{array}$ \\
\hline 4 & NCEP & FAT & + & $\begin{array}{l}\text { Choose fat-free or low-fat cheese (less than } 6 \text { to } 10 \% \text { fat) such as } \\
\text { fat-free mozzarella or cottage cheese. }\end{array}$ \\
\hline 5 & NCEP & FAT & + & $\begin{array}{l}\text { Use frozen yogurt, sherbert, or low fat ice cream in place of ice } \\
\text { cream. }\end{array}$ \\
\hline 6 & DGA & FAT & - & $\begin{array}{l}\text { Eat or drink } 2 \text { to } 3 \text { servings daily of skim to } 1 \% \text { milk, yogurt, } \\
\text { and soy beverage with calcium or low-fat cheeses (fat-free to } \\
<10 \% \text { fat). }\end{array}$ \\
\hline \multirow[t]{2}{*}{7} & AHA & FAT & + & $\begin{array}{l}\text { If you are used to whole-milk products, tapering off may be } \\
\text { easier. Try } 2 \% \text { milk for two weeks, then change to } 11 / 2 \% \text { milk, } \\
\text { then } 1 \% \text { and less. }\end{array}$ \\
\hline & & & & Breads, Cereals, Pasta \\
\hline \multirow[t]{2}{*}{8} & $\begin{array}{l}\text { DGA (p } \\
21)\end{array}$ & fiber & + & $\begin{array}{l}\text { Eat at least } 6 \text { servings a day of whole grains such as } 100 \% \text { whole } \\
\text { wheat bread (or whole wheat flour listed as first ingredient), } \\
\text { oatmeal, brown rice, whole wheat pasta, corn tortillas. A serving } \\
\text { is } 1 \text { slice of bread, } 1 / 2 \text { cup cooked grain or cereal, or } 1 \text { cup } \\
\text { commercial cereal. }\end{array}$ \\
\hline & & & & Meat, Poultry, Seafood, Eggs, Dried beans, and Peas \\
\hline 9 & $\begin{array}{l}\mathrm{NCEP}+ \\
\text { ground }\end{array}$ & FAT & + & $\begin{array}{l}\text { Eat only lean cuts of beef, pork, and lamb with visible fat } \\
\text { removed. Examples include chuck roast, flank steak, round } \\
\text { steak, and extra-lean ground beef ( } 15 \% \text { fat or less) or center loin } \\
\text { pork chops. }\end{array}$ \\
\hline 10 & $\begin{array}{l}\text { NCEP } 5 \\
\text { oz }\end{array}$ & combo & $+/-$ & $\begin{array}{l}\text { Eat no more than } 6 \text { oz total meat, poultry with all visible fat } \\
\text { trimmed off), fish, and shellfish per day ( } 3 \text { ounces is the size of a } \\
\text { deck of cards). }\end{array}$ \\
\hline 11 & $\begin{array}{l}\text { NCEP+ } \\
\text { poultry } \\
\text { dogs }\end{array}$ & FAT & - & $\begin{array}{l}\text { Avoid full-fat processed meats such as bacon, lunch meats, } \\
\text { sausage, } 1 / 4 \text { pound burger, hot dogs (includes regular poultry hot } \\
\text { dogs), ham (bone-end) and ground turkey. }\end{array}$ \\
\hline 12 & $\begin{array}{l}\mathrm{DGA}+ \\
\text { roast }\end{array}$ & FAT & - & $\begin{array}{l}\text { Trim all fat from meat and remove skin from poultry before } \\
\text { cooking. (If roasting a whole turkey or chicken, remove skin } \\
\text { before serving.) Choose extra lean ground beef. }\end{array}$ \\
\hline 13 & DGA & combo & + & $\begin{array}{l}\text { Choose } 2 \text { to } 3 \text { servings a day of fish, shellfish, lean poultry, other } \\
\text { lean meats, beans, tofu, or nuts daily. Choose dry beans, } \\
\text { chickpeas, and lentils often. Trim fat from meat and skin from } \\
\text { poultry. }\end{array}$ \\
\hline
\end{tabular}




\begin{tabular}{|c|c|c|c|c|}
\hline & Source & Type & & Message \\
\hline 14 & NCEP & FAT & - & $\begin{array}{l}\text { Reduce your intake of shrimp, shellfish, and organ meats to } \\
\text { decrease cholesterol. }\end{array}$ \\
\hline 15 & $\begin{array}{l}\text { NCEP } \\
1 \text { yolk }\end{array}$ & FAT & - & $\begin{array}{l}\text { Reduce some egg yolks by using additional egg whites or egg } \\
\text { replacer. }\end{array}$ \\
\hline 16 & DGA & combo & + & $\begin{array}{l}\text { Choose one or more meatless meals per day such as beans with } \\
\text { tortillas, lentils with pilaf, tofu with brown rice, pasta with a } \\
\text { non-meat sauce, green salad with chickpeas. }\end{array}$ \\
\hline \multirow[t]{2}{*}{17} & DGA & combo & + & $\begin{array}{l}\text { Choose meatless meals often (several times a week or more), } \\
\text { meals such as beans with tortillas, lentils with pilaf, tofu with } \\
\text { brown rice, pasta with a non-meat sauce, green salad with } \\
\text { chickpeas. }\end{array}$ \\
\hline & & & & Fats and Oils \\
\hline 18 & DGA & FAT & + & $\begin{array}{l}\text { Use liquid vegetable oils or tub margarines INSTEAD of solid } \\
\text { fats such as butter, stick margarine, lard, hydrogenated vegetable } \\
\text { oil, or shortening. }\end{array}$ \\
\hline 19 & DGA & FAT & $+/-$ & $\begin{array}{l}\text { Decrease portions of high-fat foods such as margarine and salad } \\
\text { dressing to reduce overall fat intake. }\end{array}$ \\
\hline 20 & NCEP & FAT & + & $\begin{array}{l}\text { Use tub and liquid margarine, salad dressings (low-fat or made } \\
\text { with liquid vegetable oils), and fat free or low-fat mayonnaise in } \\
\text { place of those made with full fat cheese, cream, butter, or solid } \\
\text { fats. }\end{array}$ \\
\hline 21 & NCEP & FAT & $+/-$ & $\begin{array}{l}\text { Use low-fat cooking methods such as baking, broiling, grilling, } \\
\text { poaching, roasting, stewing, and steaming }\end{array}$ \\
\hline 22 & NCEP & FAT & - & $\begin{array}{l}\text { Limit fried foods such as french fries, fried chicken or fish to } \\
\text { once per week or less. }\end{array}$ \\
\hline \multirow[t]{2}{*}{23} & $\begin{array}{l}\mathrm{NCEP} \backslash \mathrm{D} \\
\mathrm{GA} \\
\text { candy }\end{array}$ & FAT & $+/-$ & Eat chocolate candy in moderation ( 1 or 2 times per week). \\
\hline & & & & Snacks, Desserts \\
\hline 24 & NCEP & FAT & - & $\begin{array}{l}\text { Limit high-fat snacks like chips (potato, corn, bagel) cheese } \\
\text { puffs, snack mix, regular crackers, and regular popcorn. }\end{array}$ \\
\hline 25 & NCEP & FAT & + & $\begin{array}{l}\text { Choose lower fat snacks like pretzels, fat-free chips, low-fat } \\
\text { crackers, fruit, hard bread sticks, and unbuttered or low-fat } \\
\text { popcorn. }\end{array}$ \\
\hline \multirow[t]{2}{*}{26} & $\begin{array}{l}\text { NCEP - } \\
\text { butter } \\
\text { rolls }\end{array}$ & FAT & - & $\begin{array}{l}\text { Limit high-fat baked goods (such as doughnuts, biscuits, regular } \\
\text { muffins, sweet rolls, croissants, cakes, pies, and cookies) to once } \\
\text { a week or less. }\end{array}$ \\
\hline & & & & Other \\
\hline \multirow[t]{2}{*}{27} & DGA & other & - & $\begin{array}{l}\text { Limit your intake of drinks and foods high in added sugars such } \\
\text { as soft drinks or sweetened tea. }\end{array}$ \\
\hline & DGA & other & - & $\begin{array}{l}\text { Take care not to let soft drinks or other sweets crowd out healthy } \\
\text { foods such as low-fat milk and other sources of calcium. }\end{array}$ \\
\hline 28 & DGA & other & - & $\begin{array}{l}\text { As you can see from your feedback report, your eating habits } \\
\text { generally meet the suggested USDA guidelines. Additional } \\
\text { considerations from the guidelines follow. }\end{array}$ \\
\hline
\end{tabular}




\begin{tabular}{|l|l|l|l|l|}
\hline & Source & Type & & \multicolumn{1}{c|}{ Message } \\
\hline 29 & DGA & h2o & + & $\begin{array}{l}\text { Deverages } \\
\text { Drink at least 8 glasses of water daily (8 ounce glass or 64 } \\
\text { ounces). Do NOT count soft drinks, juice, fruitades, sports } \\
\text { drinks, or caffeinated beverages like coffee or tea. }\end{array}$ \\
\hline
\end{tabular}

Message Sources:

AHA - American Heart Association Eating Plan for Healthy Americans

DGA - Dietary Guidelines for Americans

NCEP - National Cholesterol Education Program report on cholesterol detection and treatment

\section{References}

American Heart Association. (n.d.). Basic food groups. Retrieved January 12, 2002, from http://www.americanheart.org/presenter.jhtml?identifier $=779$

American Heart Association. (n.d.). Goals of the American Heart Association Eating Plan.

Retrieved January 12, 2002, from http://www.americanheart.org/presenter.jhtml

?identifier $=9203$

National Cholesterol Education Program (NCEP). Second report of the expert panel on detection, evaluation, and treatment of high blood cholesterol in adults. (Adult Treatment Panel II, 1994). Circulation, 89, 1333-1445.

National Cholesterol Education Program (NCEP). Third report of the expert panel on detection, evaluation, and treatment of high blood cholesterol in adults. (Adult Treatment Panel III, NIH Pub. No. 02-5215). Bethesda, MD: National Heart, Lung, and Blood Institute, 2002.

U.S. Department of Agriculture. (2000). Nutrition and your health: Dietary guidelines for Americans. 5th ed. (USDA: Home and garden bulletin; no. 232). Washington, DC: U.S. Government Printing Office. 
Appendix K: Sample Enhanced Feedback Report

\section{This report prepared for Participant Name}

\section{Suggestions for Changing Your Eating Habits}

Based on your Food Frequency Questionnaire, several suggested changes in your eating behavior have been prepared. These changes have been tailored to fit your individual eating habits.

1. Limit high-fat baked goods (such as doughnuts, biscuits, regular muffins, sweet rolls, croissants, cakes, pies, and cookies) to once a week or less.

2. If you are used to whole-milk products, tapering off may be easier. Try $2 \%$ milk for two weeks, then change to $11 / 2 \%$ milk, then $1 \%$ and less.

3. Use low-fat cooking methods such as baking, broiling, grilling, poaching, roasting, stewing, and steaming

4. Eat chocolate candy in moderation (1 or 2 times per week).

5. Eat 2 to 3 servings of fruit per day ( 1 medium piece fresh or $1 / 2$ cup frozen or canned preferably without syrup).

6. Eat one or more meatless meals per day such as beans with tortillas, lentils with pilaf, tofu with brown rice, pasta with a non-meat sauce, green salad with chickpeas. 


\section{Appendix L: Summary Tables for Statistical Analysis}

Summary Tables for Table 4:

Differences in Mean Age for Stages in Low-fat SOC

One-way ANOVA

\begin{tabular}{lrrrrr}
\hline & \multicolumn{1}{c}{$\begin{array}{c}\text { Sum of } \\
\text { Squares }\end{array}$} & df & Mean Square & F & Sig. \\
\hline Between Groups & 4997.474 & 4 & 1249.368 & 6.537 & .000 \\
Within Groups & 51030.225 & 267 & 191.124 & & \\
Total & 56027.698 & 271 & & & \\
\hline
\end{tabular}

Multiple Comparisons by Tukey HSD for Age by Low-fat SOC

\begin{tabular}{|c|c|c|c|c|c|}
\hline \multirow[t]{2}{*}{ Low-fat Stage } & \multirow[t]{2}{*}{ Mean Difference } & \multirow[t]{2}{*}{ S.E. } & \multirow[t]{2}{*}{ Sig. } & \multicolumn{2}{|c|}{$95 \% \mathrm{CI}$} \\
\hline & & & & Lower & Upper \\
\hline \multicolumn{6}{|l|}{ Precontemplation } \\
\hline Contemplation & $1.794 *$ & 3.667 & .988 & -8.210 & 11.798 \\
\hline Preparation & $1.549 *$ & 3.357 & .991 & -7.609 & 10.707 \\
\hline Action & $2.750^{*}$ & 3.091 & .901 & -5.682 & 11.183 \\
\hline Maintenance & $-6.777 *$ & 2.832 & .117 & -14.501 & .947 \\
\hline \multicolumn{6}{|l|}{ Contemplation } \\
\hline Precontemplation & $-1.794 *$ & 3.667 & .988 & -11.798 & 8.210 \\
\hline Preparation & $-.245^{*}$ & 3.461 & 1.000 & -9.686 & 9.196 \\
\hline Action & $.956^{*}$ & 3.204 & .998 & -7.783 & 9.696 \\
\hline Maintenance & $-8.571 *$ & 2.954 & .030 & -16.629 & -.513 \\
\hline \multicolumn{6}{|l|}{ Preparation } \\
\hline Precontemplation & $-1.549 *$ & 3.357 & .991 & -10.707 & 7.609 \\
\hline Contemplation & $.245 *$ & 3.461 & 1.000 & -9.196 & 9.686 \\
\hline Action & $1.201 *$ & 2.844 & .993 & -6.555 & 8.958 \\
\hline Maintenance & $-8.326^{*}$ & 2.559 & .010 & -15.306 & -1.346 \\
\hline \multicolumn{6}{|l|}{ Action } \\
\hline Precontemplation & $-2.750 *$ & 3.091 & .901 & -11.183 & 5.682 \\
\hline Contemplation & $-.956^{*}$ & 3.204 & .998 & -9.696 & 7.783 \\
\hline Preparation & $-1.201 *$ & 2.844 & .993 & -8.958 & 6.555 \\
\hline Maintenance & $-9.528 *$ & 2.198 & .000 & -15.524 & -3.531 \\
\hline \multicolumn{6}{|l|}{ Maintenance } \\
\hline Precontemplation & $6.777^{*}$ & 2.832 & .139 & -.947 & 14.501 \\
\hline Contemplation & $8.571^{*}$ & 2.954 & .030 & .513 & 16.629 \\
\hline Preparation & $8.326^{*}$ & 2.559 & .010 & 1.346 & 15.306 \\
\hline Action & $9.528^{*}$ & 2.198 & .000 & 3.531 & 15.524 \\
\hline
\end{tabular}

* The mean difference is significant at the .05 level. 
Summary Tables for Table 4:

Differences in Mean Age for Stages in High-fiber SOC

One-way ANOVA

\begin{tabular}{lcrrrr}
\hline & \multicolumn{1}{c}{ Sum of } & df & Mean Square & F & Sig. \\
& Squares & & & & \\
\hline Between Groups & 7028.510 & 4 & 1757.128 & 9.586 & .000 \\
Within Groups & 49123.577 & 268 & 183.297 & & \\
Total & 56152.087 & 272 & & & \\
\hline
\end{tabular}

Multiple Comparisons by Tukey HSD for Age by Low-fat SOC

\begin{tabular}{lccrrr}
\hline High-fiber Stage & Mean Difference & S.E. & Sig. & \multicolumn{2}{c}{$95 \%$ CI } \\
\cline { 5 - 6 } & & & & Lower & Upper \\
\hline Precontemplation & & & & & \\
Contemplation & -4.228 & 3.289 & .700 & -13.199 & 4.743 \\
Preparation & -8.170 & 3.361 & .107 & -17.339 & 0.999 \\
Action & -2.795 & 2.339 & .754 & -9.174 & 3.585 \\
Maintenance & $-12.156^{*}$ & 2.024 & .000 & -17.676 & -6.636 \\
Contemplation & & & & & \\
Precontemplation & 4.228 & 3.289 & .700 & -4.743 & 13.199 \\
Preparation & -3.942 & 4.337 & .894 & -15.773 & 7.889 \\
Action & 1.433 & 3.603 & .995 & -8.396 & 11.262 \\
Maintenance & -7.928 & 3.407 & .136 & -17.222 & 1.366 \\
Preparation & & & & & \\
Precontemplation & 8.170 & 3.361 & .107 & -0.999 & 17.339 \\
Contemplation & 3.942 & 4.337 & .894 & -7.889 & 15.773 \\
Action & 5.375 & 3.670 & .585 & -4.634 & 15.385 \\
Maintenance & -3.986 & 3.477 & .782 & -13.471 & 5.500 \\
Action & & & & & \\
Precontemplation & 2.795 & 2.339 & .754 & -3.585 & 9.174 \\
Contemplation & -1.433 & 3.603 & .995 & -11.262 & 8.396 \\
Preparation & -5.375 & 3.670 & .585 & -15.385 & 4.634 \\
Maintenance & $-9.361^{*}$ & 2.503 & .002 & -16.187 & -2.535 \\
Maintenance & & & & & \\
Precontemplation & $12.156^{*}$ & 2.024 & .000 & 6.636 & 17.676 \\
Contemplation & 7.928 & 3.407 & .136 & -1.366 & 17.222 \\
Preparation & 3.986 & 3.477 & .782 & -5.500 & 13.471 \\
Action & $9.361^{*}$ & 2.503 & .002 & 2.535 & 16.187 \\
\hline Then & & & & &
\end{tabular}

* The mean difference is significant at the .05 level. 
Summary Tables for Table 5:

Dietary Intake as \% of Daily Calories from Fat Compared to Gender and SOC for Low-Fat Dietary Behavior

Tests of Between-Subjects Effects

\begin{tabular}{lcrrrr}
\hline \multicolumn{1}{c}{ Source } & $\begin{array}{c}\text { Sum of } \\
\text { Squares }\end{array}$ & df & $\begin{array}{c}\text { Type III Mean } \\
\text { Square }\end{array}$ & \multicolumn{1}{c}{ F } & Sig. \\
\hline Gender & $5.026^{\mathrm{a}}$ & 1 & 5.026 & .066 & .797 \\
Low-Fat SOC & $3365.575^{\mathrm{a}}$ & 2 & $1682.787^{\mathrm{a}}$ & 22.133 & .000 \\
Gender * Low-Fat SOC & $322.143^{\mathrm{a}}$ & 2 & $161.072^{\mathrm{a}}$ & 2.119 & .122 \\
Error & $20223.734^{\mathrm{a}}$ & 266 & 76.029 & & \\
Total & $342553.330^{\mathrm{a}}$ & 272 & & & \\
Corrected Total & $24457.461^{\mathrm{a}}$ & 271 & & &
\end{tabular}

Multiple Comparisons by Tukey HSD for Fat Intake by Low-Fat SOC

\begin{tabular}{lrrrrr}
\hline \multicolumn{1}{r}{ Stage } & Mean & S.E. & Sig. & \multicolumn{2}{c}{$95 \%$ CI } \\
\cline { 5 - 6 } & Difference & & & Lower & Upper \\
\hline Early & & & & & \\
$\quad$ Action & $6.201^{*}$ & 1.435 & .000 & 2.838 & 9.564 \\
$\quad$ Maintenance & $8.504^{*}$ & 1.203 & .000 & 5.685 & 11.324 \\
Action & & & & & \\
$\quad$ Early & $-6.201^{*}$ & 1.435 & .000 & -9.564 & -2.838 \\
$\quad \begin{array}{l}\text { Maintenance } \\
\text { Maintenance }\end{array}$ & $2.303^{*}$ & 1.387 & .220 & -.946 & 5.553 \\
$\quad$ Early & & & & & \\
$\quad$ Action & $-8.504^{*}$ & 1.203 & .000 & -11.462 & -4.556 \\
\hline
\end{tabular}

* The mean difference is significant at the .05 level. 
Summary Tables for Table 5:

Dietary Intake of Fiber (gm) Compared to Gender and SOC for High-Fiber Dietary Behavior Tests of Between-Subjects Effects

\begin{tabular}{lrrrrr}
\hline \multicolumn{1}{c}{ Source } & $\begin{array}{c}\text { Type III Sum } \\
\text { of Squares }\end{array}$ & df & \multicolumn{1}{c}{$\begin{array}{c}\text { Mean } \\
\text { Square }\end{array}$} & \multicolumn{1}{c}{ F } & Sig. \\
\hline Gender & 221.461 & 1 & 221.461 & 3.914 & .049 \\
High-Fiber SOC & 1594.413 & 1 & 1594.413 & 28.157 & .000 \\
Gender * High-Fiber SOC & 23.541 & 1 & 23.541 & .416 & .520 \\
Error & $15232.114^{\mathrm{a}}$ & 269 & 56.625 & & \\
Total & $84547.980^{\mathrm{a}}$ & 273 & & & \\
Corrected Total & $16946.446^{\mathrm{a}}$ & 272 & & & \\
\hline
\end{tabular}

${ }^{\mathrm{a}}$ R Squared $=.101$ (Adjusted R Squared $=.091$ ) 
Summary Tables for Table 7:

Mean Pro and Con Ratings for General or Gender-Specific Decisional Balance (DB) Measures by Gender and Low-Fat SOC

Between Subject Effects for DB General Type of Mean Pro Ratings

\begin{tabular}{lrrrrc}
\hline \multicolumn{1}{c}{ Source } & Sum of Squares & df & Mean Square & \multicolumn{1}{c}{ F } & \multicolumn{1}{c}{ Sig. } \\
\hline GENDER & 3.679 & 1 & 3.679 & 16.974 & .000 \\
Low-Fat SOC, early/late & 3.928 & 1 & 3.928 & 18.124 & .000 \\
GENDER * Low-Fat SOC & .706 & 1 & .706 & 3.258 & .072 \\
Error & 56.789 & 262 & .217 & & \\
Total & 5410.417 & 266 & & & \\
Corrected Total & 64.341 & 265 & & & \\
\hline
\end{tabular}

Between Subject Effects for DB Gender-Specific Type of Mean Pro Ratings

\begin{tabular}{lrrrrr}
\hline \multicolumn{1}{c}{ Source } & Sum of Squares & df & Mean Square & F & Sig. \\
\hline GENDER & .557 & 1 & .557 & 1.375 & .242 \\
Low-Fat SOC & 8.963 & 1 & 8.963 & 22.116 & .000 \\
GENDER * Low-Fat SOC & .623 & 1 & .623 & 1.537 & .216 \\
Error & 106.188 & 262 & .405 & & \\
Total & 3686.703 & 266 & & & \\
Corrected Total & 115.673 & 265 & & & \\
\hline
\end{tabular}


Between Subject Effects for DB General Type of Mean Con Ratings

\begin{tabular}{lrrrrr}
\hline \multicolumn{1}{c}{ Source } & Sum of Squares & df & Mean Square & \multicolumn{1}{c}{ F } & \multicolumn{1}{c}{ Sig. } \\
\hline GENDER & .547 & 1 & .547 & .806 & .370 \\
Low-Fat SOC & 8.260 & 1 & 8.260 & 12.156 & .001 \\
GENDER * Low-Fat SOC & .497 & 1 & .497 & .731 & .393 \\
Error & 178.029 & 262 & .680 & & \\
Total & 2828.028 & 266 & & & \\
Corrected Total & 186.963 & 265 & & & \\
\hline
\end{tabular}

Between Subject Effects for DB Gender-Specific Type of Mean Con Ratings

\begin{tabular}{lrrrrr}
\hline \multicolumn{1}{c}{ Source } & Sum of Squares & df & Mean Square & \multicolumn{1}{c}{ F } & \multicolumn{1}{c}{ Sig. } \\
\hline GENDER & .982 & 1 & .982 & 2.710 & .101 \\
Low-Fat SOC & 11.157 & 1 & 11.157 & 30.804 & .000 \\
GENDER * Low-Fat SOC & 3.114 & 1 & 3.114 & 8.599 & .004 \\
Error & 94.892 & 262 & .362 & & \\
Total & 1590.859 & 266 & & & \\
Corrected Total & 107.622 & 265 & & & \\
\hline
\end{tabular}

For Male and Female Participants, Simple Effects of Low-Fat Stage Differences on Specific Con Ratings $t$-test for Equality of Means, two-tailed

\begin{tabular}{|c|c|c|c|c|c|c|c|}
\hline \multirow[t]{2}{*}{ Gender } & \multirow[t]{2}{*}{$t$} & \multirow[t]{2}{*}{$\mathrm{df}$} & \multirow[t]{2}{*}{$p$} & \multirow{2}{*}{$\begin{array}{c}\text { Mean } \\
\text { Difference }\end{array}$} & \multirow{2}{*}{$\begin{array}{c}\text { Standard. Error } \\
\text { Difference }\end{array}$} & \multicolumn{2}{|c|}{$95 \% \mathrm{CI}$} \\
\hline & & & & & & Lower & Upper \\
\hline Male & 5.176 & 97 & .000 & .6744 & .1303 & .4158 & .9331 \\
\hline Female & 2.164 & 165 & .032 & .2081 & $9.620 \mathrm{E}-02$ & 2.E-02 & .3981 \\
\hline
\end{tabular}

Note: Levene's Test for equality of variances not significant

For Early and Late Low-Fat Stages, Simple Effects of Gender Differences on Specific Con Ratings $t$-test for Equality of Means, two-tailed

\begin{tabular}{|c|c|c|c|c|c|c|c|}
\hline \multirow[t]{2}{*}{ Stages } & \multirow[t]{2}{*}{$t$} & \multirow[t]{2}{*}{$\mathrm{df}$} & \multirow[t]{2}{*}{$p$} & \multirow{2}{*}{$\begin{array}{c}\text { Mean } \\
\text { Difference }\end{array}$} & \multirow{2}{*}{$\begin{array}{l}\text { Standard. Error } \\
\text { Difference }\end{array}$} & \multicolumn{2}{|c|}{$95 \% \mathrm{CI}$} \\
\hline & & & & & & Lower & Upper \\
\hline Early & 2.878 & 91 & .005 & .3641 & .1265 & .1127 & .6154 \\
\hline Late & -1.066 & 171 & .288 & -.1023 & 9.594E-02 & -.2916 & 8.71E-02 \\
\hline
\end{tabular}

Note: Levene's Test for equality of variances not significant 
Between Subject Effects for DB General Type Pro/Con Ratio

\begin{tabular}{lrrrrr}
\hline \multicolumn{1}{c}{ Source } & Sum of Squares & df & Mean Square & \multicolumn{1}{c}{ F } & \multicolumn{1}{c}{ Sig. } \\
\hline GENDER & .158 & 1 & .158 & .406 & .525 \\
Low-Fat SOC & 5.575 & 1 & 5.575 & 14.353 & .000 \\
GENDER * Low-Fat SOC & .555 & 1 & .555 & 1.430 & .233 \\
Error & 101.775 & 262 & .388 & & \\
Total & 762.737 & 266 & & & \\
Corrected Total & 107.506 & 265 & & & \\
\hline
\end{tabular}

Between Subject Effects for DB Gender-Specific Type Pro/Con Ratio

\begin{tabular}{lrrrrr}
\hline \multicolumn{1}{c}{ Source } & Sum of Squares & df & Mean Square & \multicolumn{1}{c}{ F } & \multicolumn{1}{c}{ Sig. } \\
\hline GENDER & .511 & 1 & .511 & 1.313 & .253 \\
Low-Fat SOC & 15.110 & 1 & 15.110 & 38.848 & .000 \\
GENDER * Low-Fat SOC & 2.658 & 1 & 2.658 & 6.835 & .009 \\
Error & 101.904 & 262 & .389 & & \\
Total & 883.005 & 266 & & & \\
Corrected Total & 117.853 & 265 & & & \\
\hline
\end{tabular}

For Male and Female Participants, Simple Effects of Low-Fat Stage Differences on Specific Pro/Con Ratios $t$-test for Equality of Means, two-tailed

\begin{tabular}{|c|c|c|c|c|c|c|c|}
\hline \multirow[t]{2}{*}{ Gender } & \multirow[t]{2}{*}{$t$} & \multirow[t]{2}{*}{$\mathrm{df}$} & \multirow[t]{2}{*}{$p$} & \multirow{2}{*}{$\begin{array}{c}\text { Mean } \\
\text { Difference }\end{array}$} & \multirow{2}{*}{$\begin{array}{l}\text { Standard. Error } \\
\text { Difference }\end{array}$} & \multicolumn{2}{|c|}{$95 \% \mathrm{CI}$} \\
\hline & & & & & & Lower & Upper \\
\hline Male & $-6.881^{a}$ & 87.19 & .000 & -.7290 & .1059 & -.9395 & -.5184 \\
\hline Female & $-2.855^{b}$ & 165 & .005 & -.2981 & .1044 & -.5043 & -.0920 \\
\hline
\end{tabular}

${ }^{a}$ Levene's Test for equality of variances significant $(F=11.85, p=.001)$, t-test for "equal variances not assumed" reported above

${ }^{\mathrm{b}}$ Levene's Test for equality of variances not significant

For Early and Late Low-Fat Stages, Simple Effects of Gender Differences on Specific Pro/Con Ratios $t$-test for Equality of Means, two-tailed

\begin{tabular}{|c|c|c|c|c|c|c|c|}
\hline \multirow[t]{2}{*}{ Stages } & \multirow[t]{2}{*}{$t$} & \multirow[t]{2}{*}{ df } & \multirow[t]{2}{*}{$p$} & \multirow{2}{*}{$\begin{array}{c}\text { Mean } \\
\text { Difference }\end{array}$} & \multirow{2}{*}{$\begin{array}{l}\text { Standard. Error } \\
\text { Difference }\end{array}$} & \multicolumn{2}{|c|}{$95 \% \mathrm{CI}$} \\
\hline & & & & & & Lower & Upper \\
\hline Early & $-3.362^{a}$ & 86.0 & .001 & -.3098 & $9.217 \mathrm{E}-02$ & -.4931 & -.1266 \\
\hline Late & $1.108^{\mathrm{b}}$ & 171 & .269 & .1210 & .1092 & $-9.5 \mathrm{E}-02$ & .3365 \\
\hline
\end{tabular}


Summary Tables for Table 8:

Mean Pro and Con Ratings for General or Gender-Specific Decisional Balance (DB) Measures by Gender and High-Fiber SOC

Between Subject Effects for DB General Type of Mean Pro Ratings

\begin{tabular}{lrrrrr}
\hline \multicolumn{1}{c}{ Source } & Sum of Squares & df & Mean Square & F & \multicolumn{1}{c}{ Sig. } \\
\hline GENDER & 2.230 & 1 & 2.230 & 9.999 & .002 \\
High-Fiber SOC, early/late & 2.213 & 1 & 2.213 & 9.921 & .002 \\
GENDER * High-Fiber SOC & .339 & 1 & .339 & 1.520 & .219 \\
Error & 58.659 & 263 & .223 & & \\
Total & 5432.194 & 267 & & & \\
Corrected Total & 64.374 & 266 & & & \\
\hline
\end{tabular}

Between Subject Effects for DB Gender-Specific Type of Mean Pro Ratings

\begin{tabular}{lrrrrr}
\hline \multicolumn{1}{c}{ Source } & Sum of Squares & df & Mean Square & \multicolumn{1}{c}{ F } & \multicolumn{1}{c}{ Sig. } \\
\hline GENDER & .274 & 1 & .274 & .656 & .419 \\
High-Fiber SOC & 3.805 & 1 & 3.805 & 9.100 & .003 \\
GENDER * High-Fiber SOC & .725 & 1 & .725 & 1.734 & .189 \\
Error & 109.956 & 263 & .418 & & \\
Total & 3708.094 & 267 & & & \\
Corrected Total & 116.594 & 266 & & & \\
\hline
\end{tabular}


Between Subject Effects for DB General Type of Mean Con Ratings

\begin{tabular}{lrrrrr}
\hline \multicolumn{1}{c}{ Source } & Sum of Squares & df & Mean Square & \multicolumn{1}{c}{ F } & \multicolumn{1}{c}{ Sig. } \\
\hline GENDER & 1.129 & 1 & 1.129 & 1.617 & .205 \\
High-Fiber SOC & 2.627 & 1 & 2.627 & 3.762 & .054 \\
GENDER * High-Fiber SOC & $1.737 \mathrm{E}-02$ & 1 & $1.737 \mathrm{E}-02$ & .025 & .875 \\
Error & 183.656 & 263 & .698 & & \\
Total & 2836.056 & 267 & & & \\
Corrected Total & 187.063 & 266 & & & \\
\hline
\end{tabular}

Between Subject Effects for DB Gender-Specific Type of Mean Con Ratings

\begin{tabular}{lrrrrr}
\hline \multicolumn{1}{c}{ Source } & Sum of Squares & df & Mean Square & \multicolumn{1}{c}{ F } & \multicolumn{1}{c}{ Sig. } \\
\hline GENDER & $7.543 \mathrm{E}-03$ & 1 & $7.543 \mathrm{E}-03$ & .020 & .889 \\
High-Fiber SOC & 4.445 & 1 & 4.445 & 11.512 & .001 \\
GENDER * High-Fiber SOC & 3.001 & 1 & 3.001 & 7.774 & .006 \\
Error & 101.539 & 263 & .386 & & \\
Total & 1598.422 & 267 & & & \\
Corrected Total & 107.773 & 266 & & & \\
\hline
\end{tabular}

For Male and Female Participants, Simple Effects of High-Fiber Stage Differences on Specific Con Ratings

$t$-test for Equality of Means, two-tailed

\begin{tabular}{llllllll}
\hline \multicolumn{1}{c}{ Gender } & $t$ & $\mathrm{df}$ & $p$ & Mean & Standard. Error & \multicolumn{2}{c}{$95 \% \mathrm{CI}$} \\
\cline { 5 - 8 } & & & & Difference & \multicolumn{1}{c}{ Difference } & Lower & Upper \\
\hline Male & 3.556 & 97 & .001 & .5009 & .1409 & .2213 & .7804 \\
Female & .537 & 166 & .592 & $4.901 \mathrm{E}-02$ & $9.126 \mathrm{E}-02$ & -.1312 & .2292 \\
\hline
\end{tabular}

Note: Levene's Test for equality of variances not significant

For Early and Late High-fiber Stages, Simple Effects of Gender Differences on Specific Con Ratings $t$-test for Equality of Means, two-tailed

\begin{tabular}{|c|c|c|c|c|c|c|c|}
\hline \multirow[t]{2}{*}{ Stages } & \multirow[t]{2}{*}{$t$} & \multirow[t]{2}{*}{$\mathrm{df}$} & \multirow[t]{2}{*}{$p$} & \multirow{2}{*}{$\begin{array}{c}\text { Mean } \\
\text { Difference }\end{array}$} & \multirow{2}{*}{$\begin{array}{l}\text { Standard. Error } \\
\text { Difference }\end{array}$} & \multicolumn{2}{|c|}{$95 \% \mathrm{CI}$} \\
\hline & & & & & & Lower & Upper \\
\hline Early & $2.268^{\mathrm{a}}$ & 116.3 & .025 & .2373 & .1046 & $3.01 \mathrm{E}-02$ & .4444 \\
\hline Late & $1.681^{\mathrm{b}}$ & 120 & .095 & -.2146 & .1277 & -.4674 & $3.82 \mathrm{E}-02$ \\
\hline
\end{tabular}


Between Subject Effects for DB General Type Pro/Con Ratio

\begin{tabular}{lrrrrr}
\hline \multicolumn{1}{c}{ Source } & Sum of Squares & \multicolumn{1}{c}{ df } & Mean Square & \multicolumn{1}{c}{ F } & \multicolumn{1}{c}{ Sig. } \\
\hline GENDER & $2.435 \mathrm{E}-03$ & 1 & $2.435 \mathrm{E}-03$ & .006 & .938 \\
High-Fiber SOC & 2.322 & 1 & 2.322 & 5.818 & .017 \\
GENDER * High-Fiber SOC & $2.224 \mathrm{E}-02$ & 1 & $2.224 \mathrm{E}-02$ & .056 & .814 \\
Error & 104.979 & 263 & .399 & & \\
Total & 765.450 & 267 & & & \\
Corrected Total & 107.512 & 266 & & & \\
\hline
\end{tabular}

Between Subject Effects for DB Gender-Specific Type Pro/Con Ratio

\begin{tabular}{lrrrrr}
\hline \multicolumn{1}{c}{ Source } & Sum of Squares & df & Mean Square & \multicolumn{1}{c}{ F } & \multicolumn{1}{c}{ Sig. } \\
\hline GENDER & $9.413 \mathrm{E}-03$ & 1 & $9.413 \mathrm{E}-03$ & .023 & .881 \\
High-Fiber SOC & 7.976 & 1 & 7.976 & 19.133 & .000 \\
GENDER * High-Fiber SOC & .559 & 1 & .559 & 1.340 & .248 \\
Error & 109.639 & 263 & .417 & & \\
Total & 885.833 & 267 & & & \\
Corrected Total & 117.853 & 266 & & & \\
\hline
\end{tabular}


Summary Tables for Table 13:

Effects of Gender and Treatment Condition on Pre-post change in \% of Calories from Fat

Dependent Variable: Change in \% of Calories from Fat

\begin{tabular}{lrrrrr}
\hline \multicolumn{1}{c}{ Source } & Sum of Squares & \multicolumn{1}{c}{ df } & Mean Square & \multicolumn{1}{c}{ F } & \multicolumn{1}{c}{ Sig. } \\
\hline Gender & 79.232 & 1 & 79.232 & 1.372 & .243 \\
Treatment Group & 78.008 & 2 & 39.004 & .675 & .510 \\
Gender * Treatment Group & 452.310 & 2 & 226.155 & 3.915 & .022 \\
Error & 10974.834 & 190 & 57.762 & & \\
\hline
\end{tabular}

Levene's Test of Equality of Error Variances

\begin{tabular}{cccc}
\hline F & df1 & df2 & Sig. \\
\hline 1.950 & 5 & 190 & .088 \\
\hline
\end{tabular}

Tests the null hypothesis that the error variance of the dependent variable is equal across groups. a Design: Intercept+ Gender + Treatment Group + Gender * Treatment Group

For Wait List, Feedback, and Tailored Message Groups, Simple Effects of Genders on Change in $\%$ of Calories from Fat

Group Statistics

\begin{tabular}{ccccc}
\hline Group & $\mathrm{N}$ & Mean & $\mathrm{SD}$ & $\mathrm{SE}$ \\
\hline Waitlist & & & & \\
Male & 25 & $-1.00^{*}$ & 5.9 & 1.18 \\
Female & 44 & $2.14^{*}$ & 5.7 & .86 \\
Feedback & & & & \\
Male & 23 & 1.22 & 7.0 & 1.46 \\
Female & 39 & -1.96 & 9.3 & 1.49 \\
Message & & & & \\
Male & 23 & -3.01 & 7.5 & 1.57 \\
Female & 42 & 0.99 & 8.7 & 1.34 \\
\hline * significant difference for males and females &
\end{tabular}

\begin{tabular}{lccccccc}
\multicolumn{1}{l}{$t$-test for Equality of Means, two-tailed } & & \\
\multicolumn{1}{c}{ Gender } & $t$ & df & $p$ & Mean & Standard. Error & \multicolumn{2}{c}{$95 \%$ CI } \\
\cline { 6 - 8 } & & & & Difference & Difference & Lower & Upper \\
\hline Waitlist & -2.177 & 67 & .033 & -3.1479 & 1.4462 & -6.0345 & -.2613 \\
Feedback & 1.415 & 60 & .162 & 3.1768 & 2.2453 & -1.3145 & 7.6682 \\
Message & -1.853 & 63 & .069 & -4.0011 & 2.1591 & -8.3156 & .3134 \\
\hline
\end{tabular}

Note: Levene's Test for equality of variances not significant 
For Male and Female Participants, Simple Effects of Treatment Group on Change in \% of Calories from Fat

Descriptives

\begin{tabular}{|c|c|c|c|c|c|c|c|c|}
\hline \multirow[t]{2}{*}{ Gender } & \multirow[t]{2}{*}{$\mathrm{N}$} & \multirow[t]{2}{*}{ Mean } & \multirow[t]{2}{*}{ SD } & \multirow[t]{2}{*}{ SE } & \multicolumn{2}{|c|}{$95 \% \mathrm{CI}$} & \multirow[t]{2}{*}{ Minimum } & \multirow[t]{2}{*}{ Maximum } \\
\hline & & & & & Lower & Upper & & \\
\hline \multicolumn{9}{|l|}{ Male } \\
\hline Wait List & 25 & -1.00 & 5.9 & 1.18 & -3.43 & 1.43 & -13.94 & 8.05 \\
\hline Feedback & 23 & 1.22 & 7.0 & 1.46 & -1.81 & 4.25 & -22.52 & 11.46 \\
\hline Message & 23 & -3.01 & 7.5 & 1.57 & -6.27 & .25 & -26.68 & 7.43 \\
\hline Total & 71 & -.93 & 6.9 & .82 & -2.57 & .71 & -26.68 & 11.46 \\
\hline \multicolumn{9}{|l|}{ Female } \\
\hline Wait List & 44 & 2.14 & 5.71 & .86 & .4084 & 3.88 & -11.02 & 19.17 \\
\hline Feedback & 39 & -1.96 & 9.31 & 1.49 & -4.9745 & 1.06 & -25.92 & 10.97 \\
\hline Message & 42 & .99 & 8.72 & 1.34 & -1.7259 & 3.71 & -13.76 & 25.76 \\
\hline Total & 125 & .4776 & 8.12 & .73 & -.9601 & 1.92 & -25.92 & 25.76 \\
\hline
\end{tabular}

For Male Participants, Simple Effects for Treatment Group on Change in \% of Calories from Fat One-Way ANOVA

\begin{tabular}{llllll}
\hline & Sum of Squares & df & Mean Square & $F$ & $p$ \\
\hline Between Groups & 206.100 & 2 & 103.050 & 2.217 & .117 \\
Within Groups & 3160.780 & 68 & 46.482 & & \\
Total & 3366.880 & 70 & & & \\
\hline
\end{tabular}

Post Hoc Tests for Males

Multiple Comparisons, Tukey HSD

\begin{tabular}{cccccc}
\hline & \multicolumn{1}{c}{ Mean } & SE & $p$ & \multicolumn{2}{c}{$95 \%$ CI } \\
\cline { 5 - 6 } Comparison Group & Difference & & & Lower & Upper \\
\hline Wait List & & & & & \\
Feedback & -2.2249 & 1.9698 & .499 & -6.9448 & 2.4950 \\
Message & 2.0066 & 1.9698 & .568 & -2.7133 & 6.7265 \\
Feedback & & & & & \\
Wait List & 2.2249 & 1.9698 & .499 & -2.4950 & 6.9448 \\
Message & 4.2314 & 2.0105 & .096 & -.5858 & 9.0487 \\
Tailored Message & & & & & \\
Wait List & -2.0066 & 1.9698 & .568 & -6.7265 & 2.7133 \\
Feedback & -4.2314 & 2.0105 & .096 & -9.0487 & .5858 \\
\hline
\end{tabular}


For Female Participants, Simple Effects for Treatment Group on Change in \% of Calories from Fat

One-Way ANOVA

\begin{tabular}{lllllr}
\hline & \multicolumn{1}{c}{ Sum of Squares } & \multicolumn{1}{c}{ df } & Mean Square & $F$ & $p$ \\
\hline Between Groups & 364.181 & 2 & 182.091 & 2.843 & .062 \\
Within Groups & 7814.054 & 122 & 64.050 & & \\
Total & 8178.235 & 124 & & & \\
\hline
\end{tabular}

Post Hoc Tests for Females

Multiple Comparisons, Tukey HSD

\begin{tabular}{cccccc}
\hline & $\begin{array}{c}\text { Mean } \\
\text { Comparison Group }\end{array}$ & SE & $p$ & \multicolumn{2}{c}{ 95\% CI } \\
\cline { 5 - 6 } Difference & & & & Lower & Upper \\
\hline Wait List & & & & & \\
Feedback & 4.0998 & 1.7601 & .052 & $-2.5326 \mathrm{E}-02$ & 8.2250 \\
$\begin{array}{c}\text { Message } \\
\text { Feedback }\end{array}$ & 1.1533 & 1.7265 & .782 & -2.8930 & 5.1997 \\
Wait List & -4.0998 & 1.7601 & .052 & -8.2250 & $2.533 \mathrm{E}-02$ \\
Message & -2.9465 & 1.7797 & .223 & -7.1175 & 1.2246 \\
$\begin{array}{c}\text { Tailored Message } \\
\text { Wait List }\end{array}$ & -1.1533 & 1.7265 & .782 & -5.1997 & 2.8930 \\
Feedback & 2.9465 & 1.7797 & .223 & -1.2246 & 7.1175 \\
\hline
\end{tabular}


Effects of Gender and Treatment Condition on Pre-post change in Fiber (g/day)

\begin{tabular}{lrrrrc}
\hline \multicolumn{1}{c}{ Source } & Sum of Squares & \multicolumn{1}{c}{ df } & Mean Square & F & \multicolumn{1}{c}{ Sig. } \\
\hline Gender & 44.818 & 1 & 44.818 & .914 & .340 \\
Treatment Group & 68.126 & 2 & 34.063 & .695 & .501 \\
Gender * Treatment Group & 15.249 & 2 & 7.624 & .155 & .856 \\
Error & 9317.399 & 190 & 49.039 & & \\
\hline
\end{tabular}

Levene's Test of Equality of Error Variances

\begin{tabular}{cccc}
\hline $\mathrm{F}$ & $\mathrm{df1}$ & $\mathrm{df} 2$ & Sig. \\
\hline .478 & 5 & 190 & .793 \\
\hline
\end{tabular}

Tests the null hypothesis that the error variance of the dependent variable is equal across groups. a Design: Intercept + Gender + Treatment Group + Gender * Treatment Group 
Summary Tables for Table 14:

Effects of Stage and Treatment Condition on Pre-post change in \% of Calories from Fat and in Fiber (g/day)

SOC at baseline - Dependent Variable: Change in Dietary Fat Intake

\begin{tabular}{lrrrrr}
\hline \multicolumn{1}{c}{ Source } & Sum of Squares & \multicolumn{1}{c}{ df } & Mean Square & \multicolumn{1}{c}{ F } & \multicolumn{1}{c}{ Sig. } \\
\hline Low-Fat SOC at baseline & 63.775 & 1 & 63.775 & 1.054 & .306 \\
Group & 122.734 & 2 & 61.367 & 1.014 & .365 \\
Low-Fat SOC * Group & 13.807 & 2 & 6.903 & .114 & .892 \\
Error & 11439.637 & 189 & 60.527 & & \\
\hline
\end{tabular}

Levene's Test of Equality of Error Variances

\begin{tabular}{cccc}
\hline $\mathrm{F}$ & $\mathrm{df1}$ & $\mathrm{df} 2$ & Sig. \\
\hline 1.067 & 5 & 189 & .380 \\
\hline
\end{tabular}

Tests the null hypothesis that the error variance of the dependent variable is equal across groups. a Design: Intercept+ Low-Fat Stage + Group + Low-Fat Stage * Group 
Dependent Variable: Pre-Post Change in Fiber Intake

\begin{tabular}{lrrrrc}
\hline \multicolumn{1}{c}{ Source } & Sum of Squares & \multicolumn{1}{c}{ df } & Mean Square & F & \multicolumn{1}{c}{ Sig. } \\
\hline High-fiber SOC & .101 & 1 & .101 & .002 & .964 \\
Group & 73.302 & 2 & 36.651 & .750 & .474 \\
High-fiber SOC * Group & 89.324 & 2 & 44.662 & .913 & .403 \\
Error & 9290.104 & 190 & 48.895 & & \\
\hline
\end{tabular}

Levene's Test of Equality of Error Variances

\begin{tabular}{cccc}
\hline $\mathrm{F}$ & $\mathrm{df} 1$ & $\mathrm{df} 2$ & Sig. \\
\hline 1.237 & 5 & 190 & .293 \\
\hline
\end{tabular}

Tests the null hypothesis that the error variance of the dependent variable is equal across groups. a Design: Intercept+ High-Fiber Stage + Group + High-Fiber Stage * Group 
Effects of Stage and Treatment Condition on \% of Calories from Fat and in Fiber (g/day)

Phase 2 - Dependent Variable: Pre, Post Change in \% Calories from Fat

\begin{tabular}{lrrrrr}
\hline \multicolumn{1}{c}{ Source } & Sum of Squares & \multicolumn{1}{c}{ df } & Mean Square & \multicolumn{1}{c}{ F } & \multicolumn{1}{c}{ Sig. } \\
\hline Low-Fat SOC at Phase & 150.173 & 1 & 150.173 & 2.536 & .113 \\
Group & 66.141 & 2 & 33.071 & .558 & .573 \\
Low-Fat SOC * Group & 110.396 & 2 & 55.198 & .932 & .395 \\
Error & 11250.656 & 190 & 59.214 & & \\
\hline
\end{tabular}

Dependent Variable: Pre, Post Change in Fiber (g)

\begin{tabular}{lrrrrr}
\hline \multicolumn{1}{c}{ Source } & Sum of Squares & \multicolumn{1}{c}{ df } & Mean Square & F & \multicolumn{1}{c}{ Sig. } \\
\hline High-fiber SOC at Phase & 8.075 & 1 & 8.075 & .165 & .685 \\
Group & 76.180 & 2 & 38.090 & .780 & .460 \\
High-fiber SOC ${ }^{*}$ Group & 12.405 & 2 & 6.203 & .127 & .881 \\
Error & 9182.925 & 188 & 48.845 & & \\
\hline
\end{tabular}

Effects of Stage and Treatment Condition on in \% of Calories from Fat and in Fiber (g/day)

Phase 3 (Follow-up) - Dependent Variable: Pre, Post Change in \% Calories from Fat

\begin{tabular}{lrrrrr}
\hline \multicolumn{1}{c}{ Source } & Sum of Squares & \multicolumn{1}{c}{ df } & Mean Square & \multicolumn{1}{c}{ F } & \multicolumn{1}{c}{ Sig. } \\
\hline Low-Fat SOC at Phase 3 & 246.975 & 1 & 246.975 & 4.475 & .036 \\
Group & 4.421 & 2 & 2.210 & .040 & .961 \\
Low-Fat SOC * Group & 249.849 & 2 & 124.925 & 2.264 & .107 \\
Error & 10430.483 & 189 & 55.188 & & \\
\hline
\end{tabular}

Dependent Variable: Pre, Post Change in Fiber (g)

\begin{tabular}{lrrrrr}
\hline \multicolumn{1}{c}{ Source } & Sum of Squares & \multicolumn{1}{c}{ df } & Mean Square & F & \multicolumn{1}{c}{ Sig. } \\
\hline Low-Fat SOC at Phase & .239 & 1 & .239 & .005 & .944 \\
Group & 60.085 & 2 & 30.042 & .626 & .536 \\
Low-Fat SOC * Group & 36.330 & 2 & 18.165 & .378 & .686 \\
Error & 9075.607 & 189 & 48.019 & & \\
\hline
\end{tabular}

